\title{
Benzhydryl as an Efficient Selective Nitrogen Protecting Group for Uracils
}

\author{
Fan Wu, ${ }^{\dagger+*}$ Musole G. Buhendwa, ${ }^{\dagger}$ and Donald F. Weaver ${ }^{\dagger, *, \xi^{*}}$ \\ Departments of Chemistry, ${ }^{\dagger}$ Medicine (Neurology), ${ }^{\ddagger}$ and School of Biomedical Engineering, ${ }^{\S}$ \\ Dalhousie University, Halifax, Nova Scotia, Canada, B4H 4J3 \\ donald.weaver@dal.ca
}

\section{Supporting Information}

\section{Contents}

General Information

${ }^{1} \mathrm{H},{ }^{13} \mathrm{C}$, and 1D NOE NMR spectrum of compound $\mathbf{2 a}$

${ }^{1} \mathrm{H},{ }^{13} \mathrm{C}$, and 1D NOE NMR spectrum of compound $\mathbf{2 b}$

${ }^{1} \mathrm{H},{ }^{13} \mathrm{C}$, and 1D NOE NMR spectrum of compound 2c

${ }^{1} \mathrm{H},{ }^{13} \mathrm{C}$, and 1D NOE NMR spectrum of compound 2d

${ }^{1} \mathrm{H},{ }^{13} \mathrm{C}$, and 1D NOE NMR spectrum of compound $\mathbf{2 e}$

${ }^{1} \mathrm{H},{ }^{13} \mathrm{C}$, and 1D NOE NMR spectrum of compound $\mathbf{2 f}$

S19-S21 
${ }^{1} \mathrm{H},{ }^{13} \mathrm{C}$, and 1D NOE NMR spectrum of compound $\mathbf{2 g}$

${ }^{1} \mathrm{H},{ }^{13} \mathrm{C}$, and 1D NOE NMR spectrum of compound $\mathbf{2 h}$

S25-S27

${ }^{1} \mathrm{H}$, and ${ }^{13} \mathrm{C}$ NMR spectrum of compound $\mathbf{3 a}$

S28-S29

${ }^{1} \mathrm{H}$, and ${ }^{13} \mathrm{C}$ NMR spectrum of compound $\mathbf{3 b}$

S30-S31

${ }^{1} \mathrm{H}$, and ${ }^{13} \mathrm{C}$ NMR spectrum of compound $\mathbf{3 c}$

${ }^{1} \mathrm{H}$, and ${ }^{13} \mathrm{C}$ NMR spectrum of compound $\mathbf{3 d}$

${ }^{1} \mathrm{H}$, and ${ }^{13} \mathrm{C}$ NMR spectrum of compound $\mathbf{3 e}$

${ }^{1} \mathrm{H}$, and ${ }^{13} \mathrm{C}$ NMR spectrum of compound $\mathbf{3 f}$

S38-S39

${ }^{1} \mathrm{H}$, and ${ }^{13} \mathrm{C}$ NMR spectrum of compound $\mathbf{3 g}$

S40-S41

${ }^{1} \mathrm{H}$, and ${ }^{13} \mathrm{C}$ NMR spectrum of compound $\mathbf{3 h}$

S42-S43

${ }^{1} \mathrm{H}$, and ${ }^{13} \mathrm{C}$ NMR spectrum of compound $\mathbf{3 i}$

S44-S45

${ }^{1} \mathrm{H}$, and ${ }^{13} \mathrm{C}$ NMR spectrum of compound $\mathbf{3 j}$

S46-S47

${ }^{1} \mathrm{H}$, and ${ }^{13} \mathrm{C}$ NMR spectrum of compound $\mathbf{3 k}$

S48-S49

${ }^{1} \mathrm{H}$, and ${ }^{13} \mathrm{C}$ NMR spectrum of compound $\mathbf{3 l}$

S50-S51

${ }^{1} \mathrm{H}$, and ${ }^{13} \mathrm{C}$ NMR spectrum of compound $\mathbf{3 m}$

S52-S53

${ }^{1} \mathrm{H}$, and ${ }^{13} \mathrm{C}$ NMR spectrum of compound $\mathbf{4 a}$

S54-S55

${ }^{1} \mathrm{H}$, and ${ }^{13} \mathrm{C}$ NMR spectrum of compound $\mathbf{4 b}$

S56-S57

${ }^{1} \mathrm{H}$, and ${ }^{13} \mathrm{C}$ NMR spectrum of compound $\mathbf{4 c}$

S58-S59

${ }^{1} \mathrm{H}$, and ${ }^{13} \mathrm{C}$ NMR spectrum of compound $\mathbf{4 d}$

S60-S61

${ }^{1} \mathrm{H}$, and ${ }^{13} \mathrm{C}$ NMR spectrum of compound $4 \mathbf{e}$

S62-S63

${ }^{1} \mathrm{H}$, and ${ }^{13} \mathrm{C}$ NMR spectrum of compound $\mathbf{4 f}$

S64-S65

${ }^{1} \mathrm{H}$, and ${ }^{13} \mathrm{C}$ NMR spectrum of compound $\mathbf{4 g}$

S66-S67 
${ }^{1} \mathrm{H}$, and ${ }^{13} \mathrm{C}$ NMR spectrum of compound $\mathbf{4 h}$

${ }^{1} \mathrm{H}$, and ${ }^{13} \mathrm{C}$ NMR spectrum of compound $\mathbf{4 i}$

S70-S71

${ }^{1} \mathrm{H}$, and ${ }^{13} \mathrm{C}$ NMR spectrum of compound $\mathbf{4 j}$

S72-S73

${ }^{1} \mathrm{H}$, and ${ }^{13} \mathrm{C}$ NMR spectrum of compound $\mathbf{4 k}$

S74-S75

${ }^{1} \mathrm{H}$, and ${ }^{13} \mathrm{C}$ NMR spectrum of compound $4 \mathbf{l}$

S76-S77

${ }^{1} \mathrm{H}$, and ${ }^{13} \mathrm{C}$ NMR spectrum of compound $\mathbf{4 m}$

S78-S79

General. ${ }^{1} \mathrm{H}$ and 1D NOE NMR spectra were obtained at $500 \mathrm{MHz}$ in DMSO. ${ }^{13} \mathrm{C}$ NMR were obtained at $125 \mathrm{MHz}$ in DMSO except that compound 3k was recorded in $\mathrm{CDCl}_{3}$. $\mathrm{HRMS}$ were obtained by HR-EI method. 

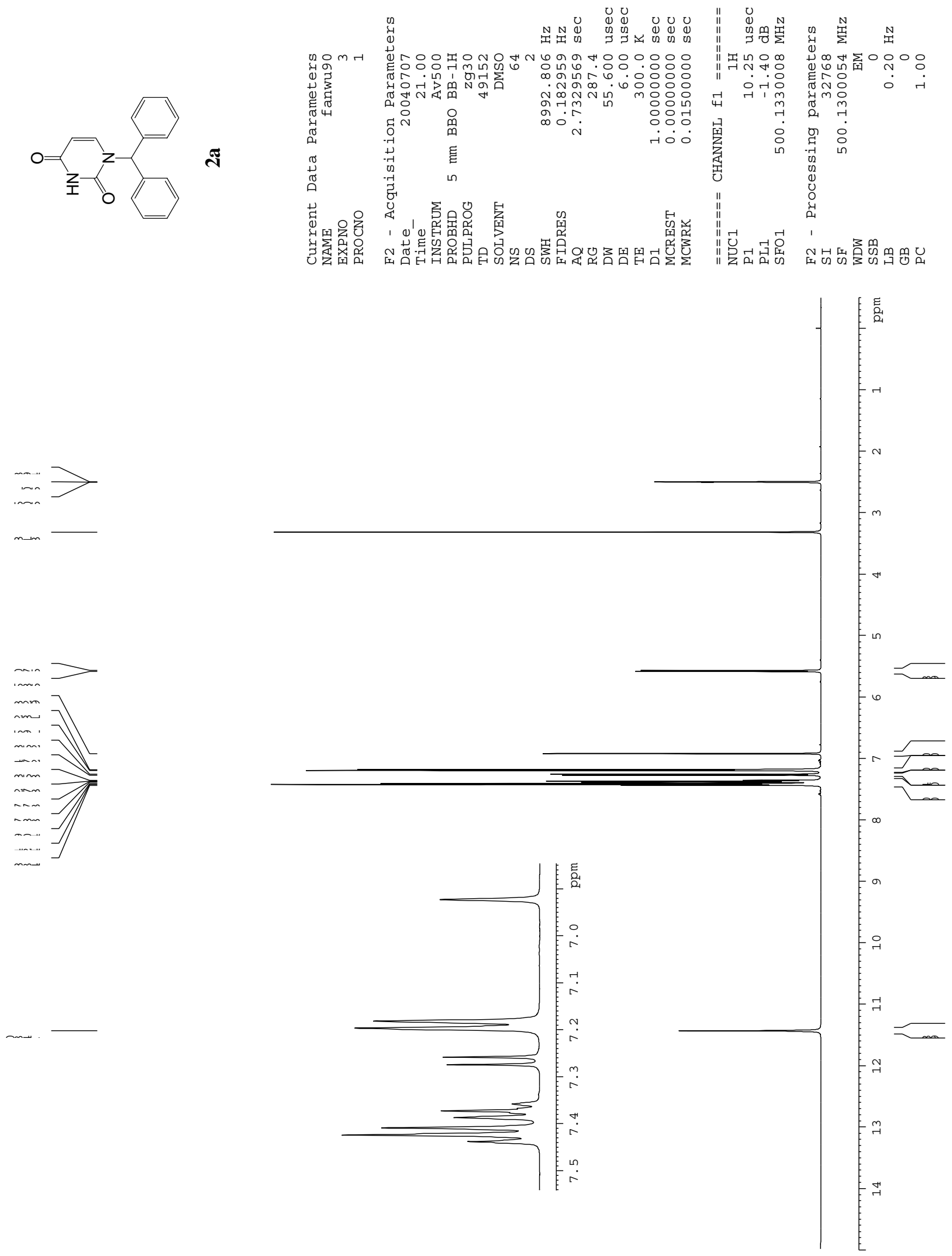

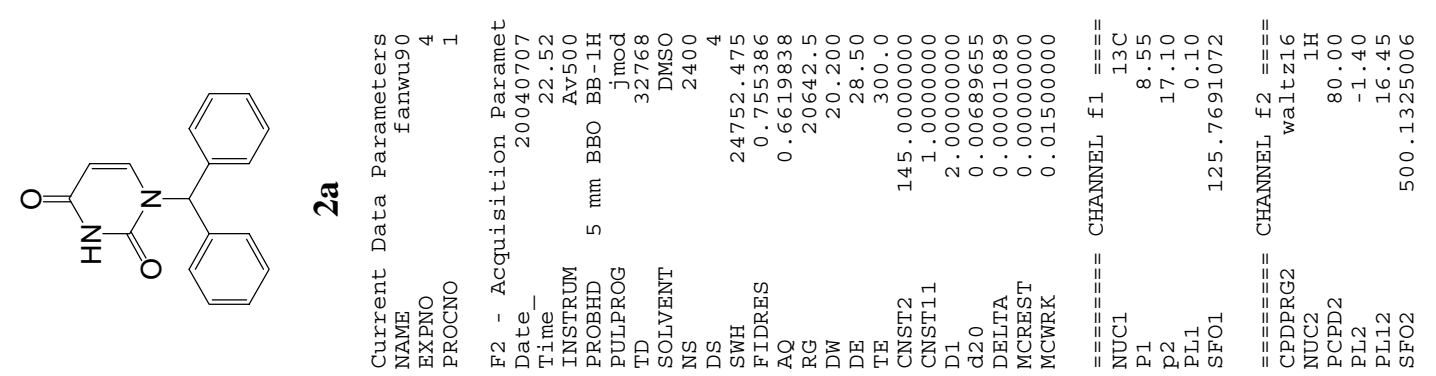

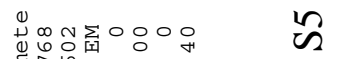

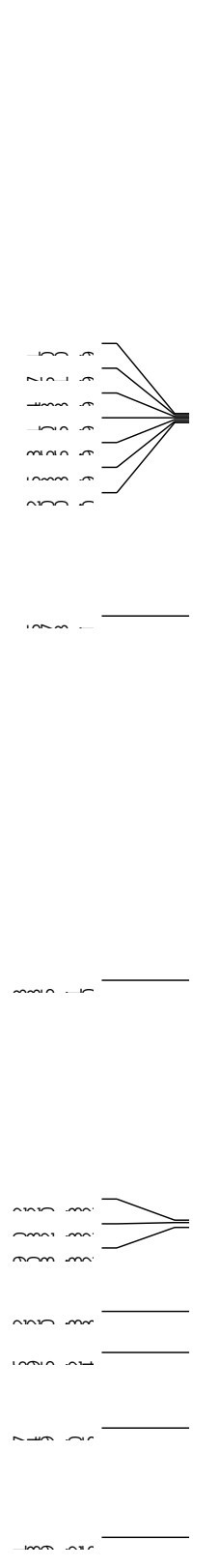

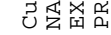

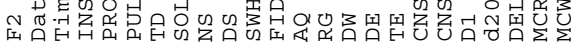
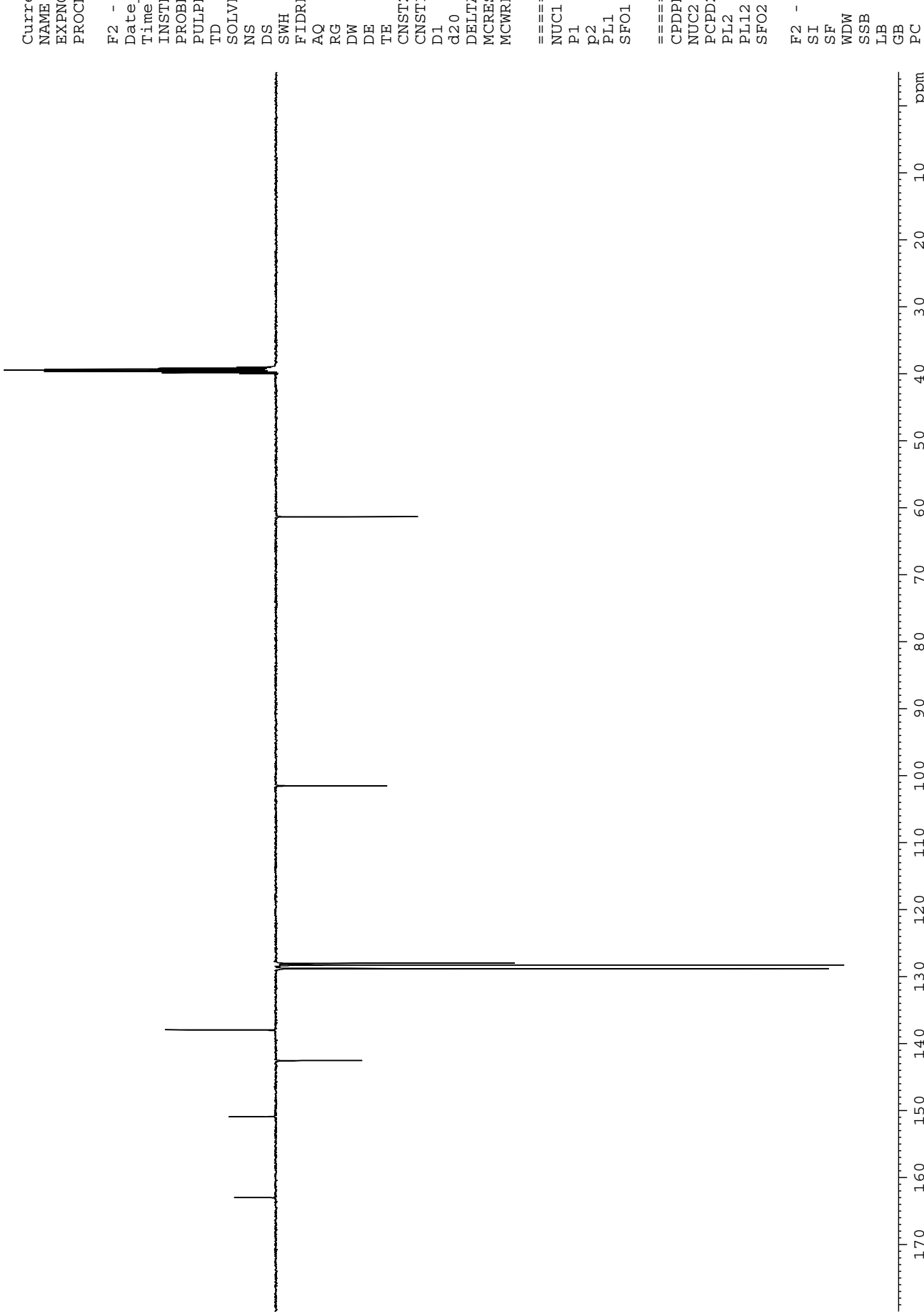

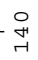




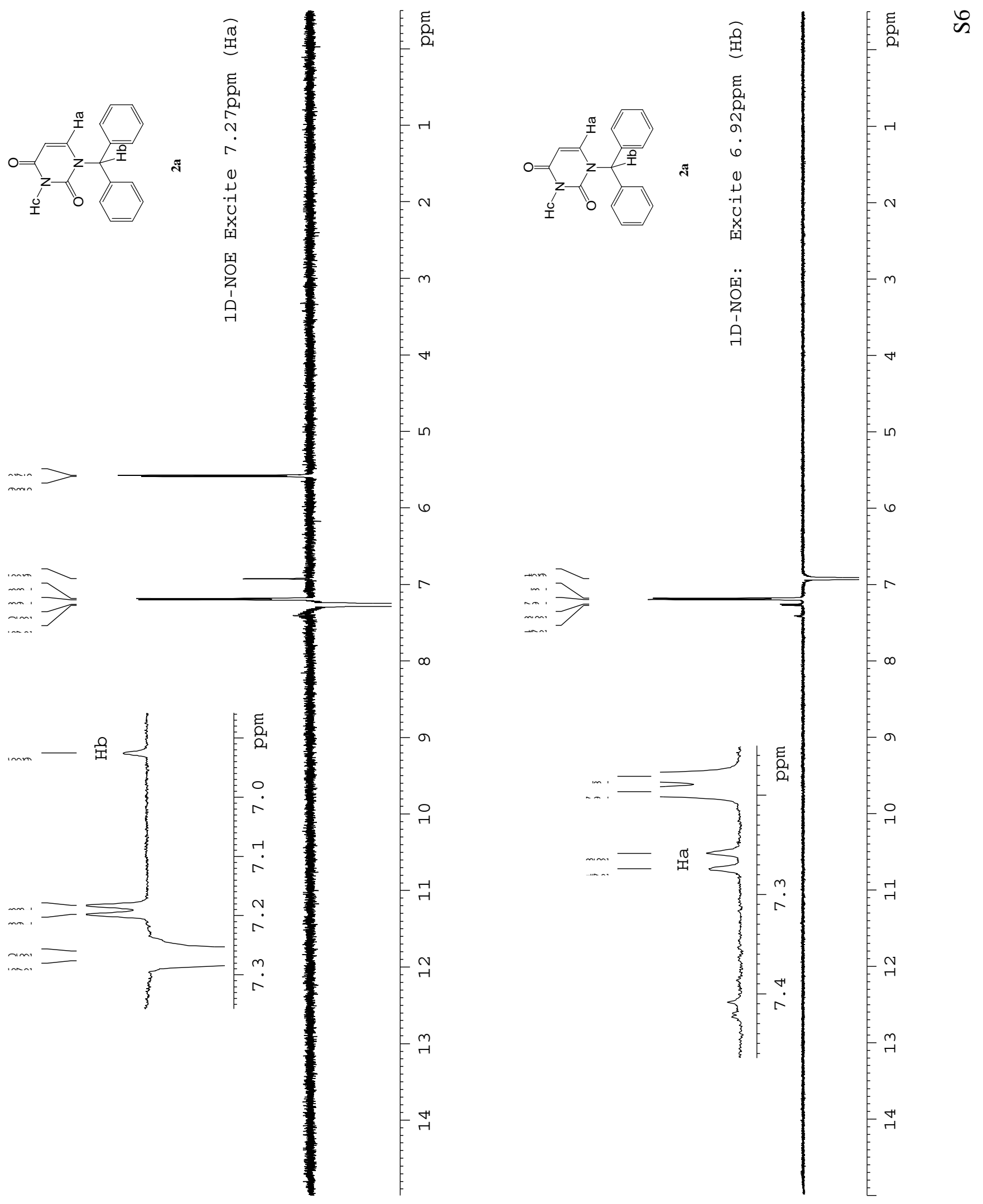




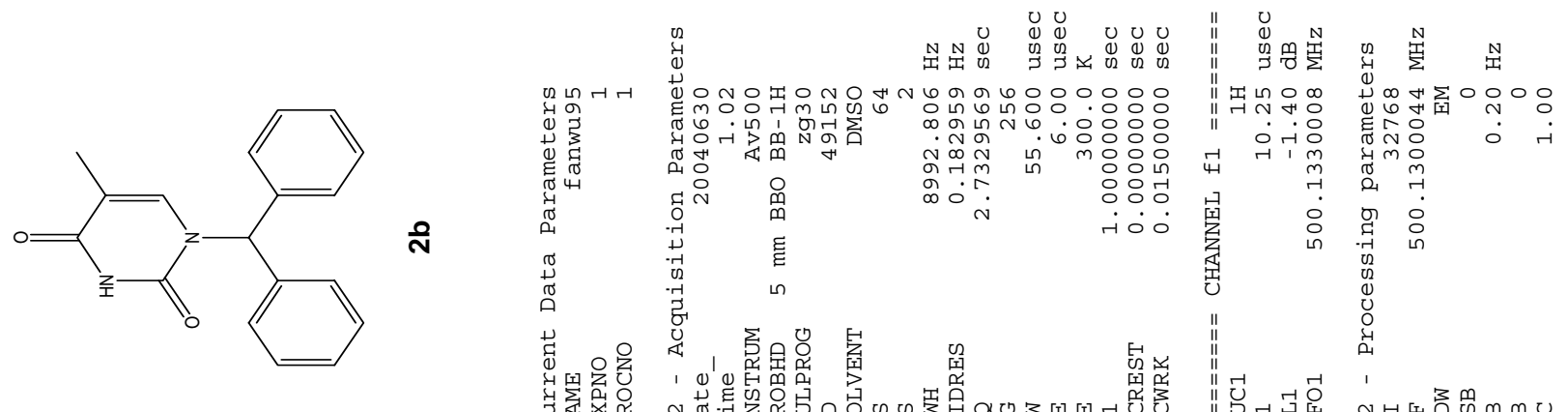

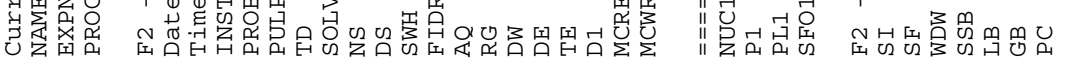
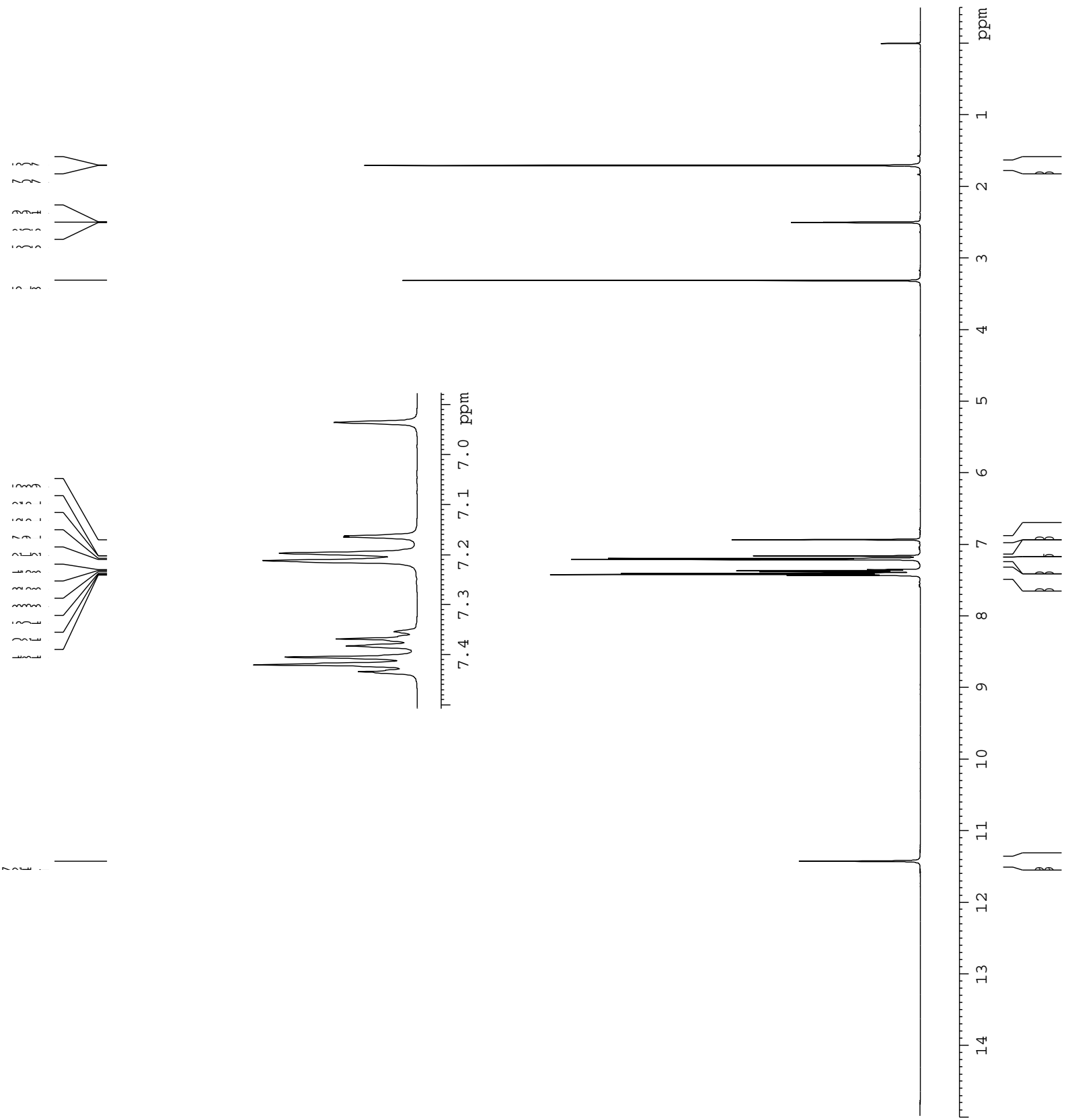

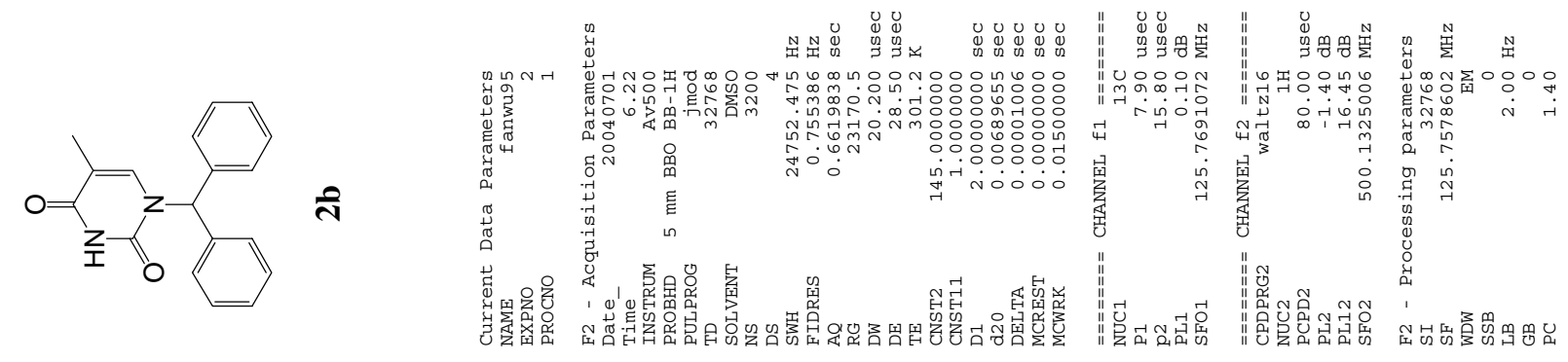

$\stackrel{\infty}{\sim}$
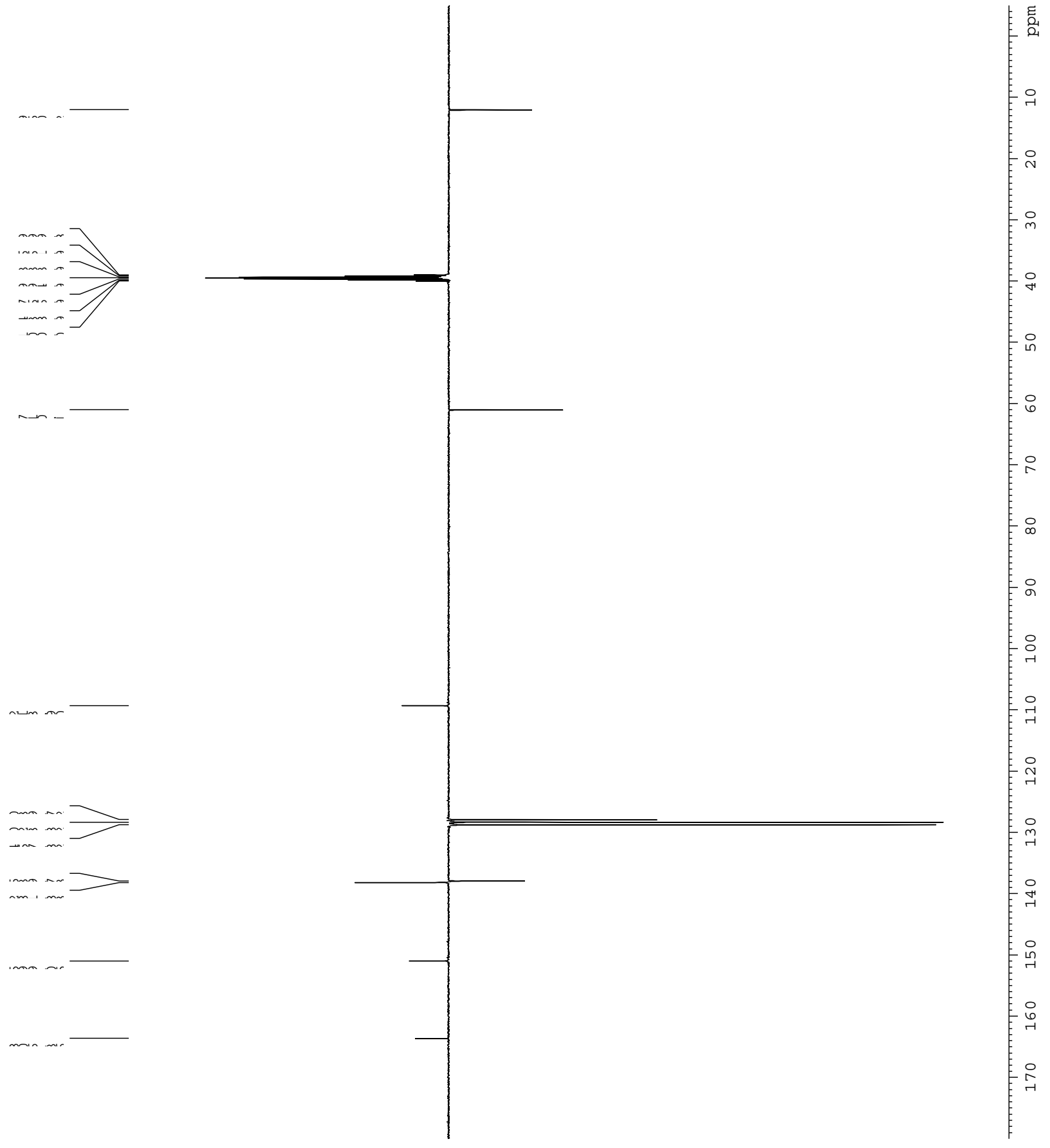


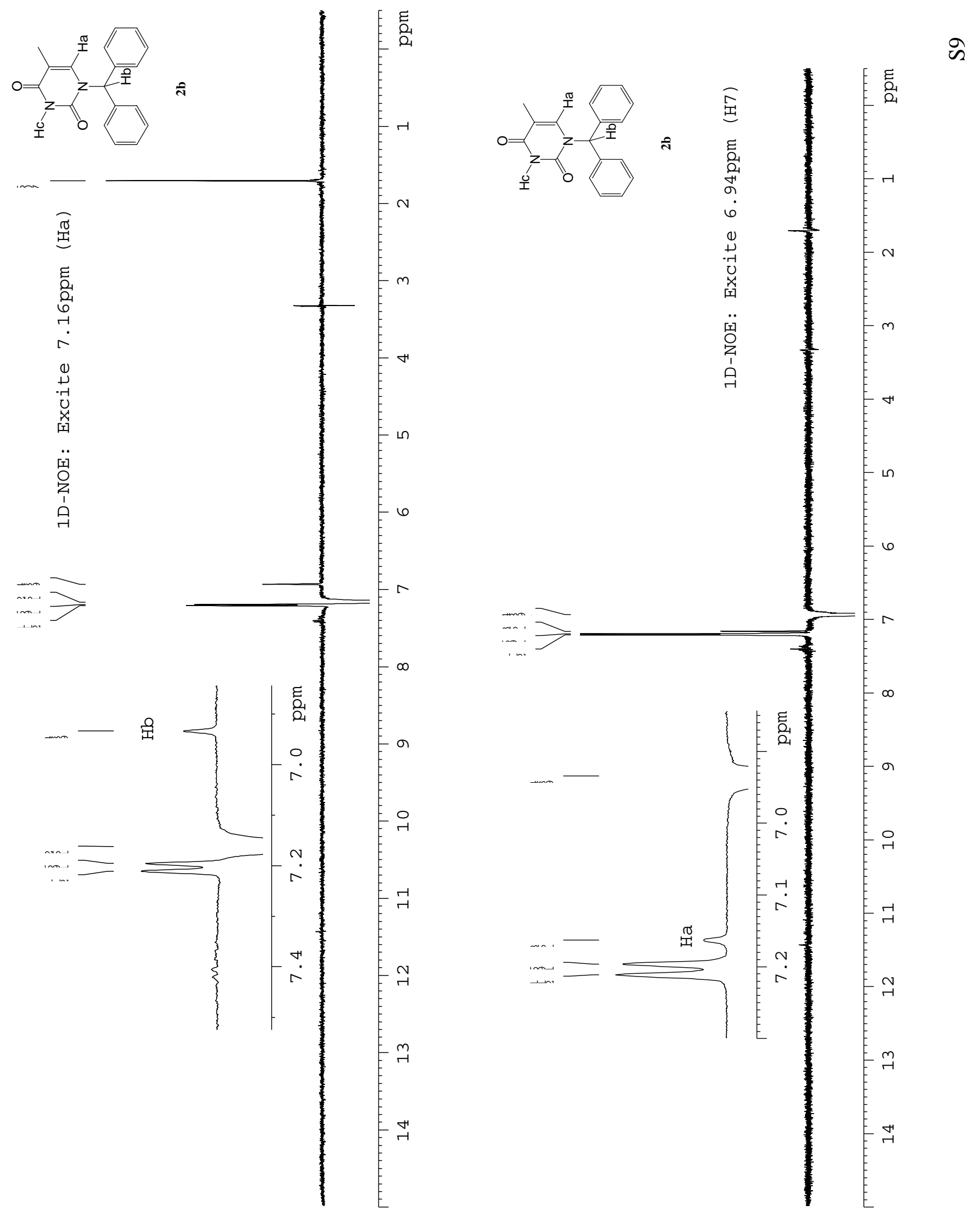



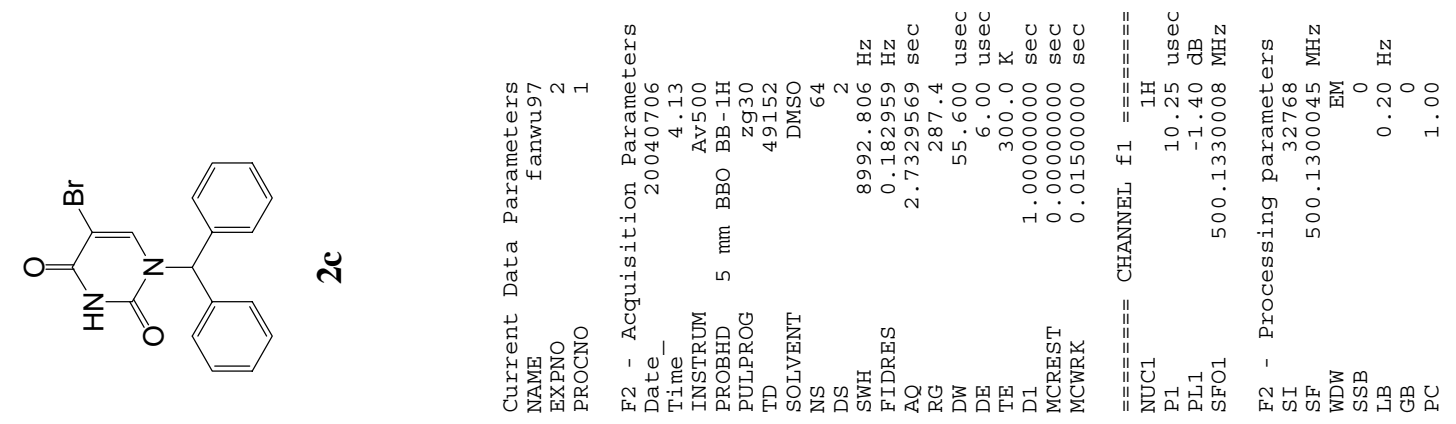

$\frac{0}{\sim}$
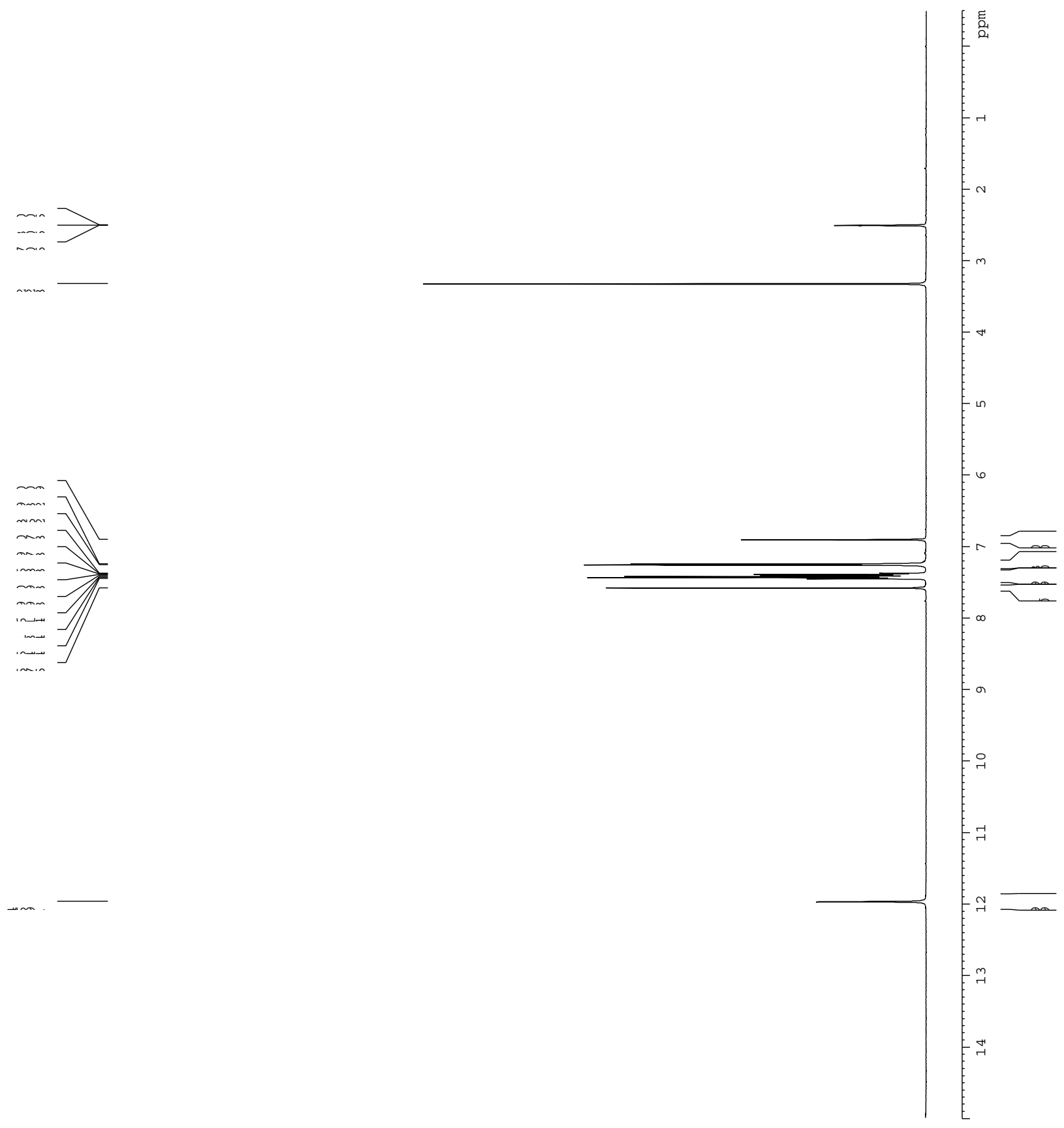

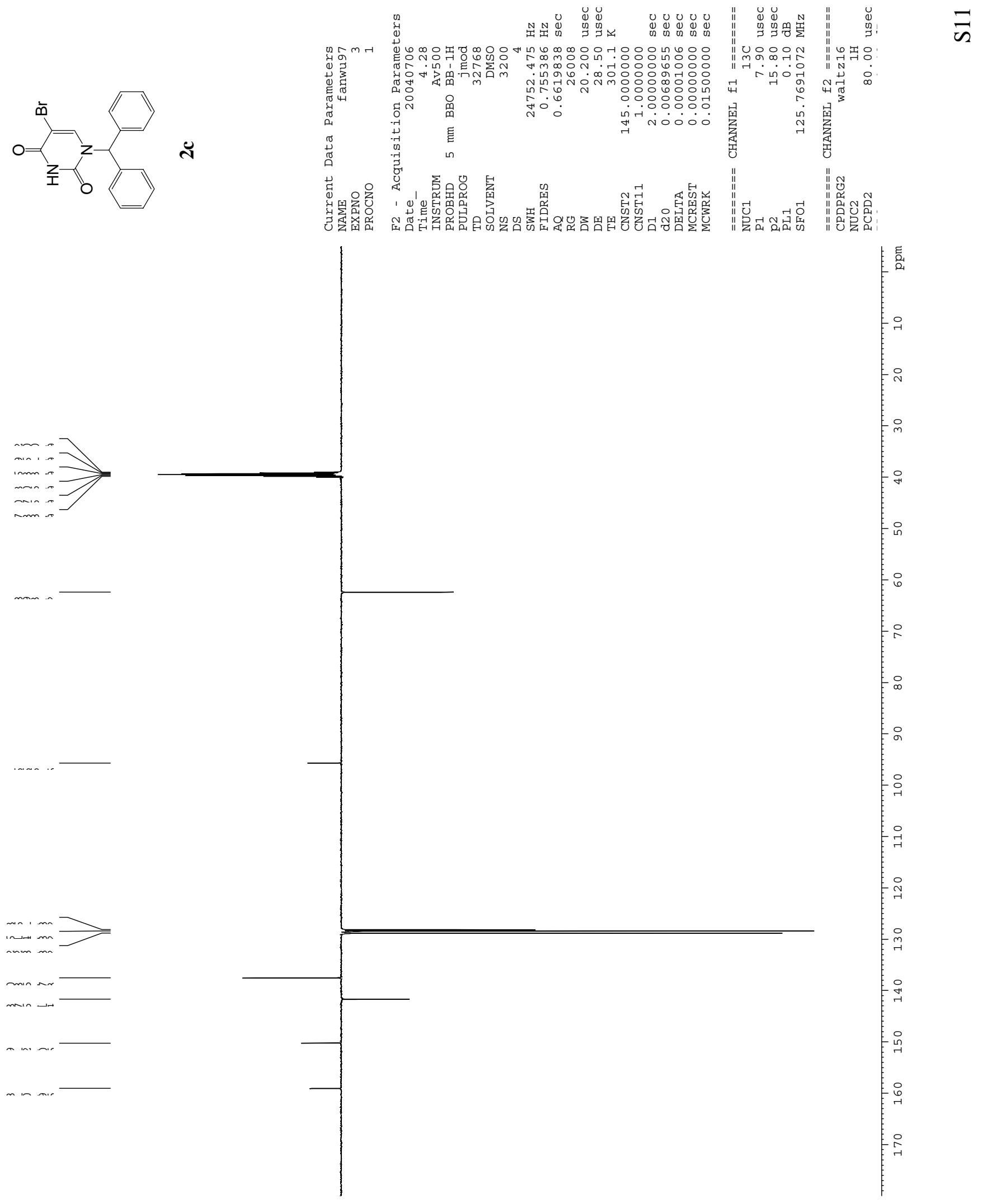


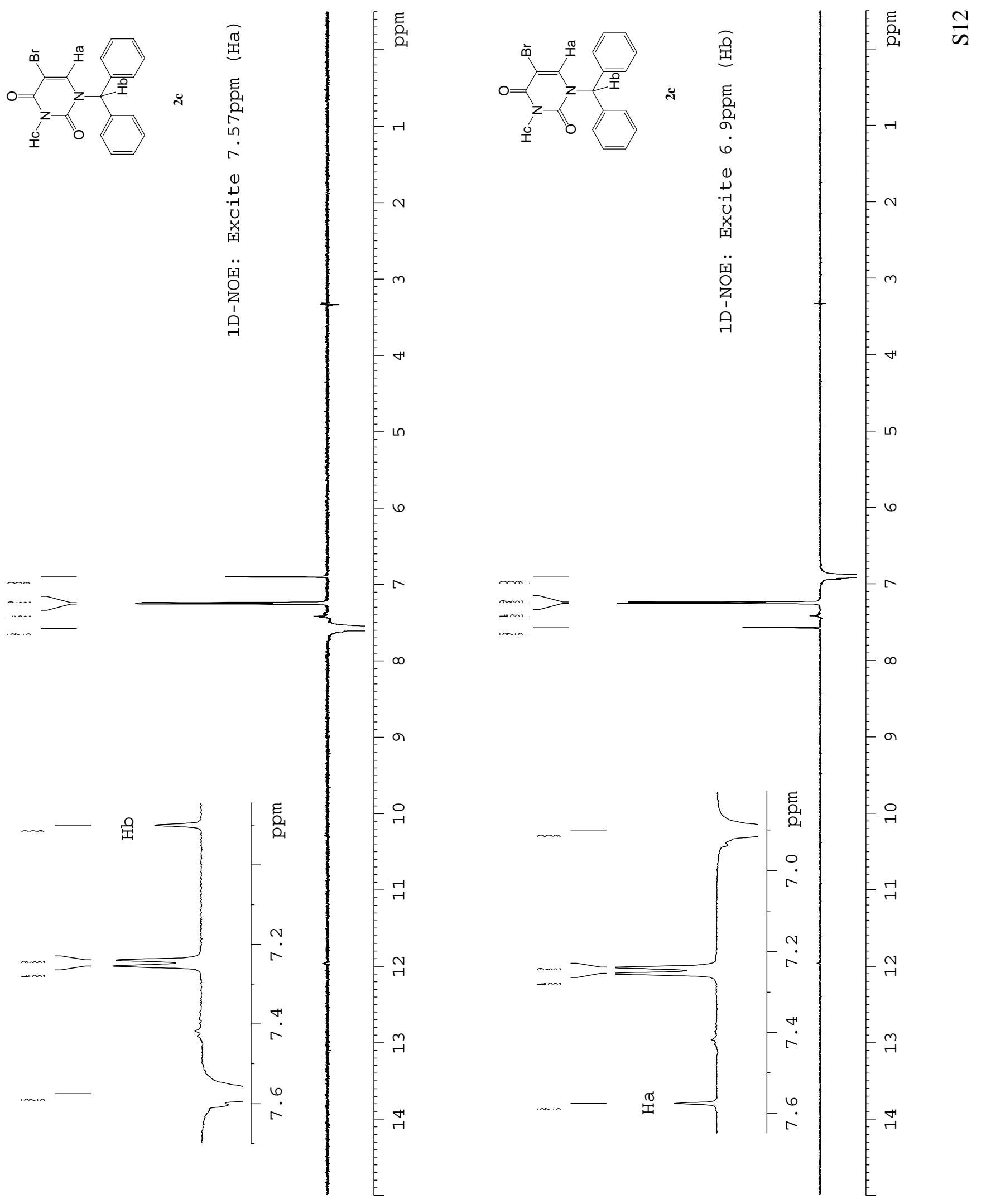



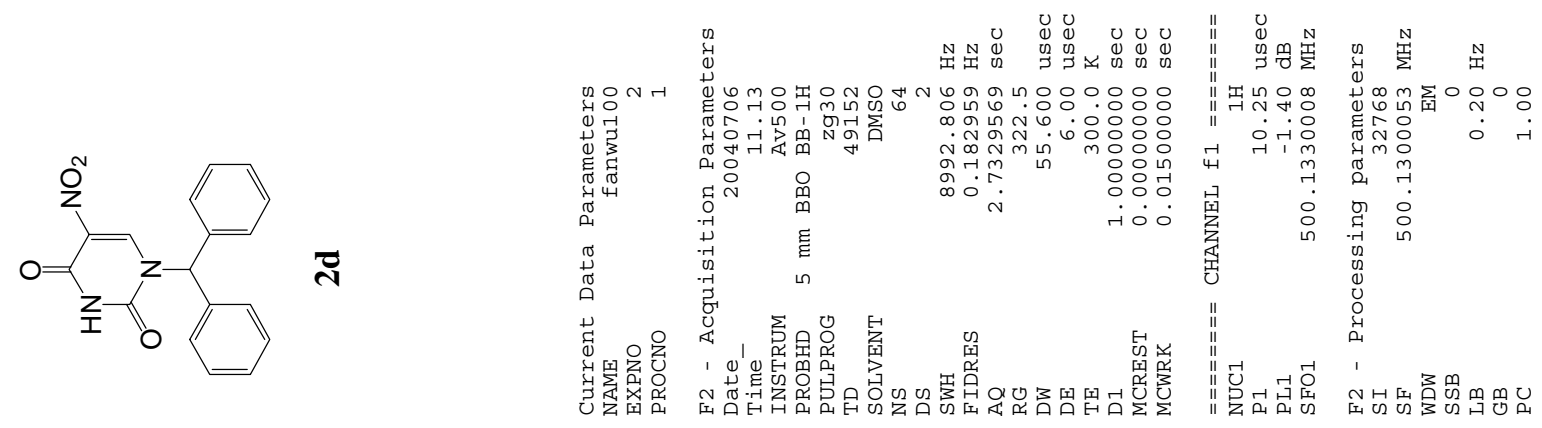

$\frac{n}{n}$
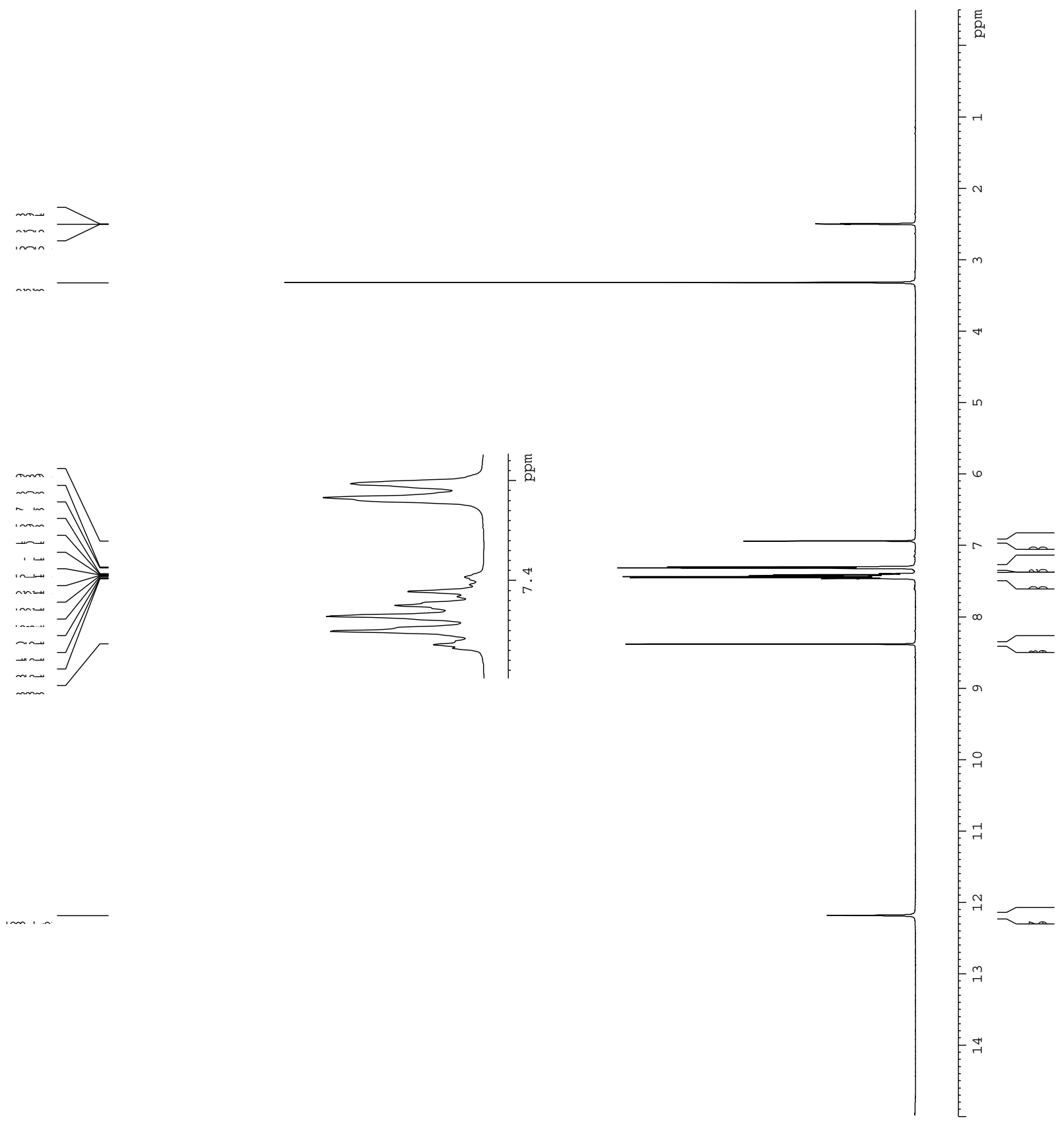

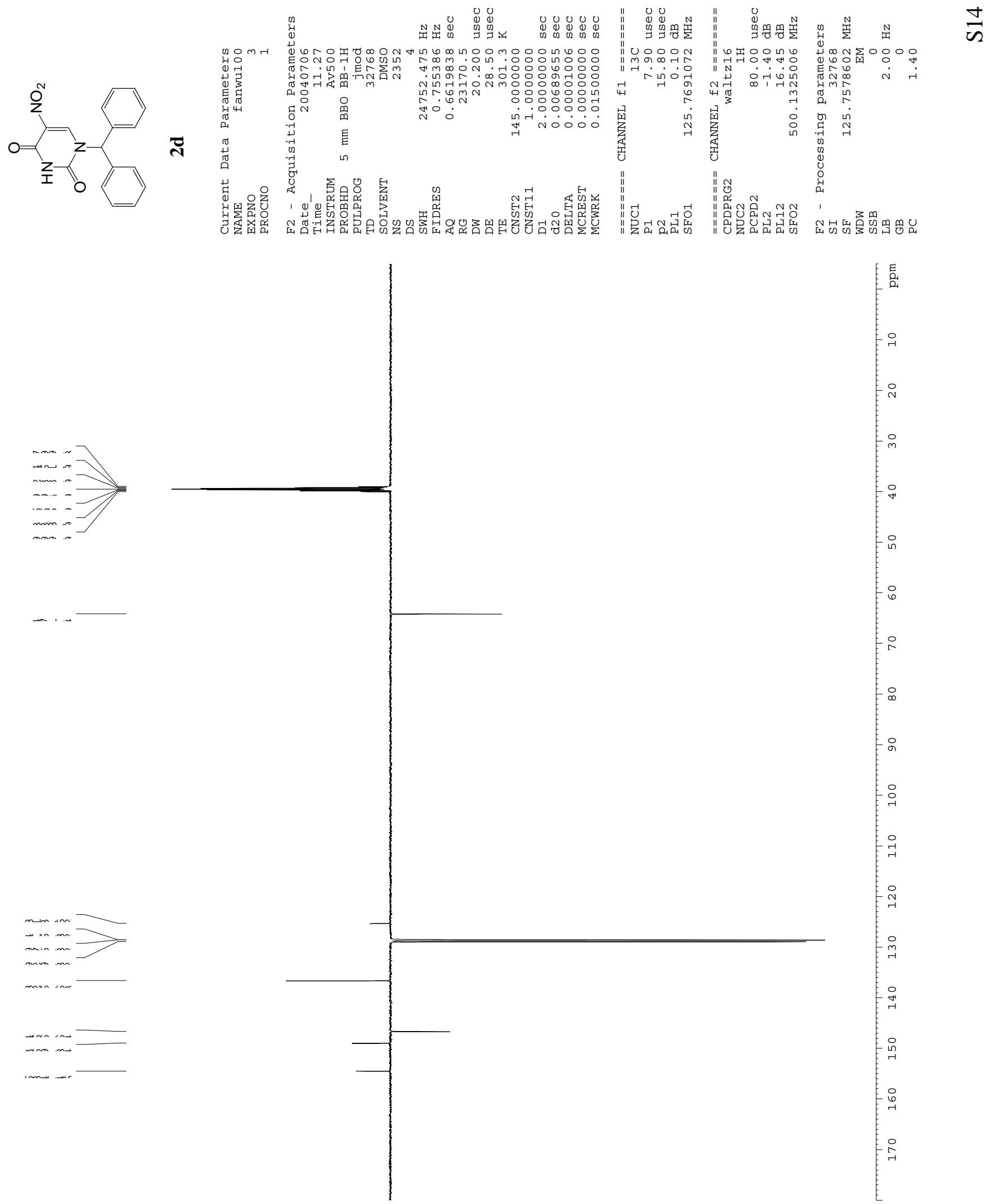


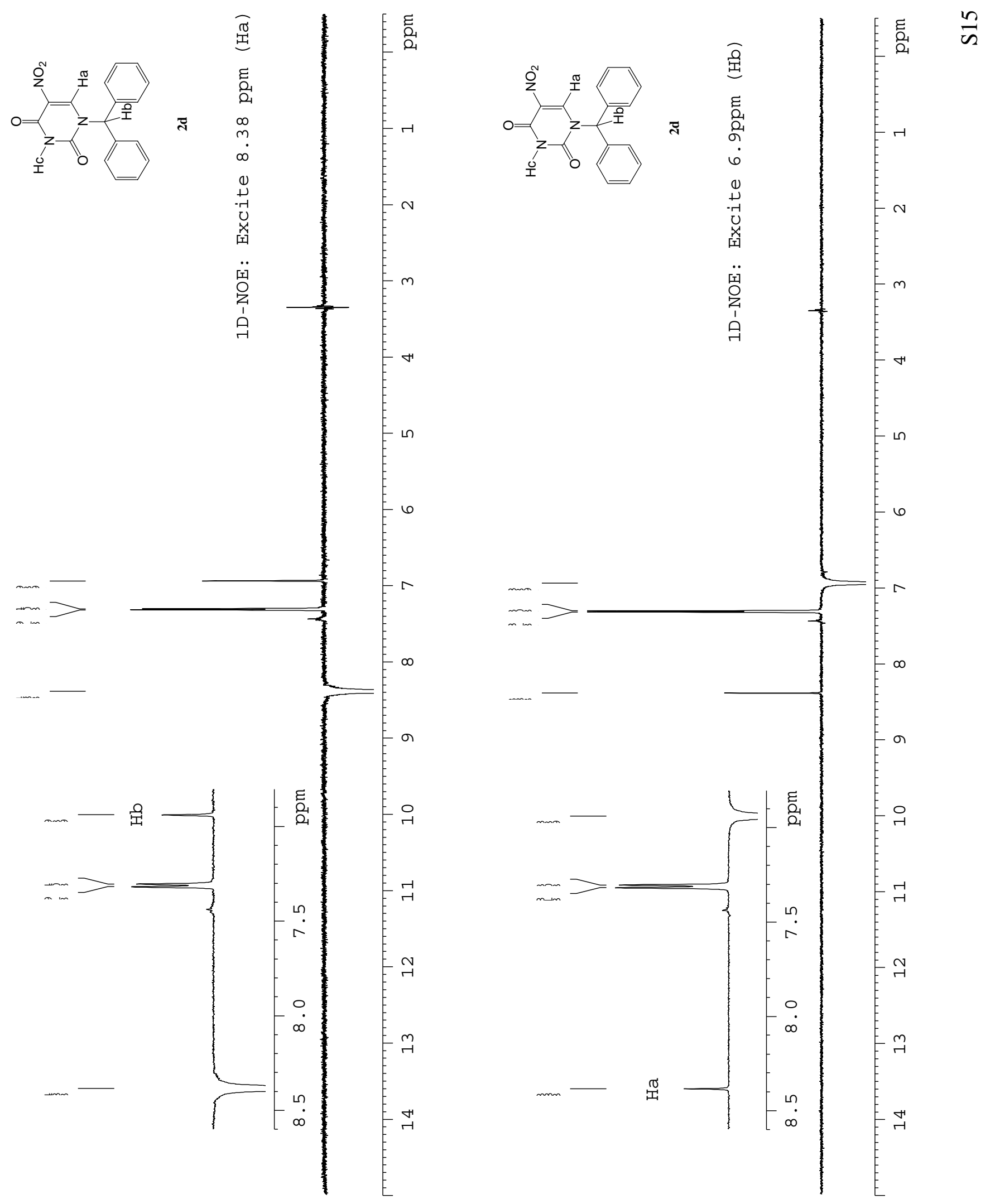



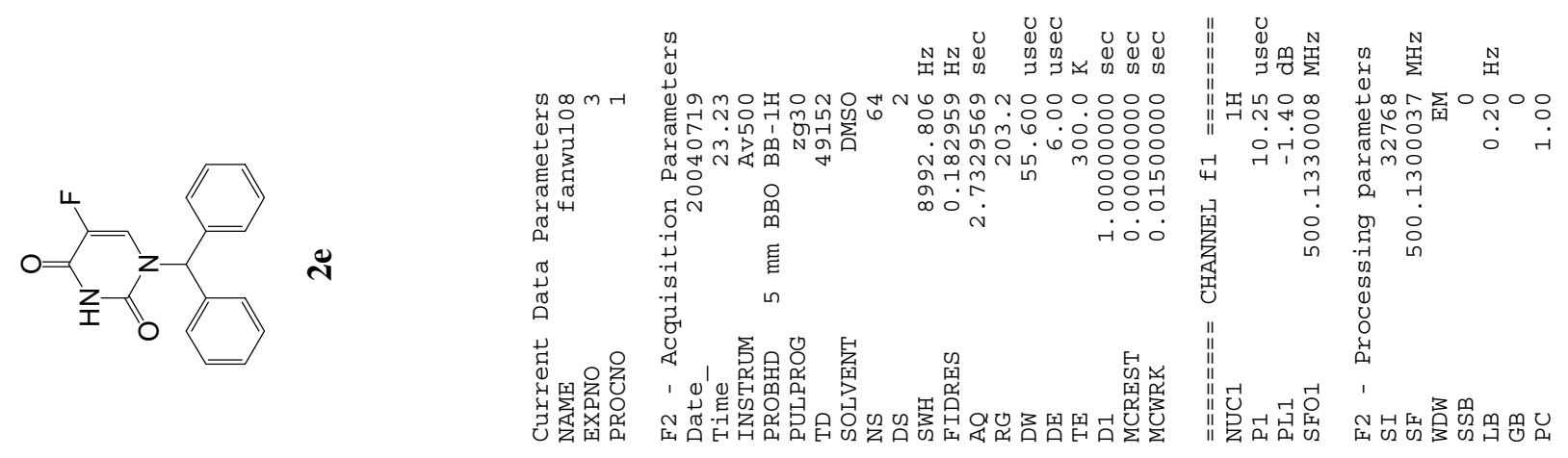

$\frac{0}{n}$
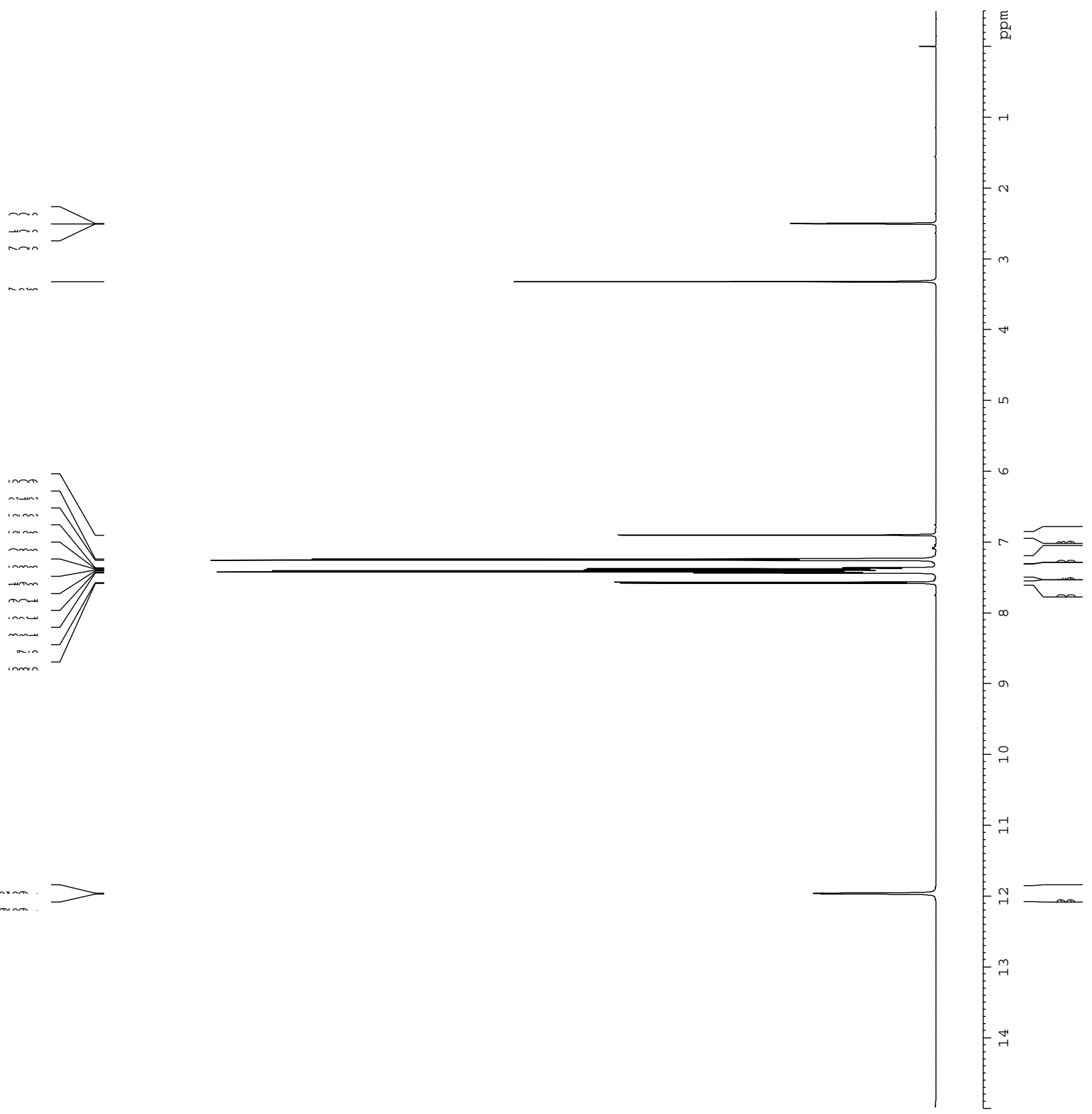

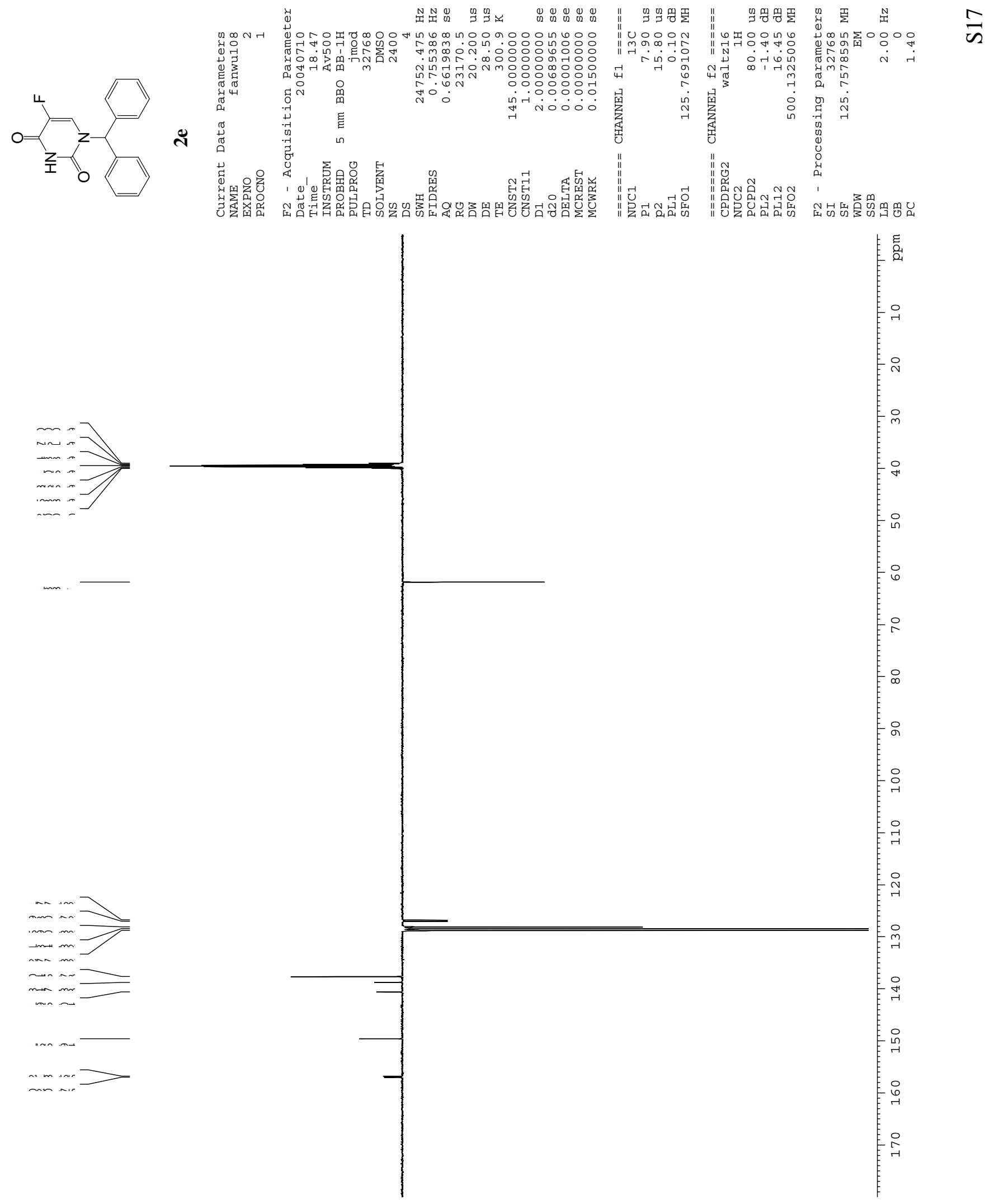


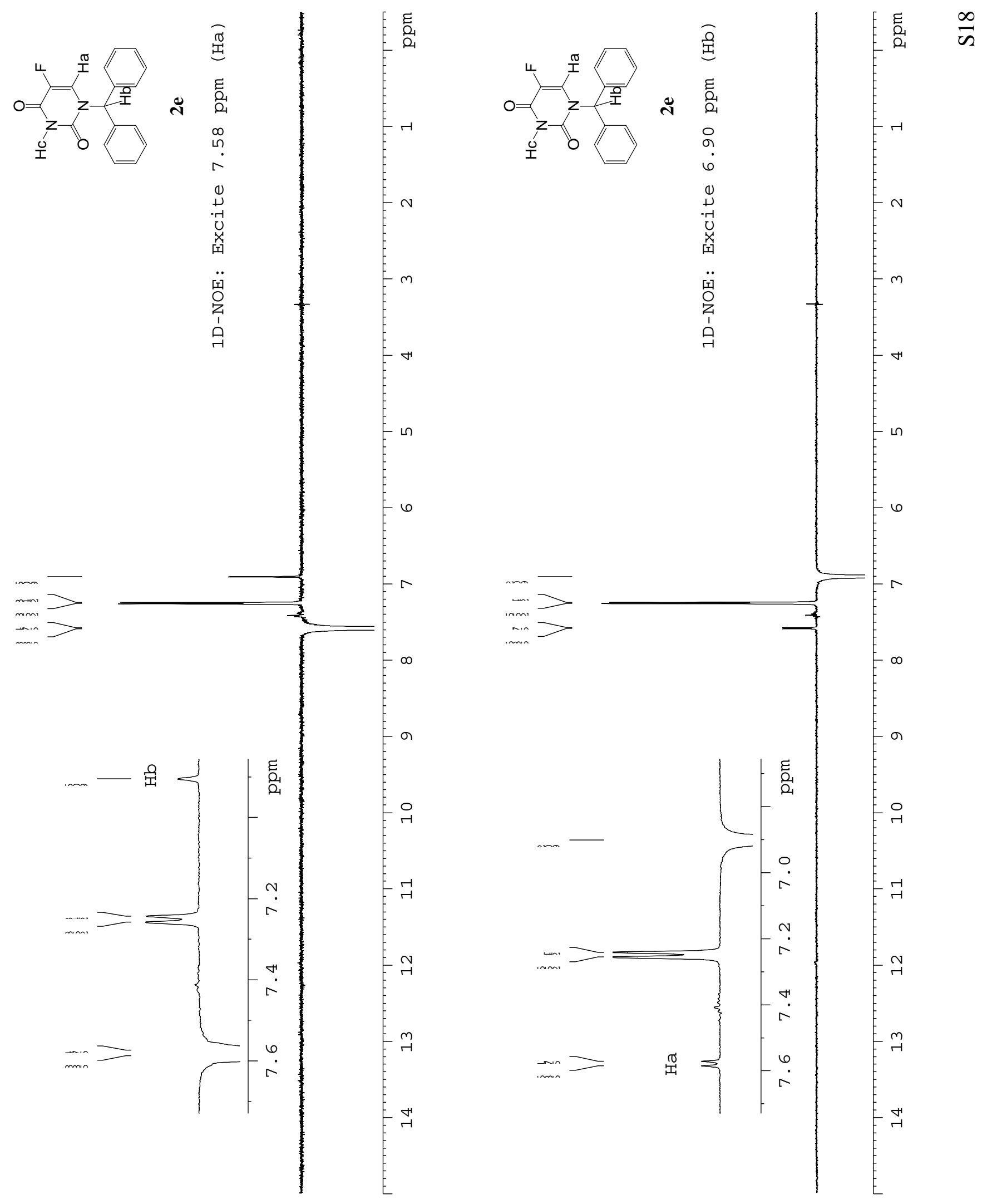



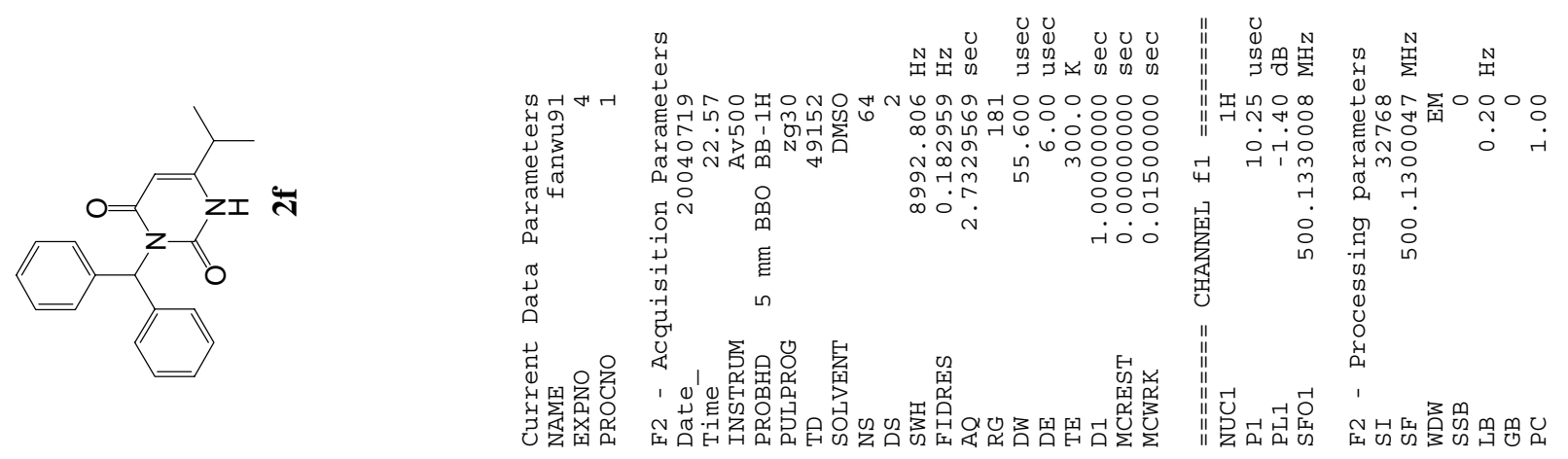

$\frac{a}{n}$
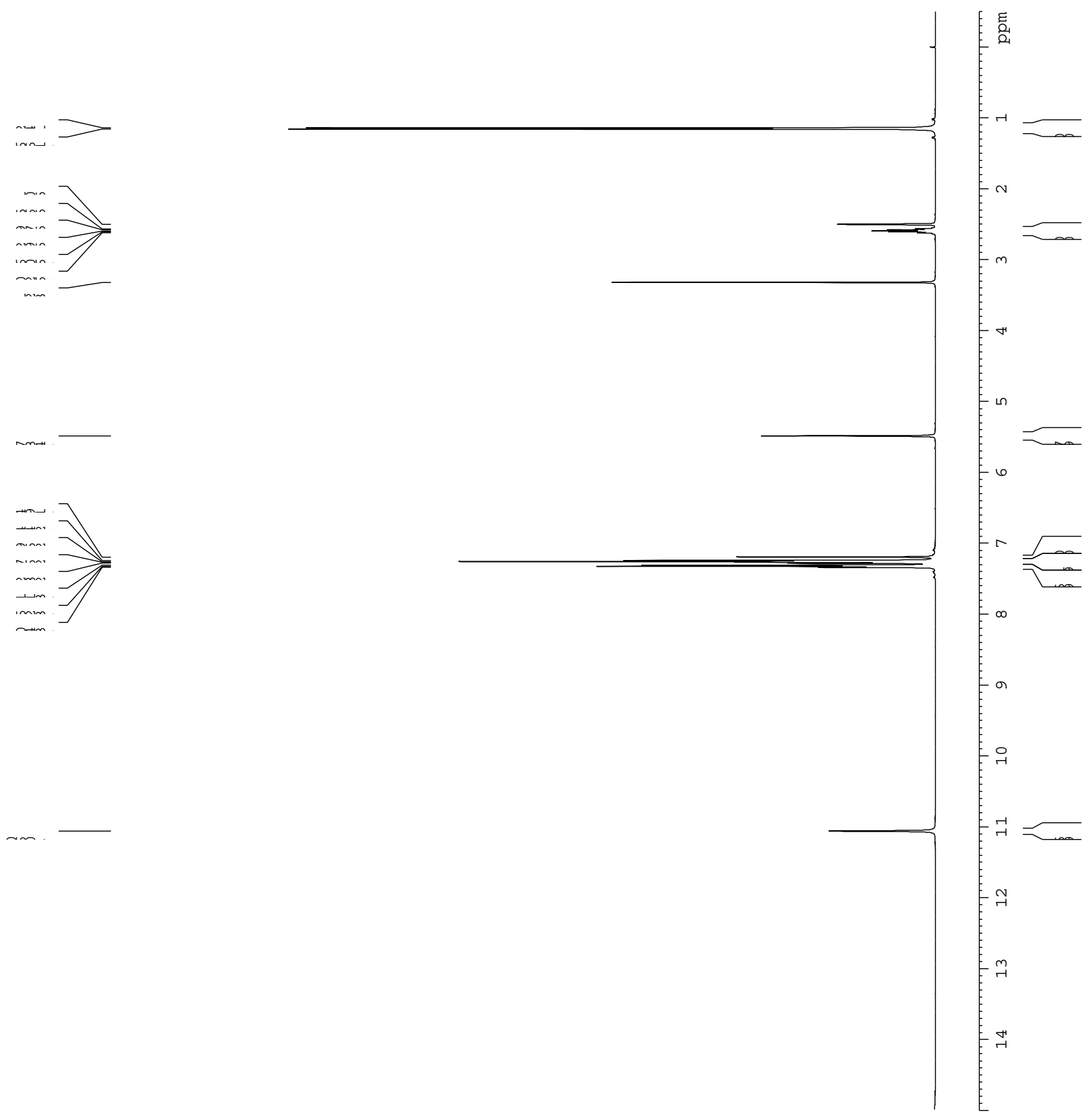

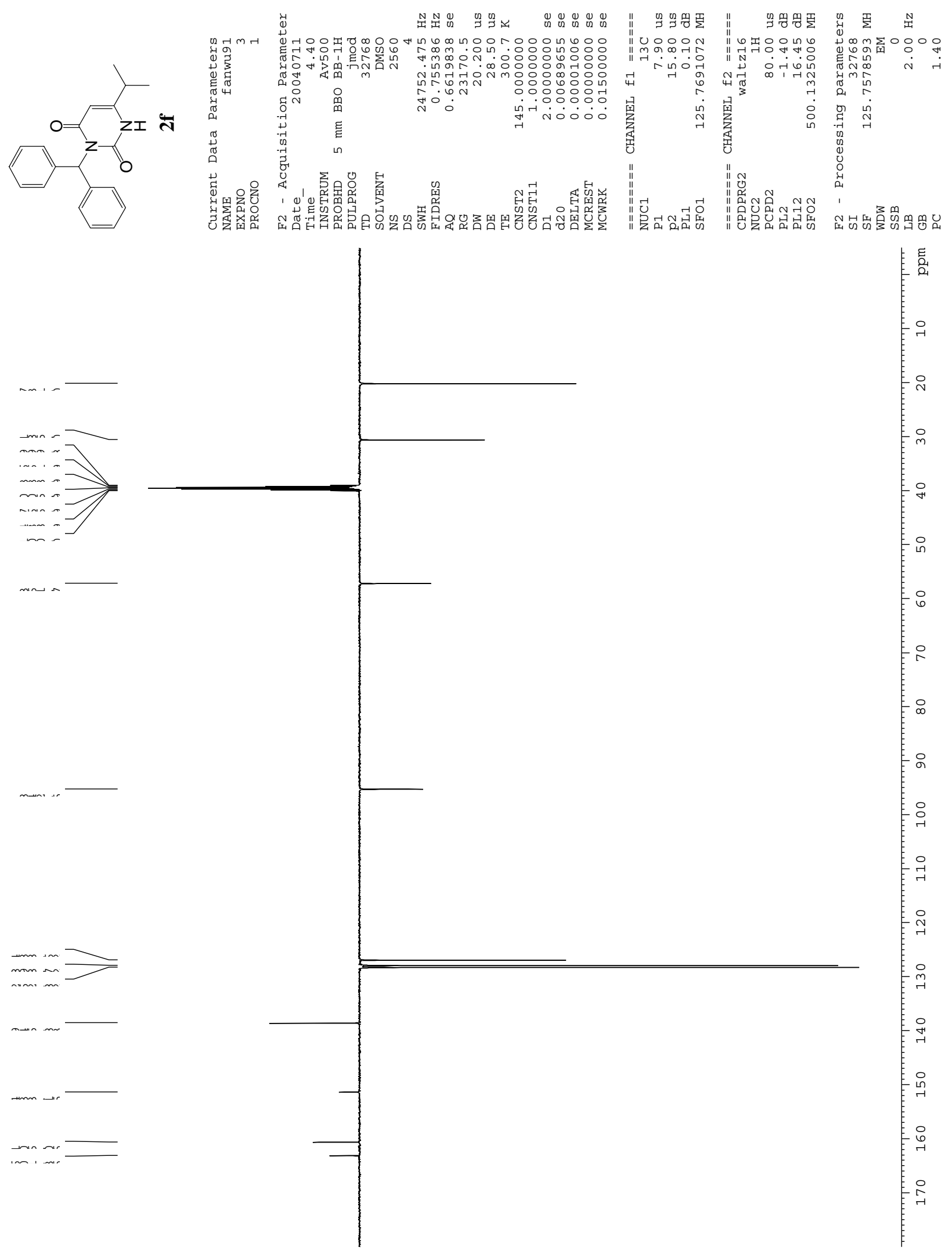


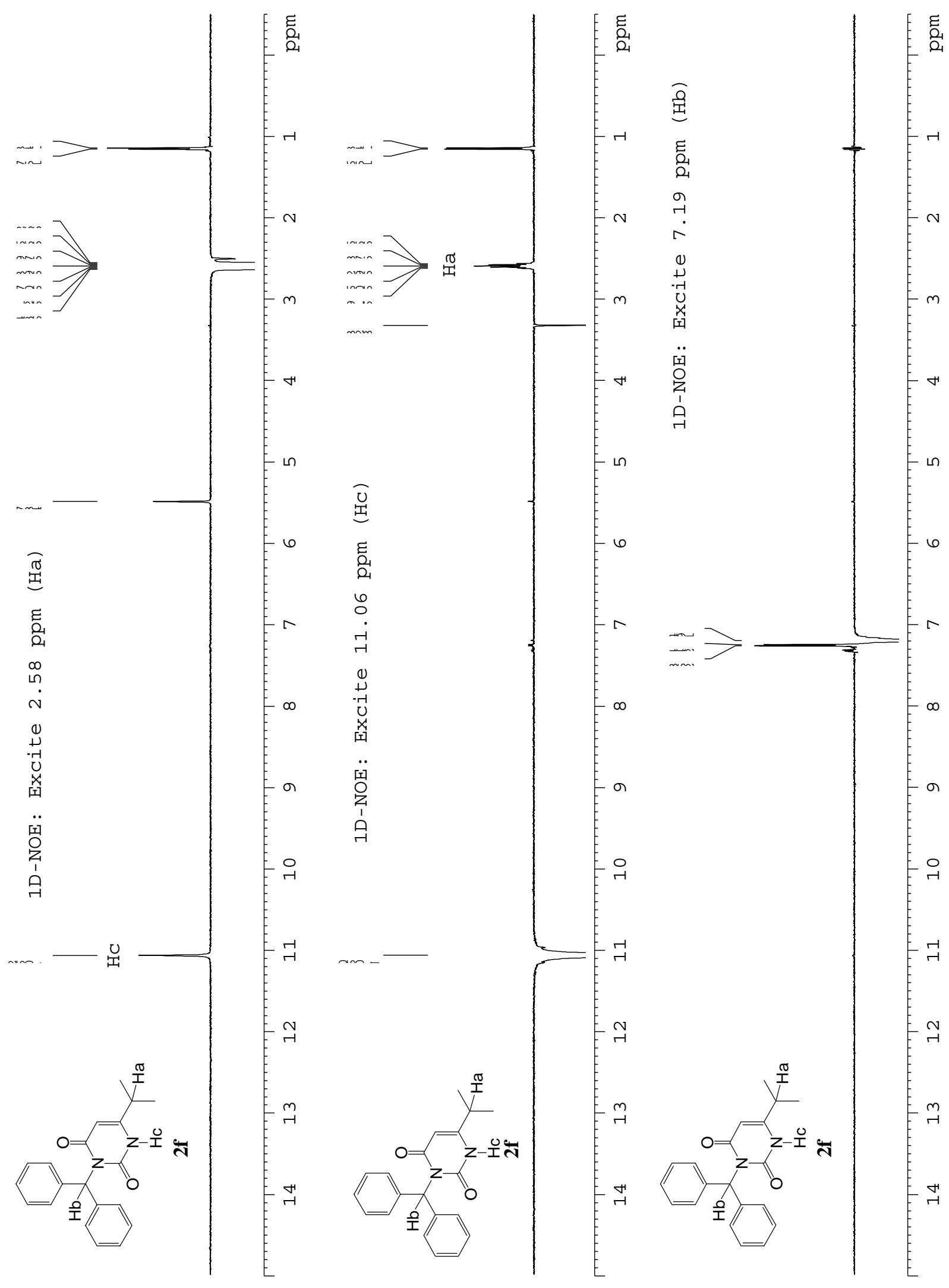



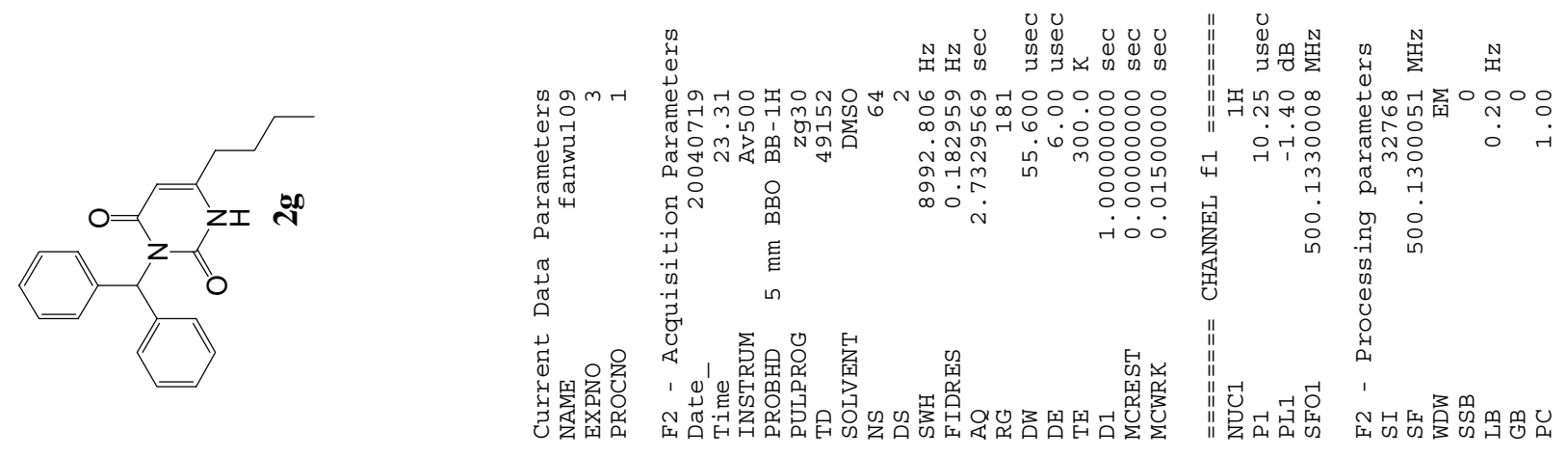

ถี
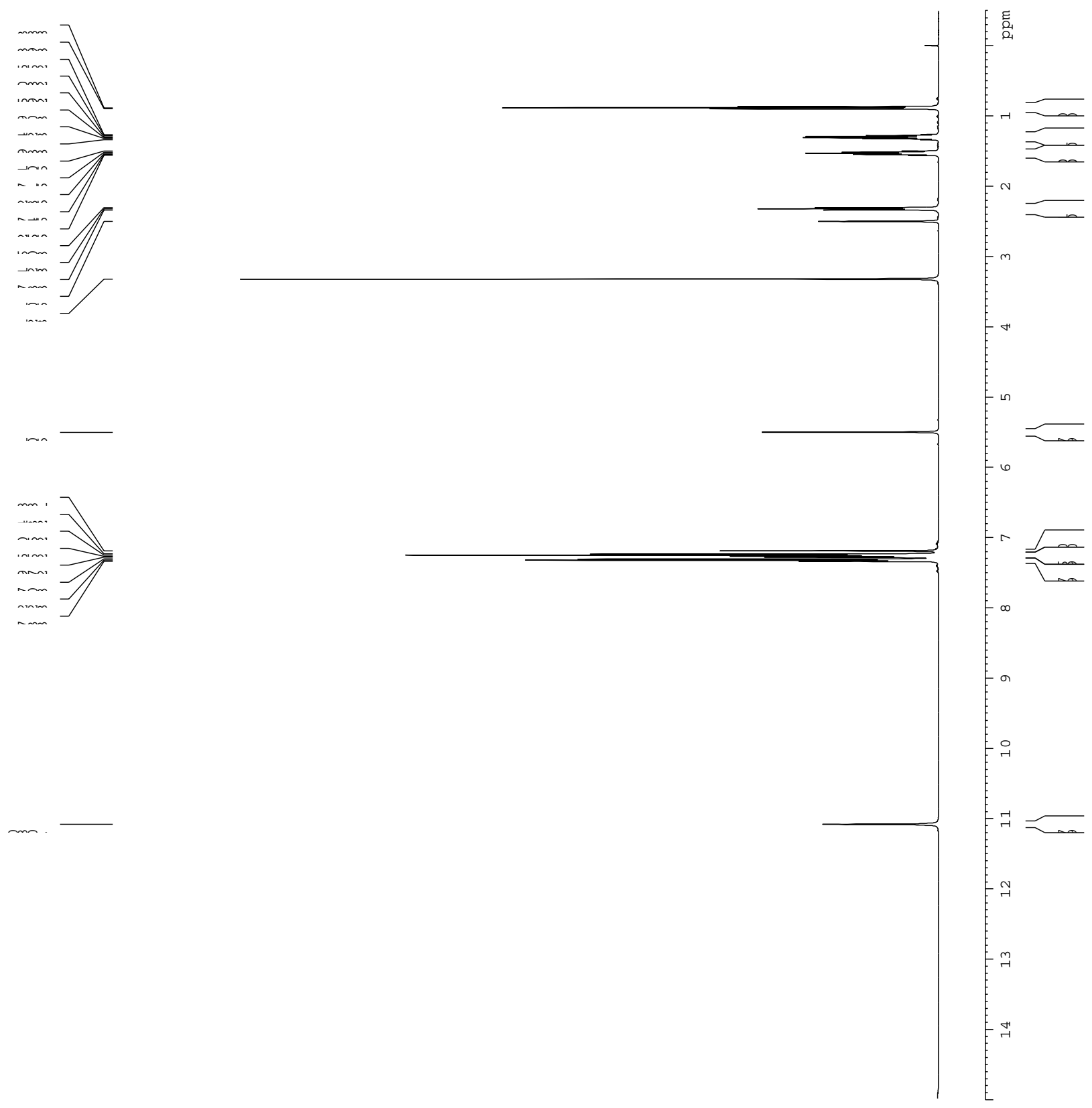

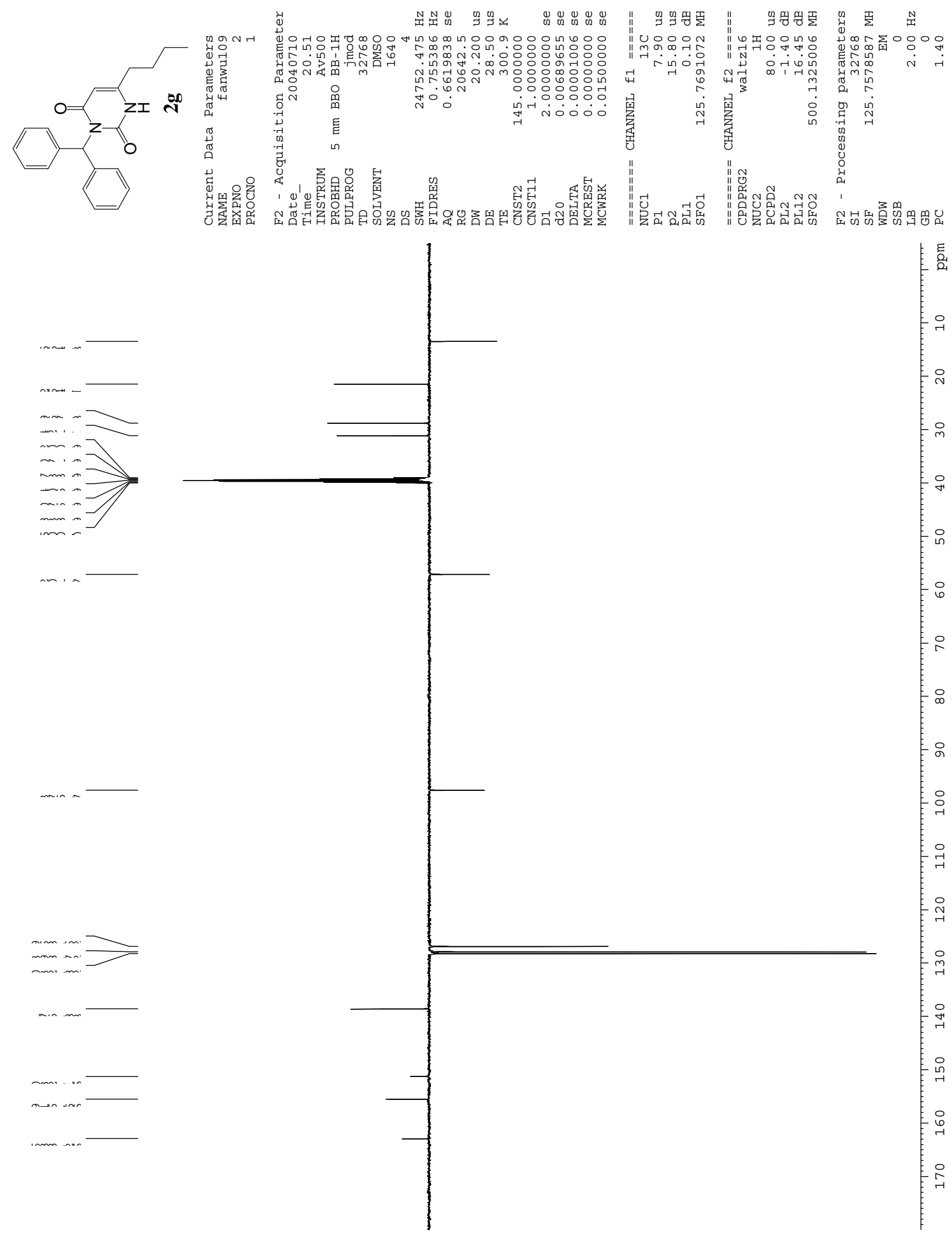


$$
\|
$$



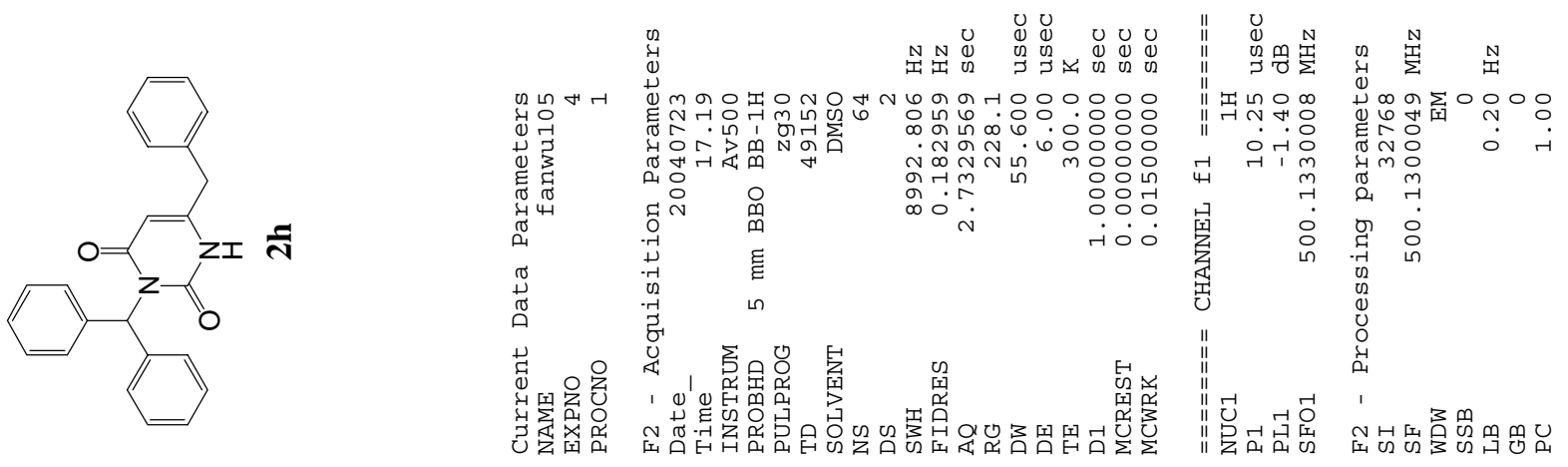

กิ
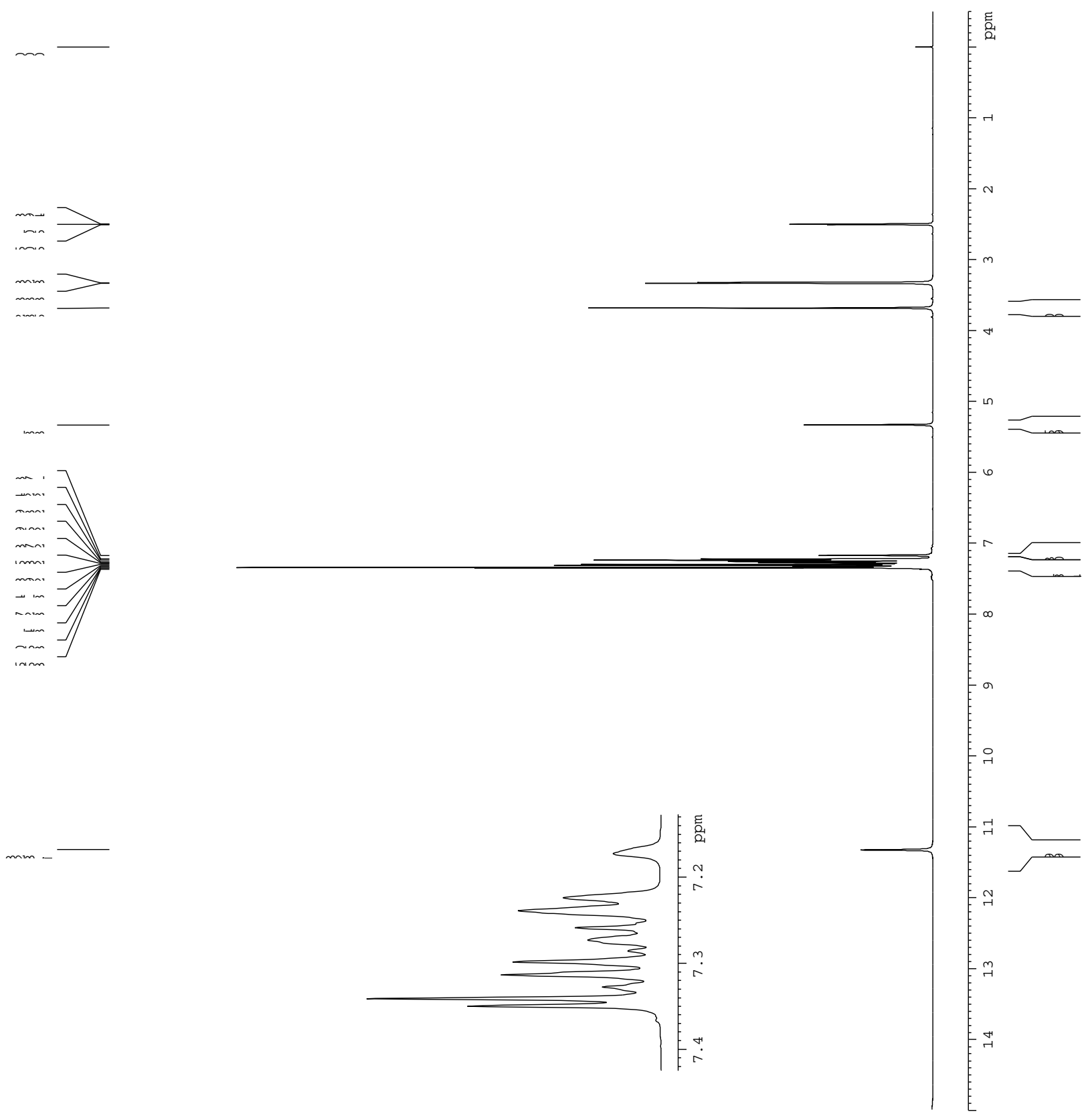

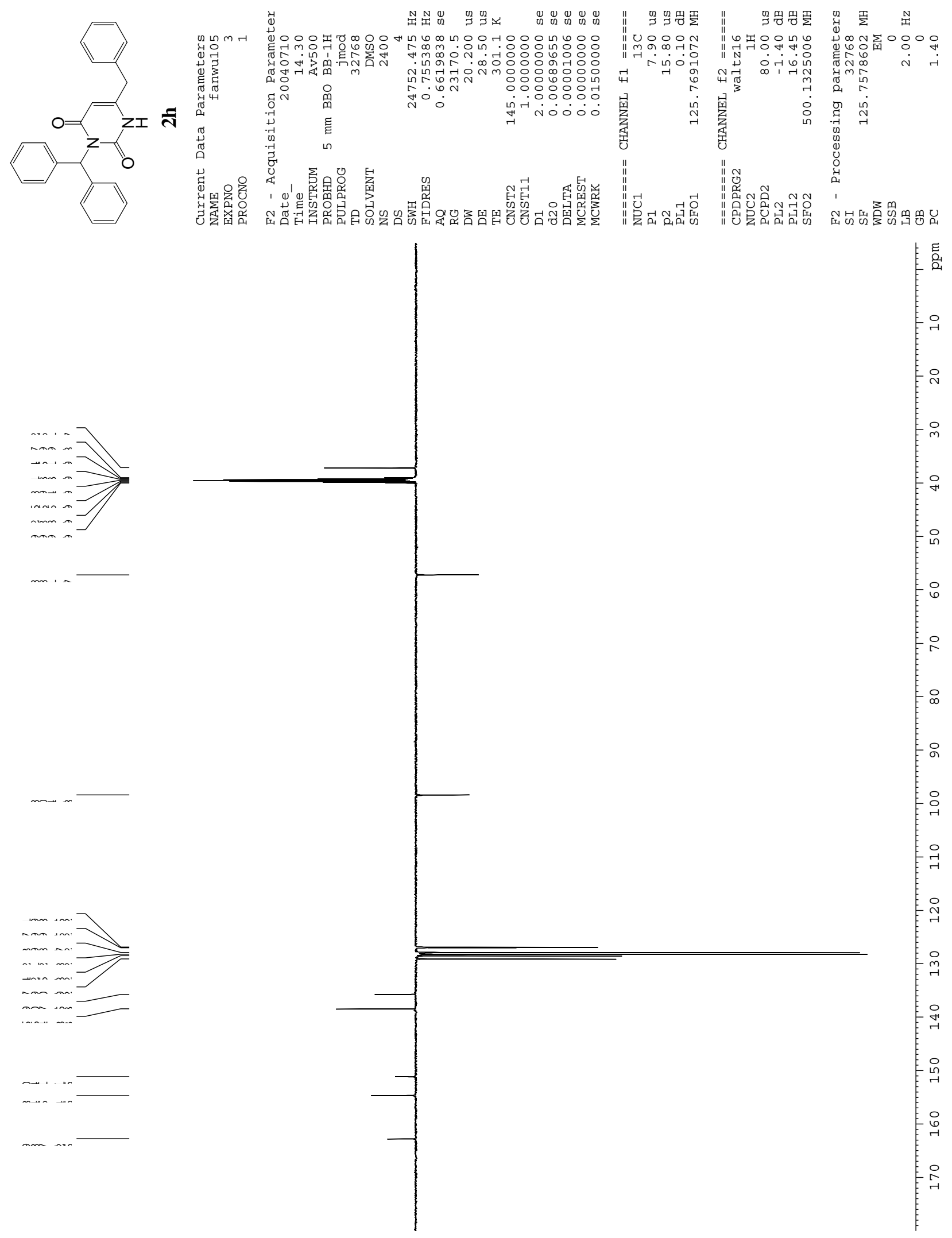


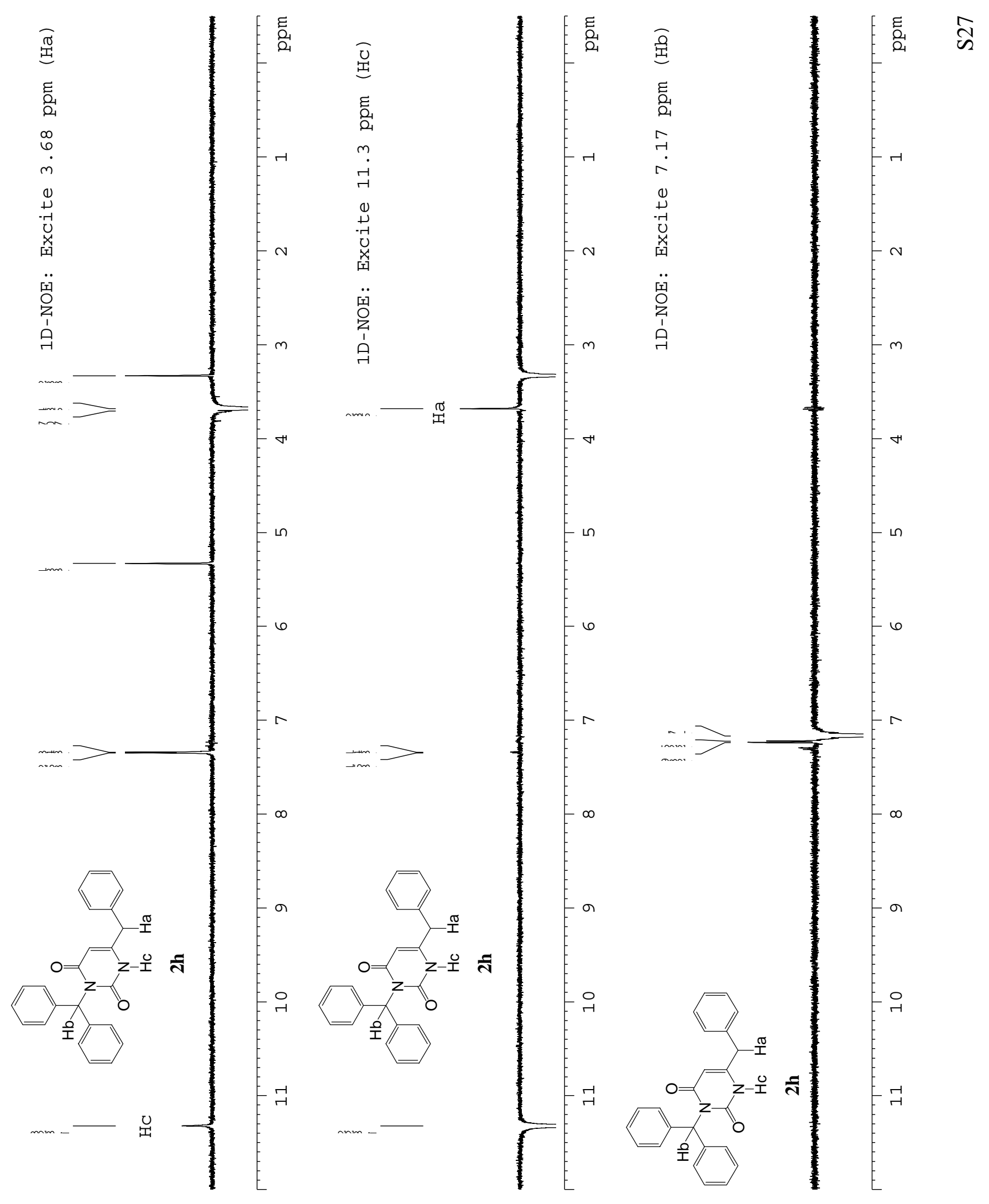



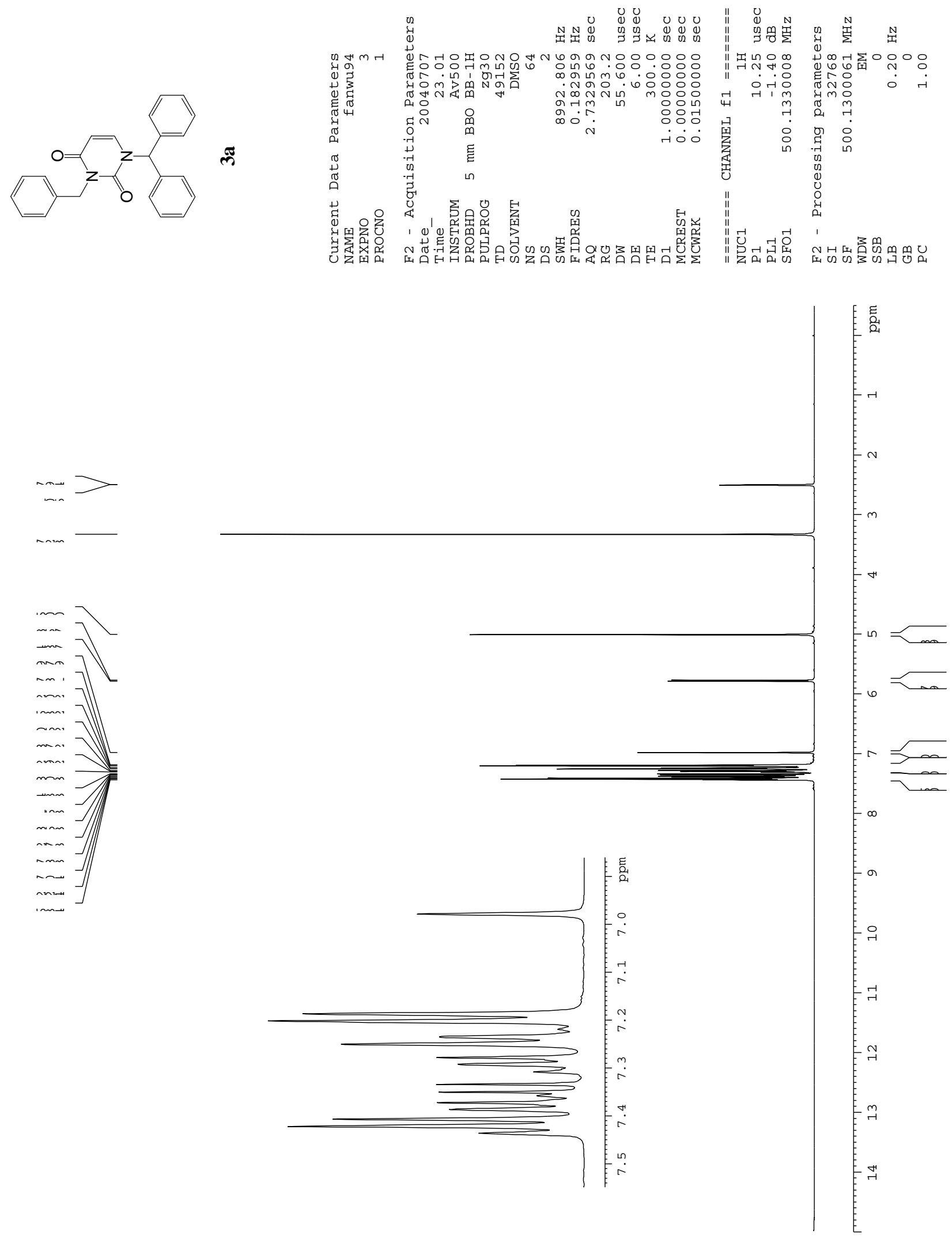

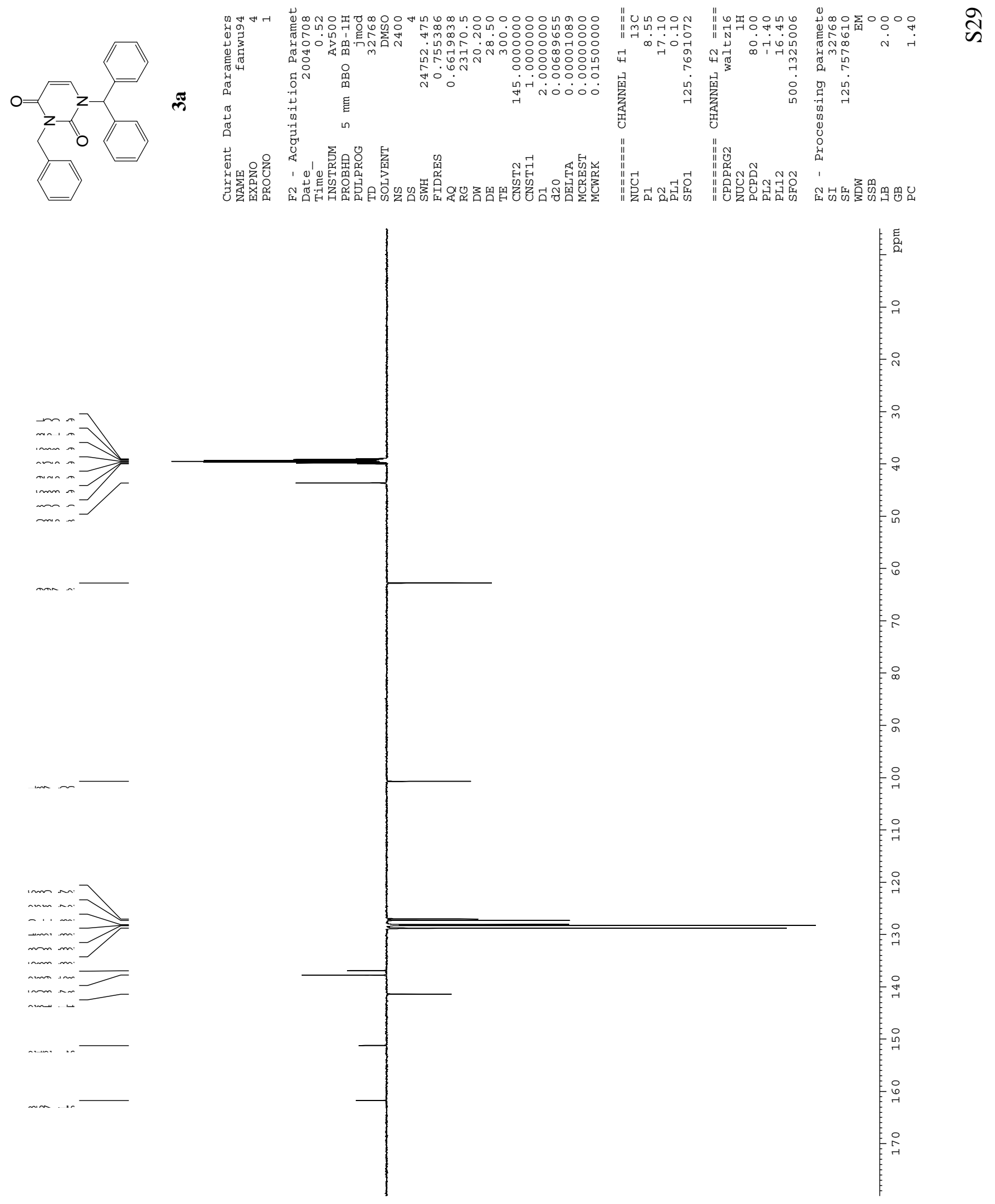


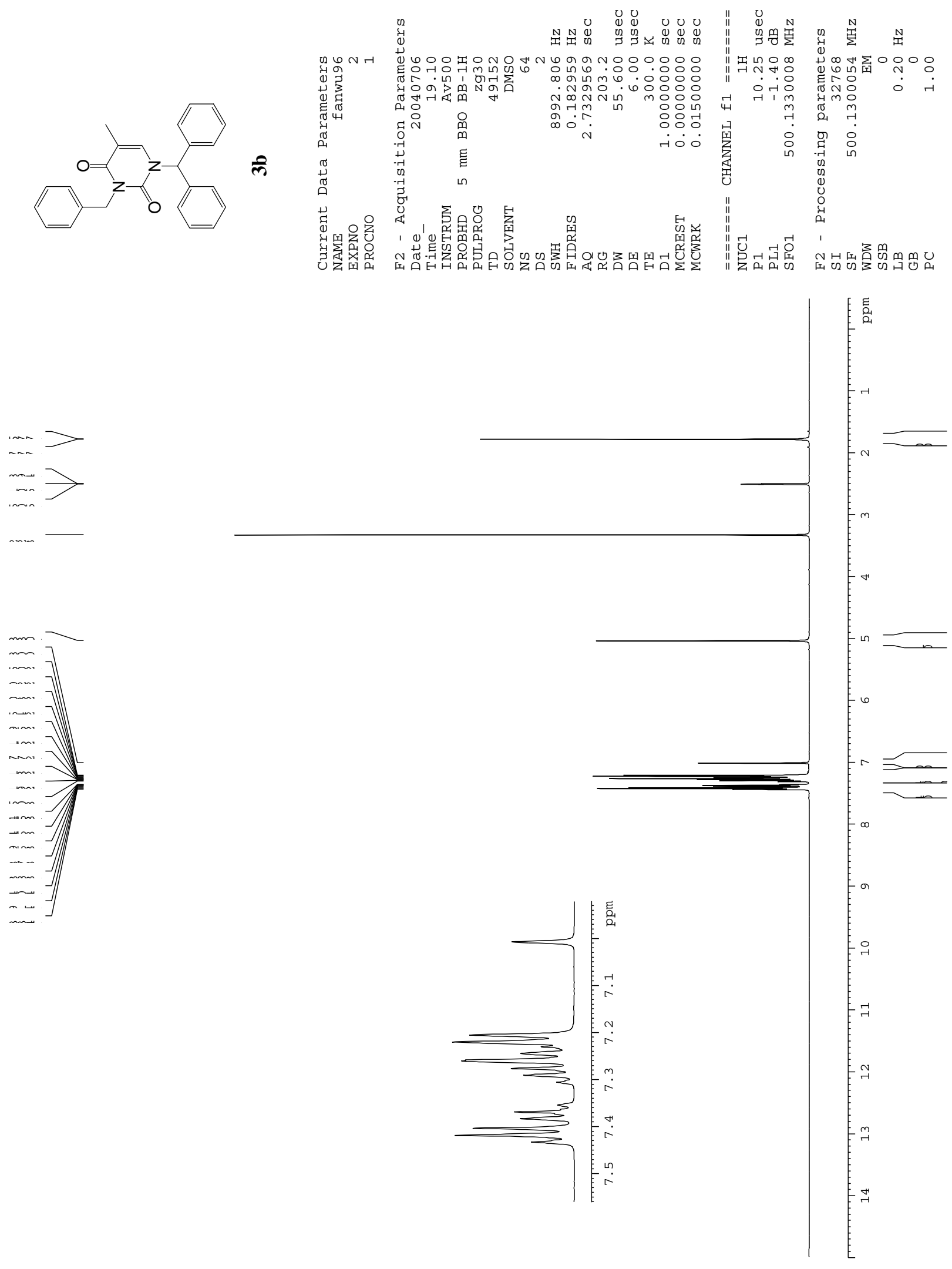




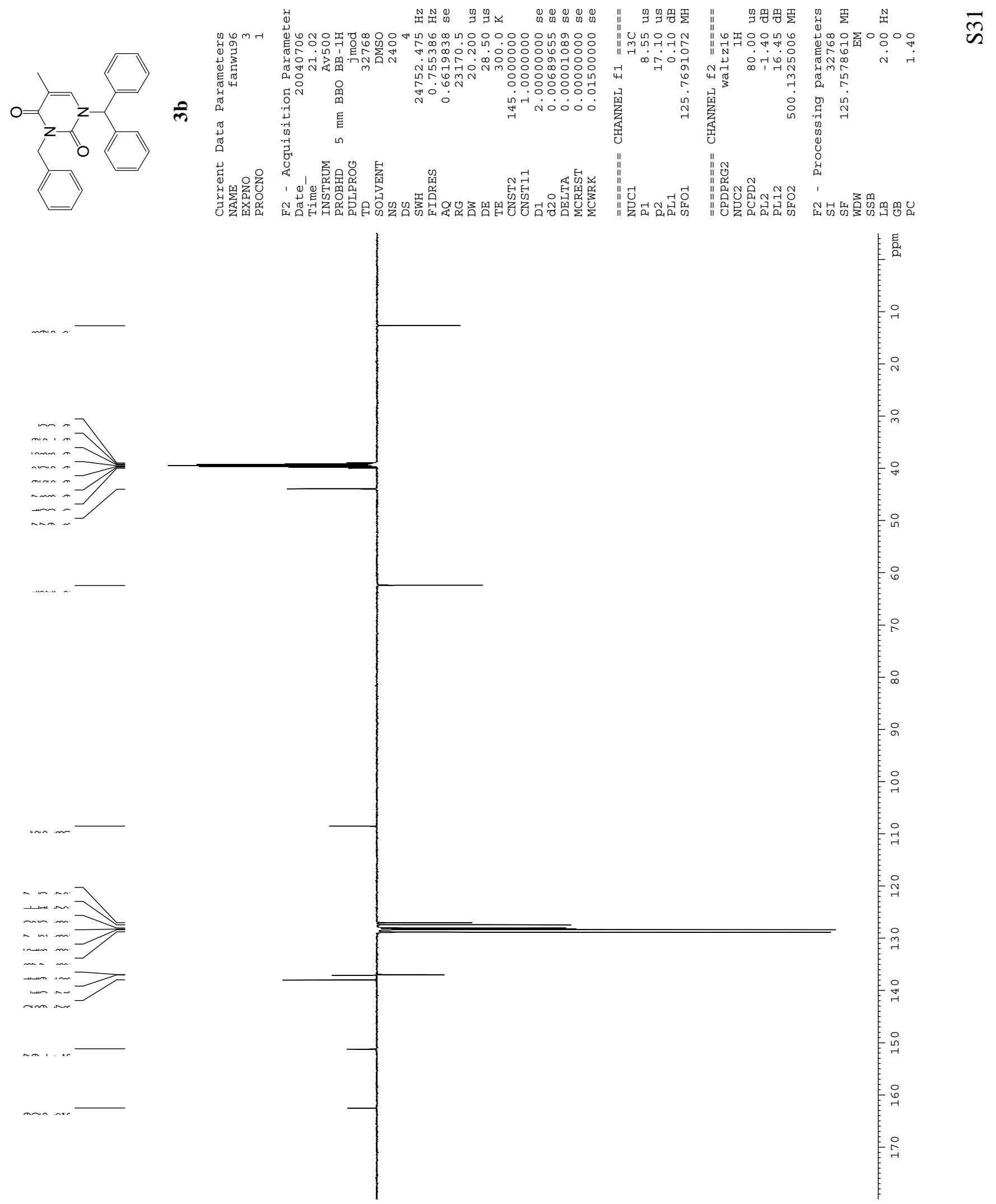



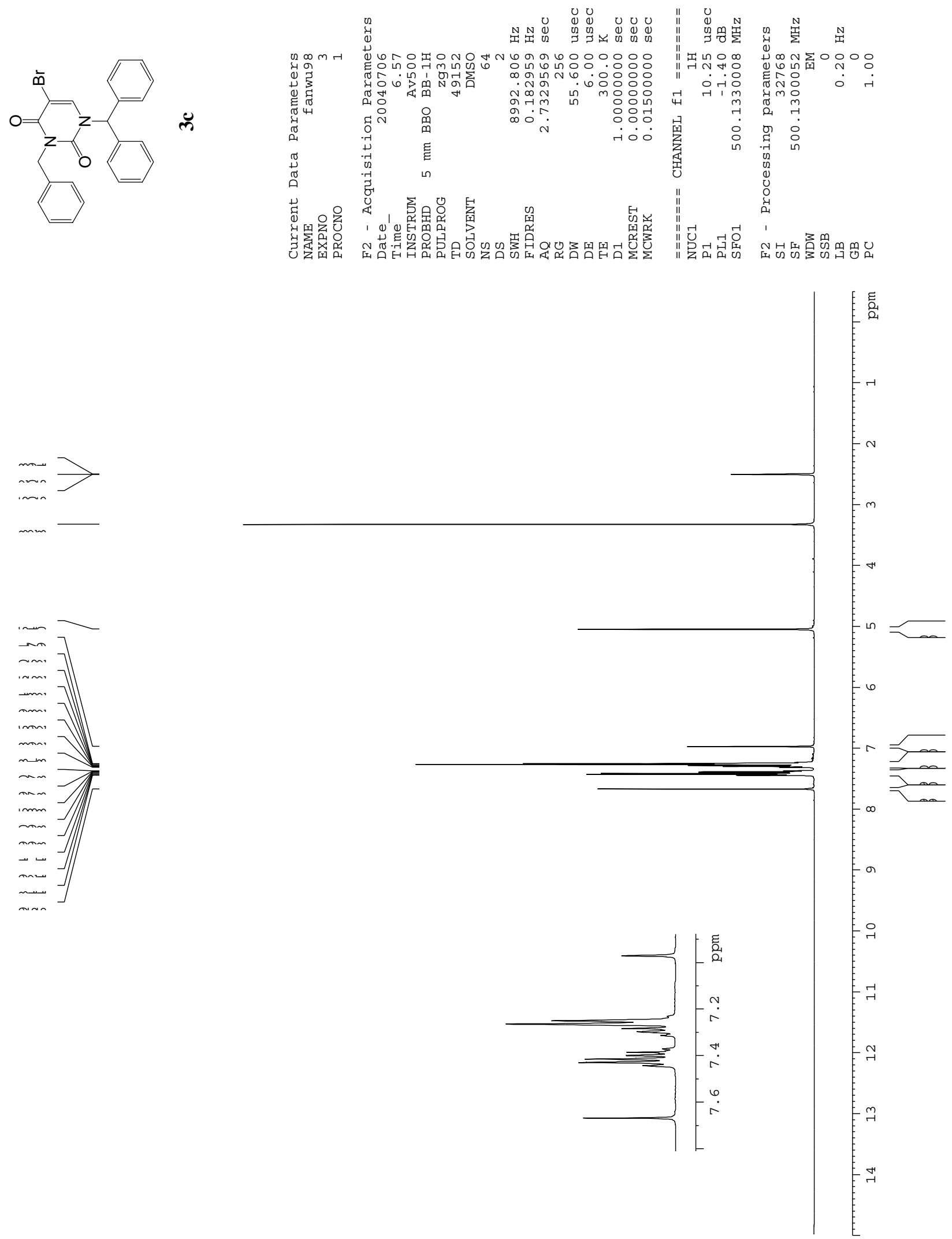

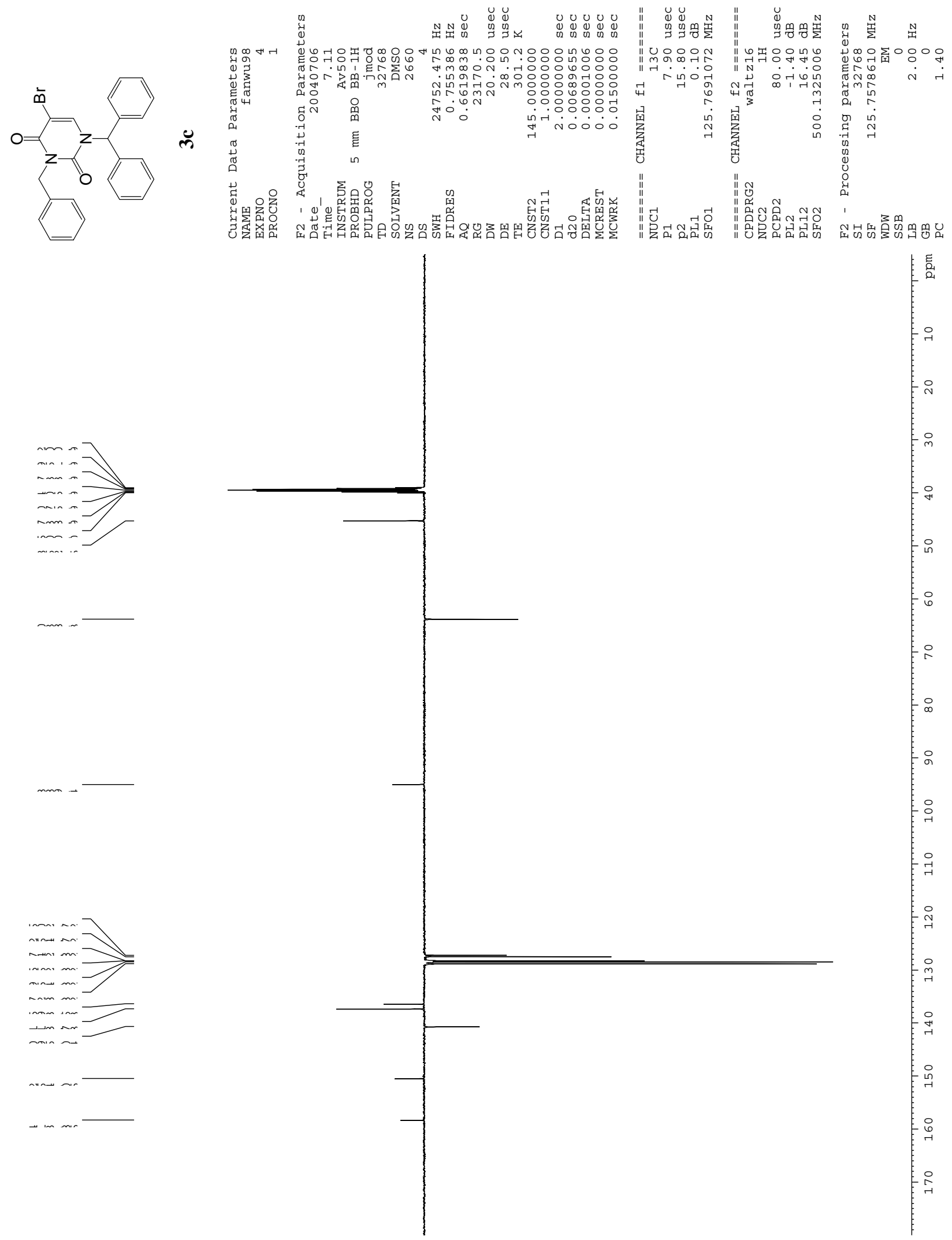


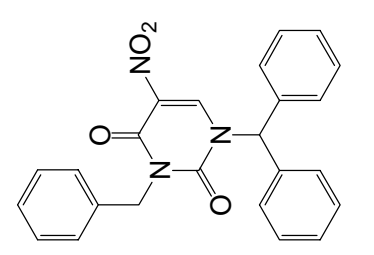

표

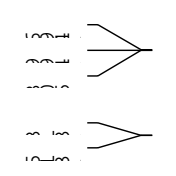

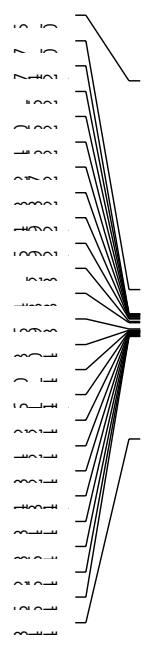
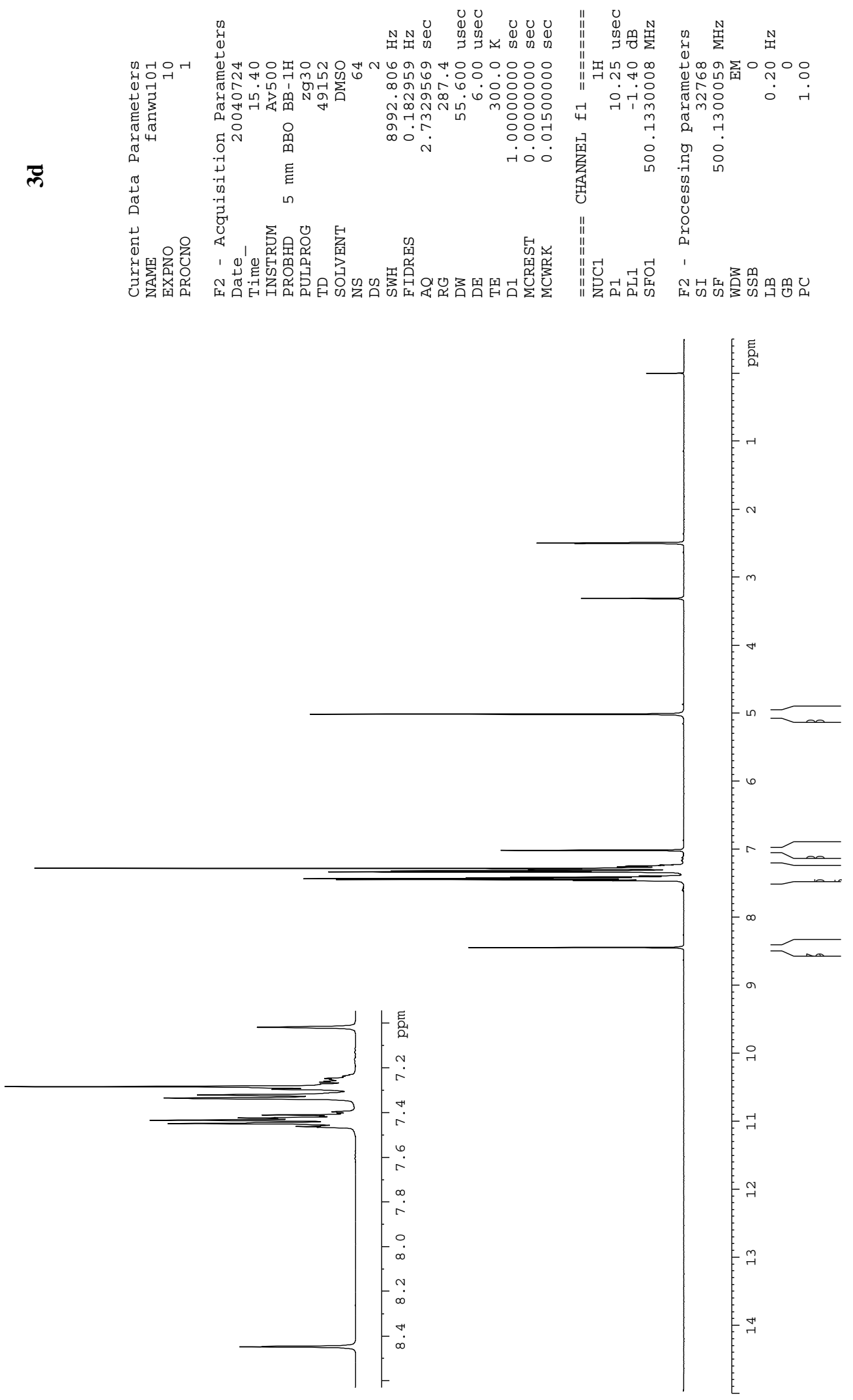

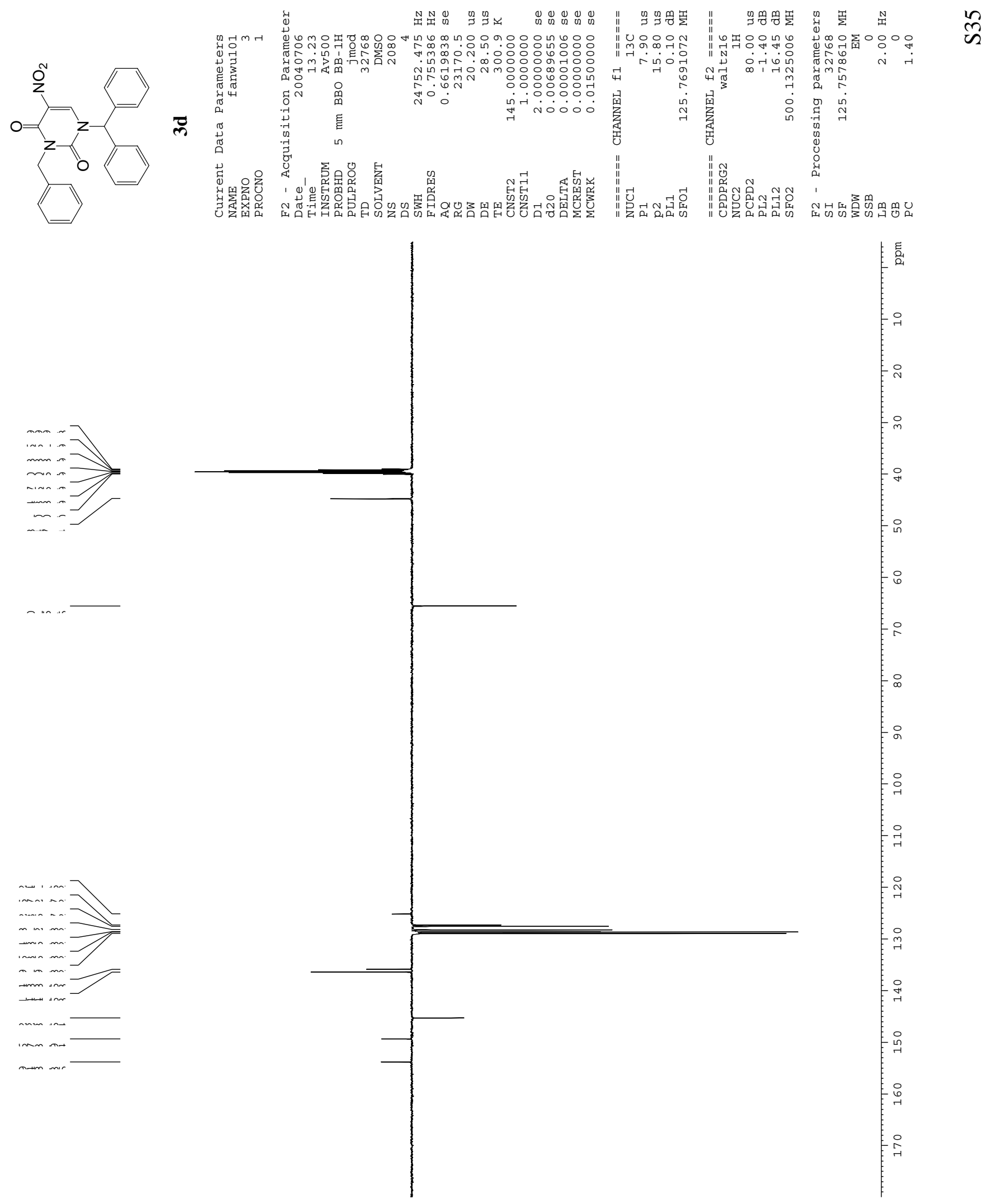


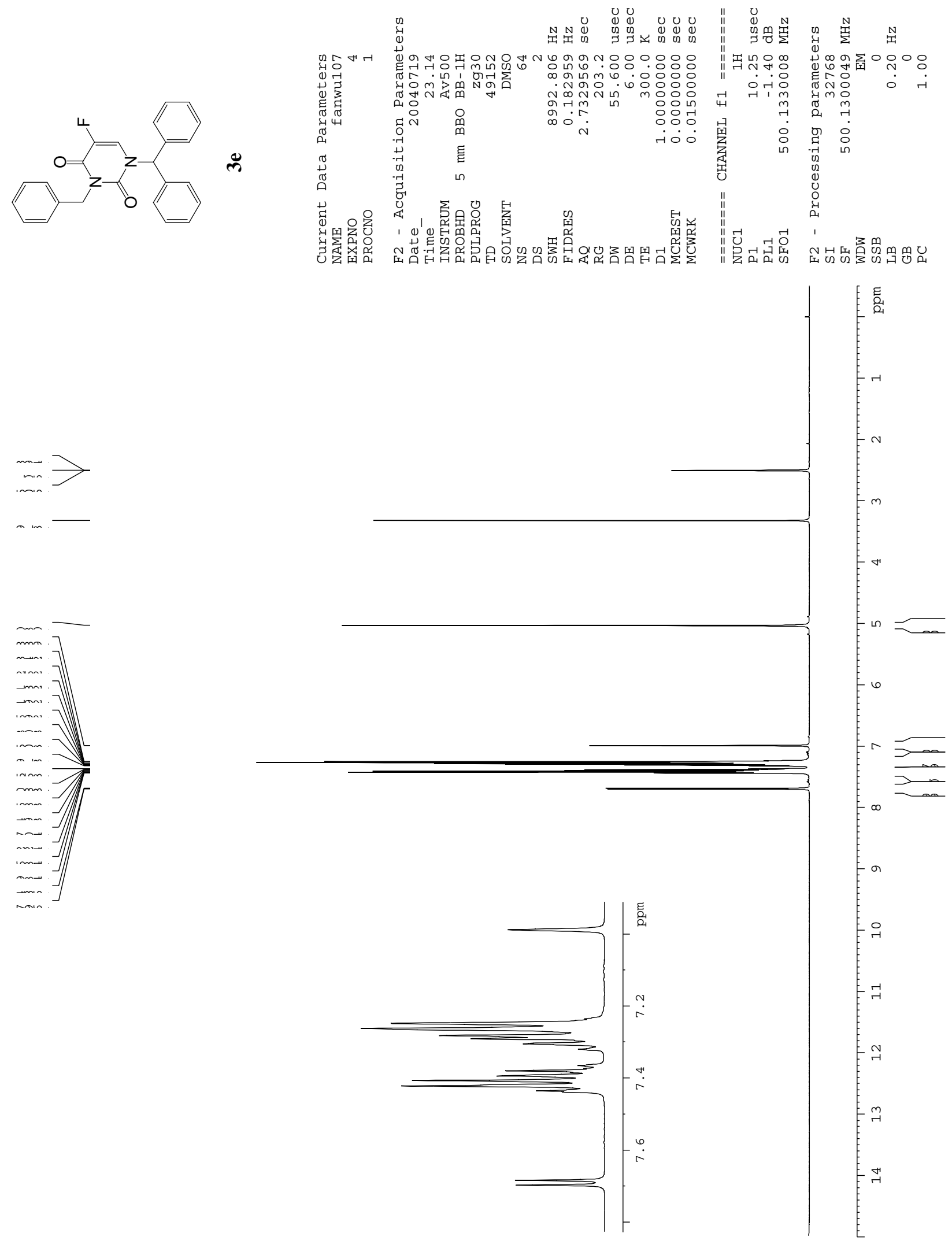



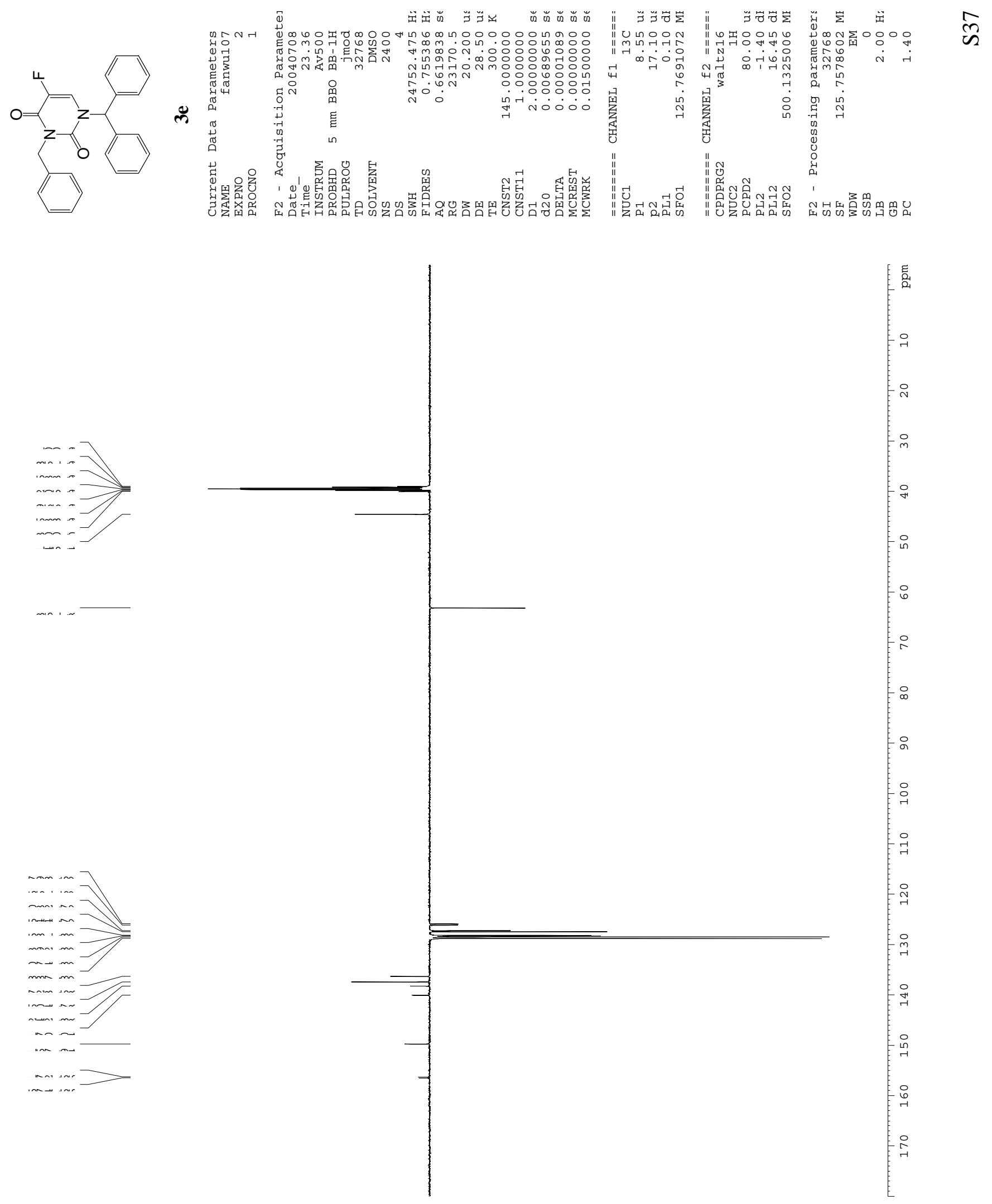

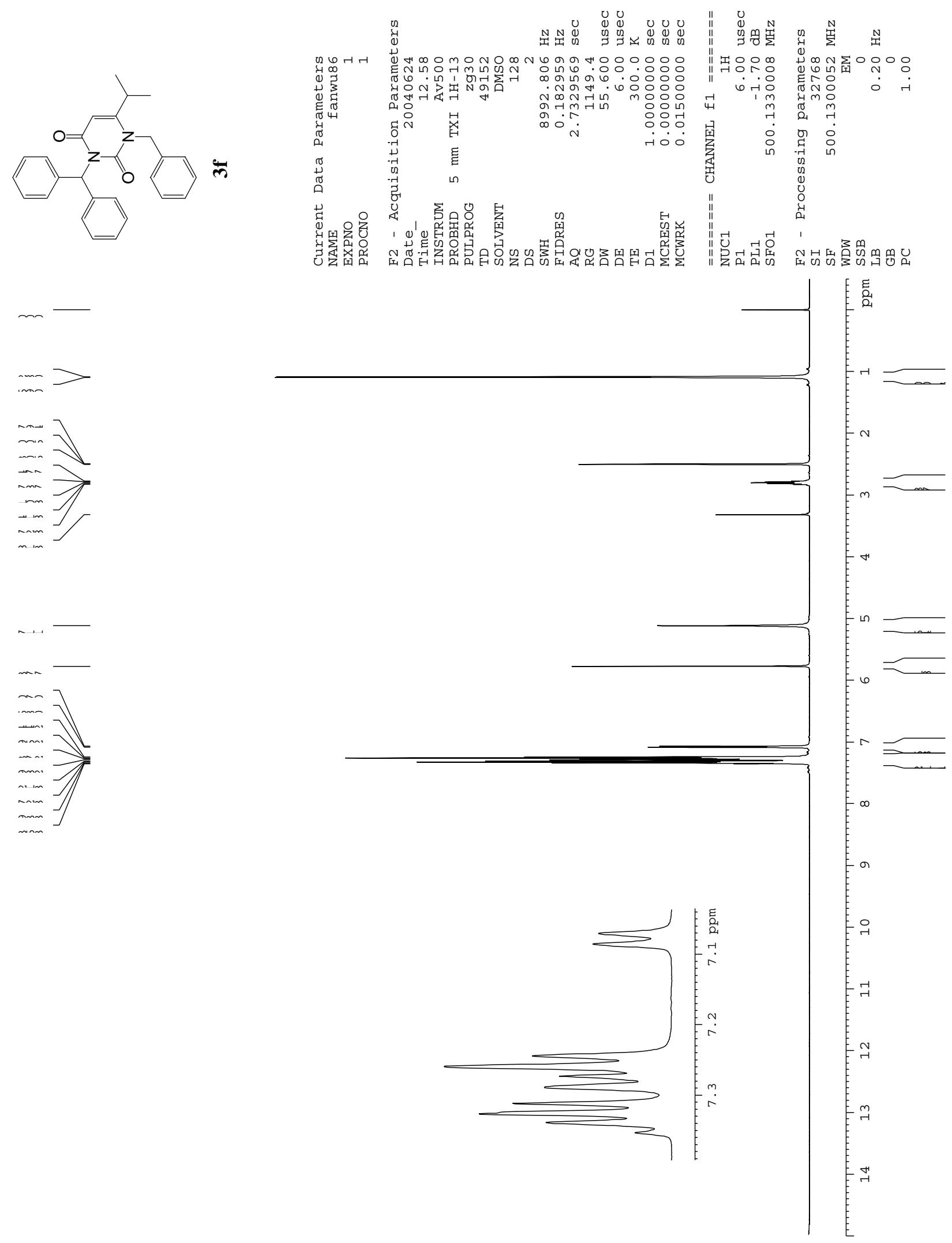

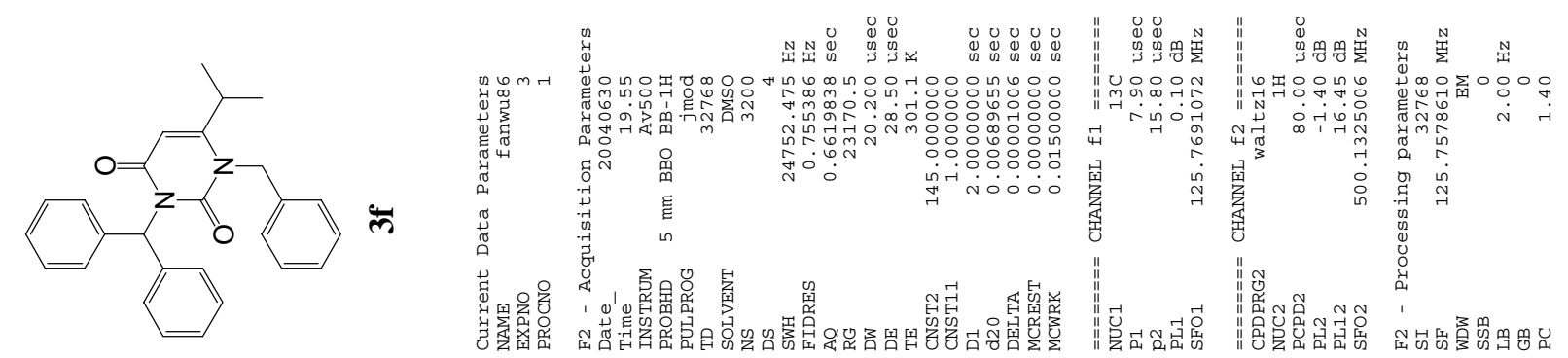

is

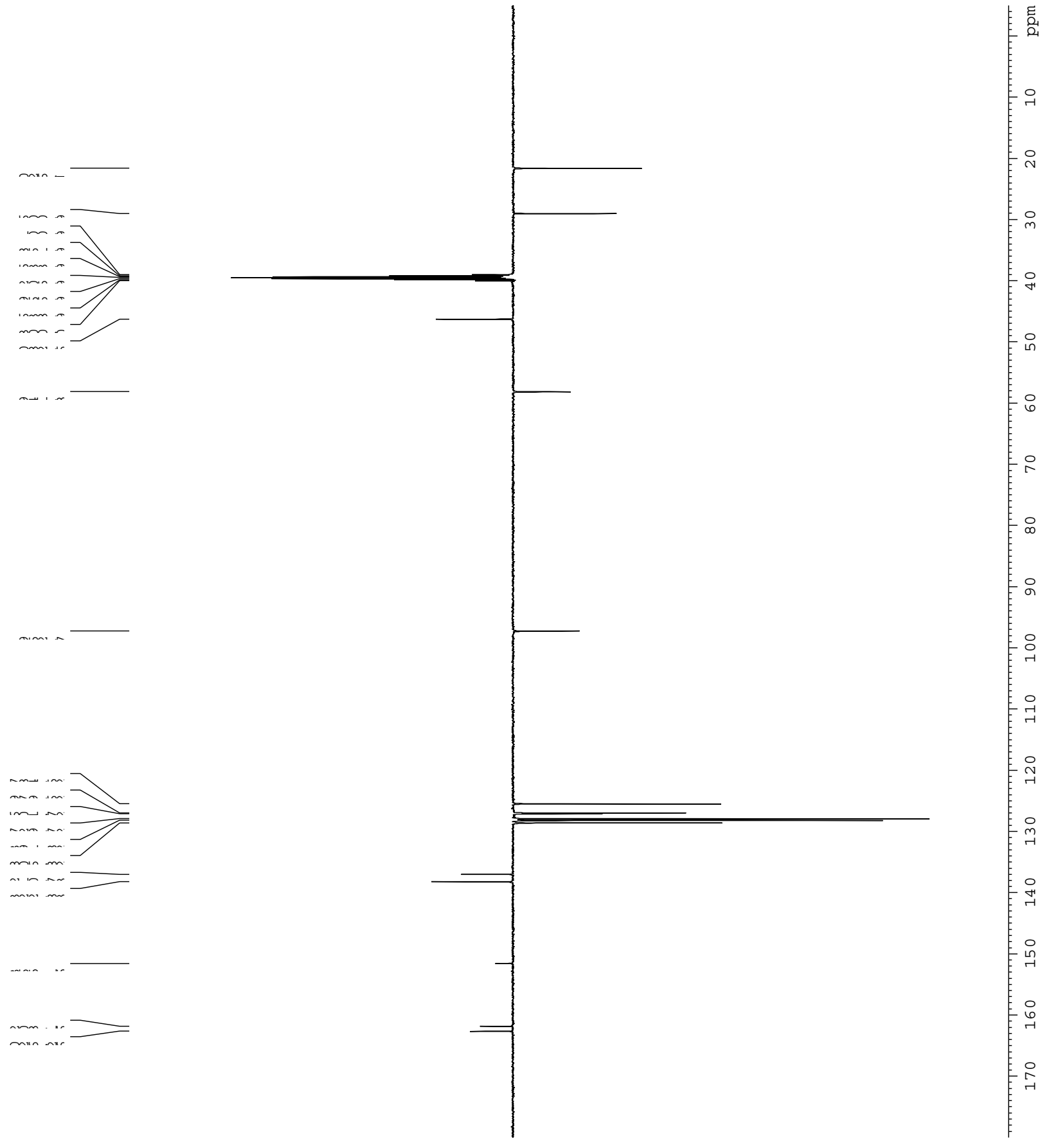



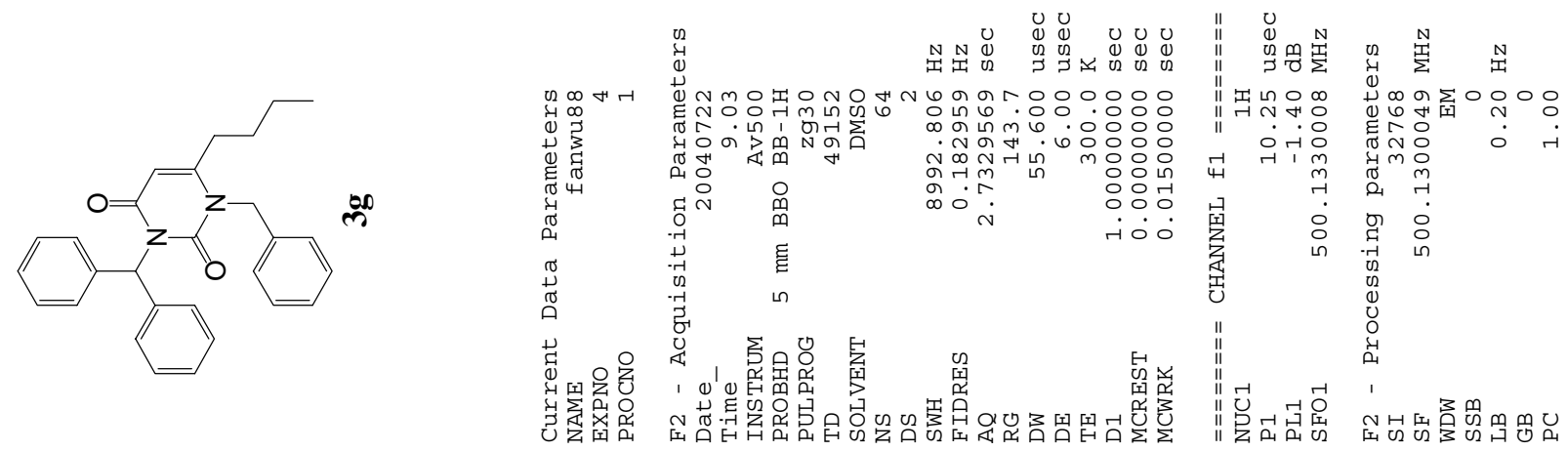

ษ
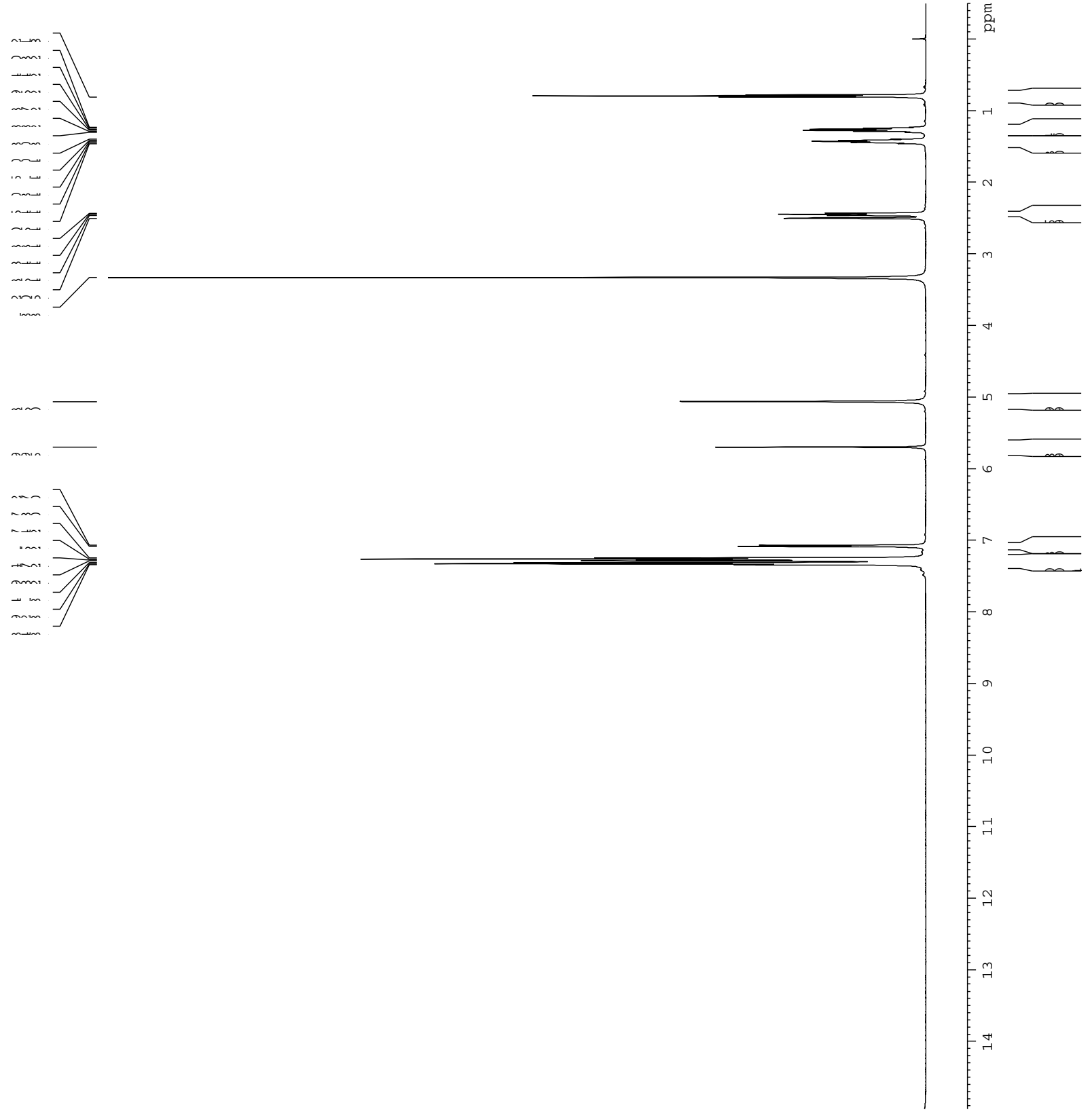

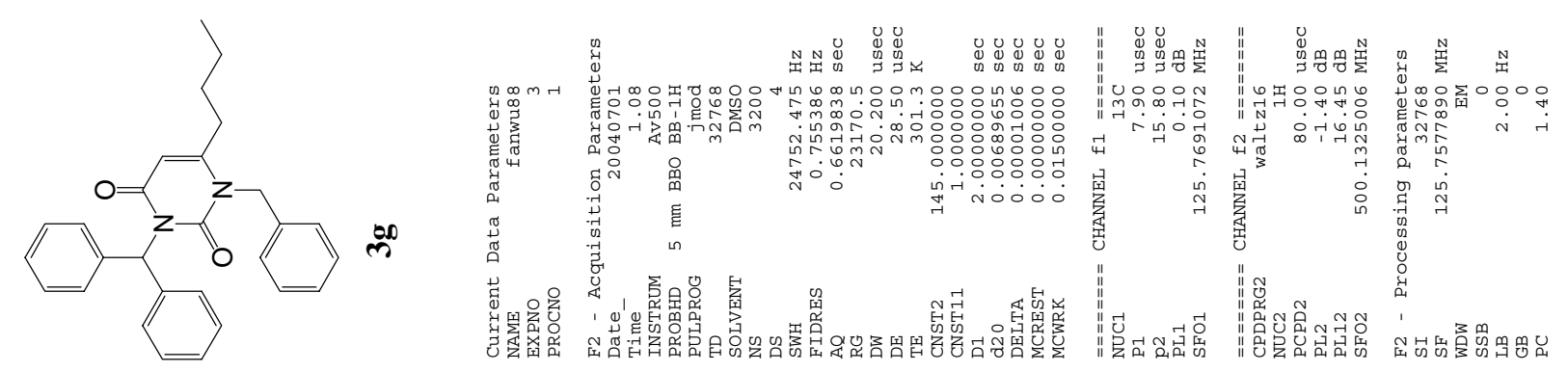

孚
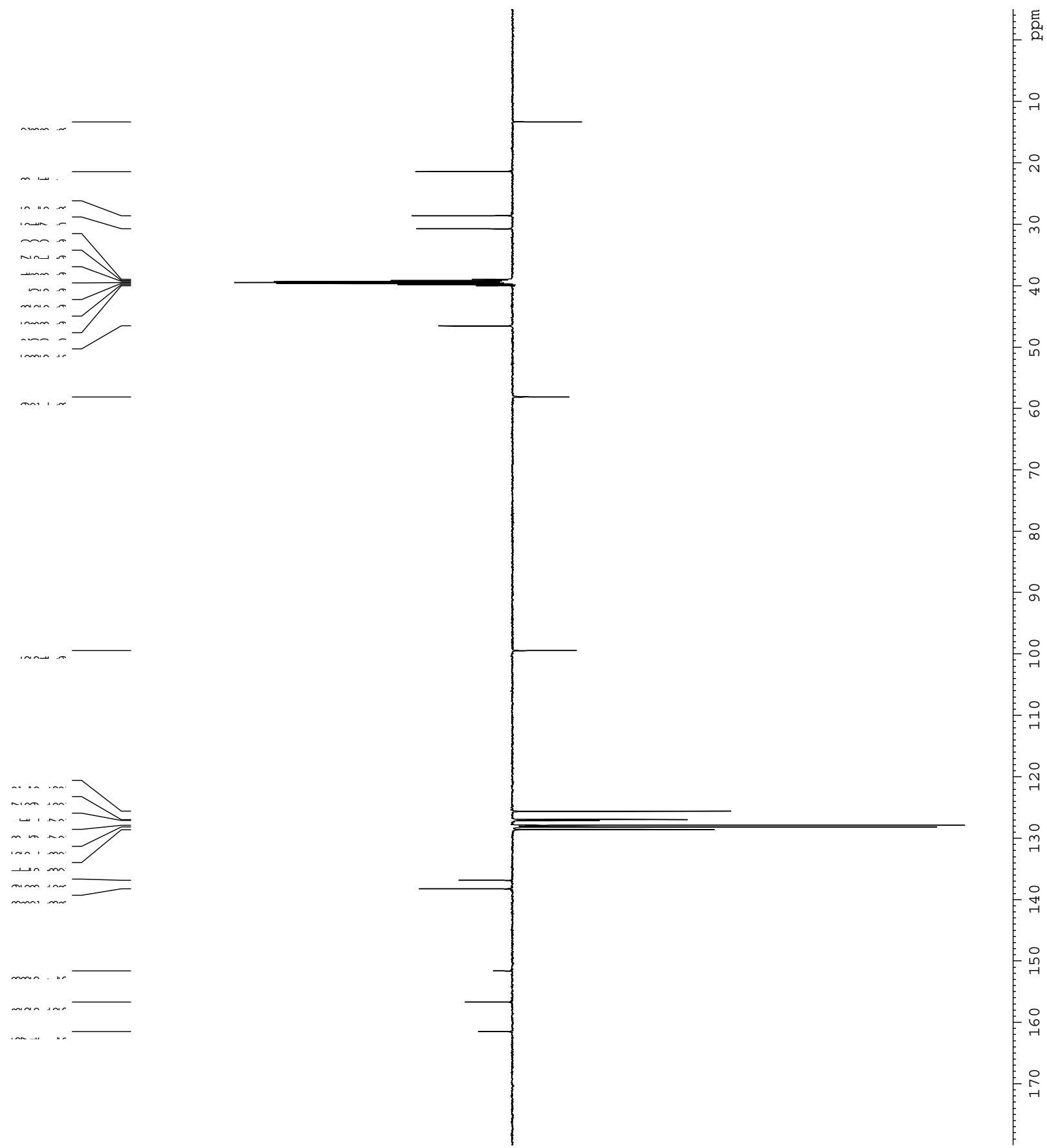

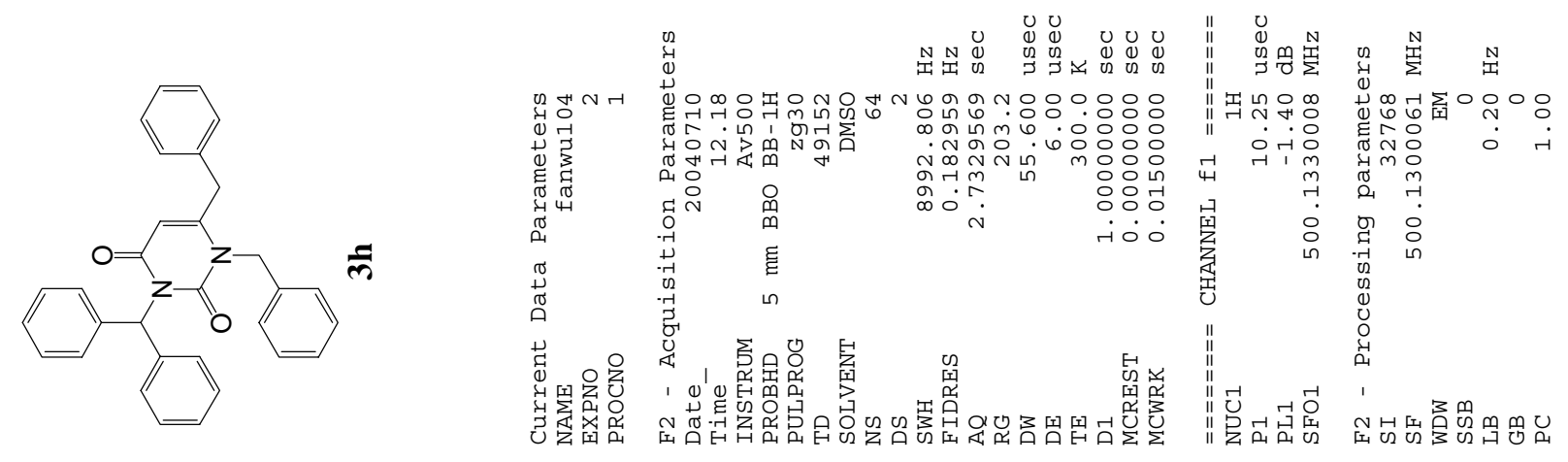

f
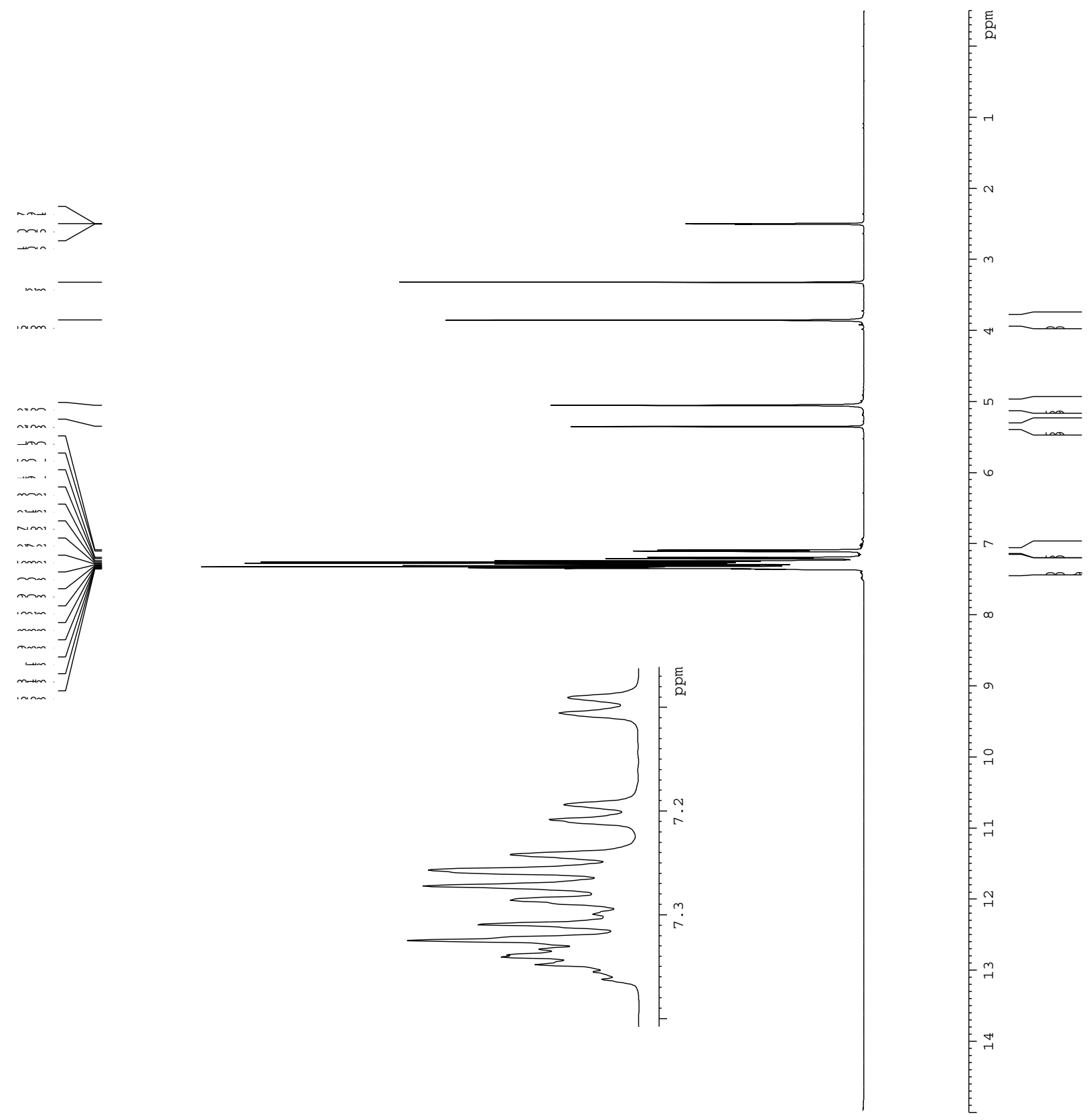

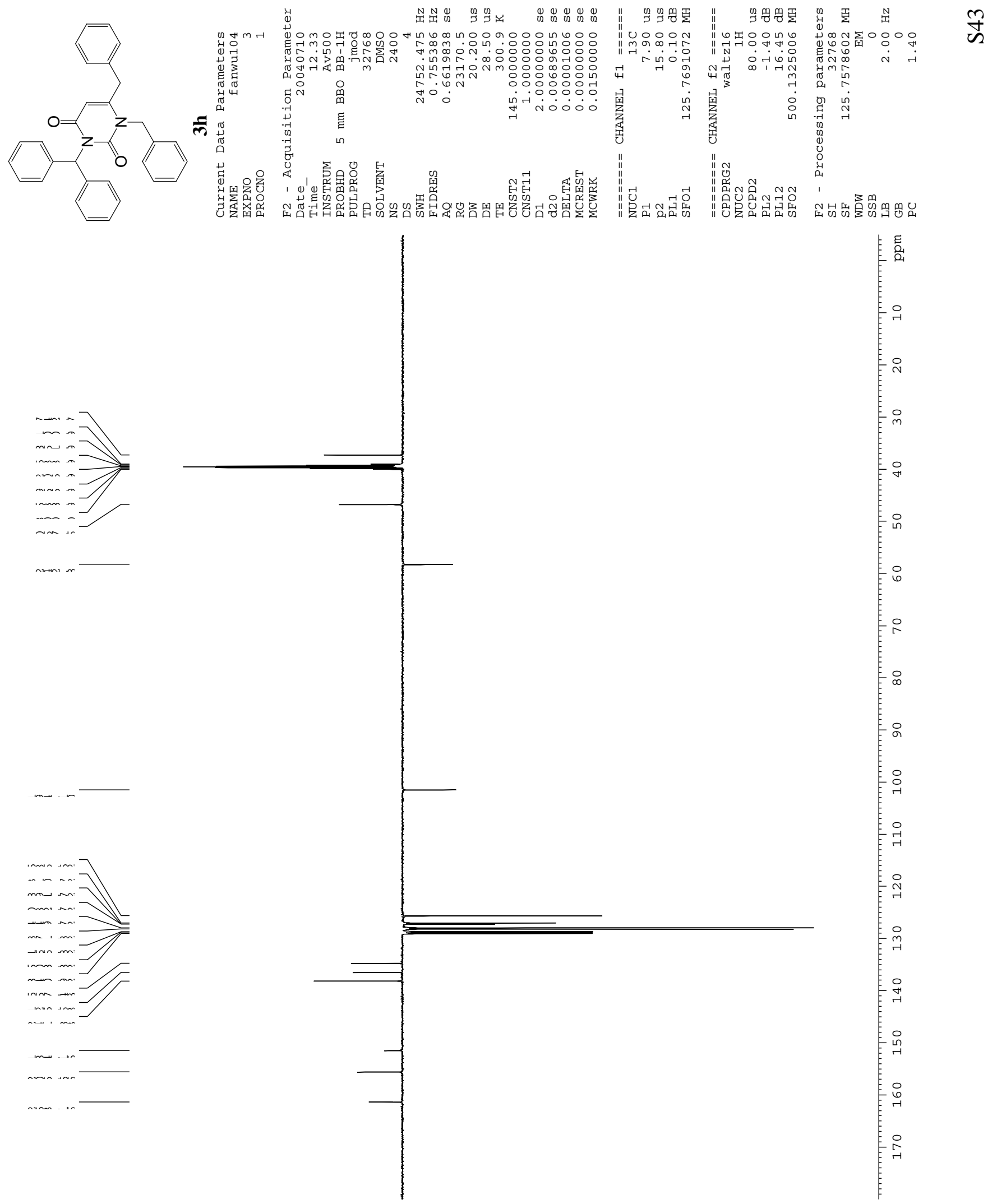

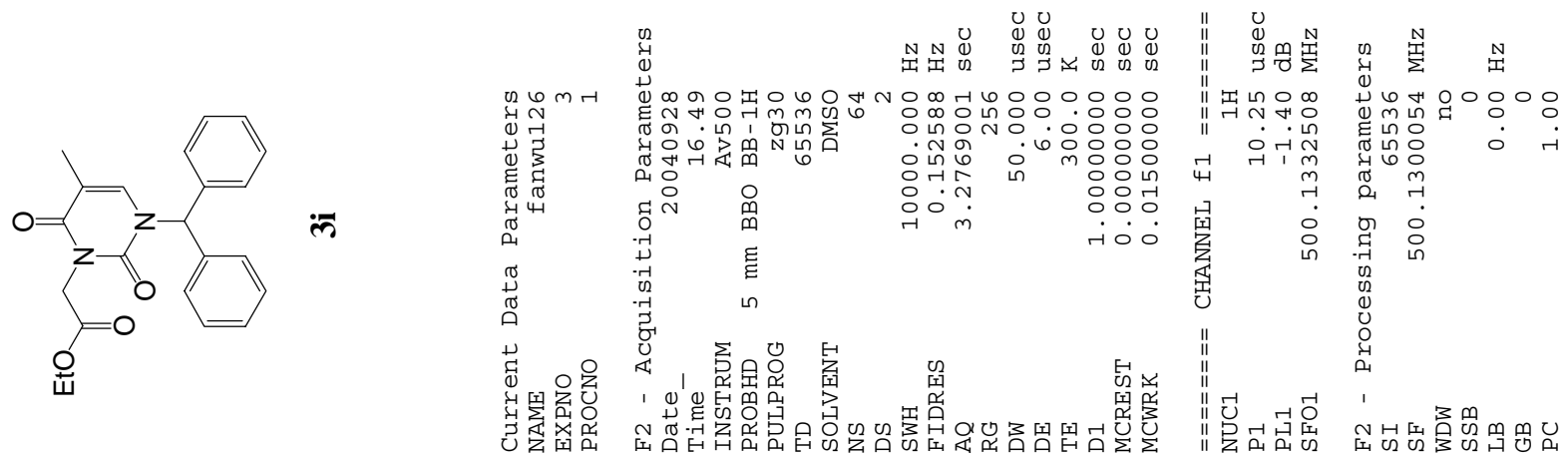

考
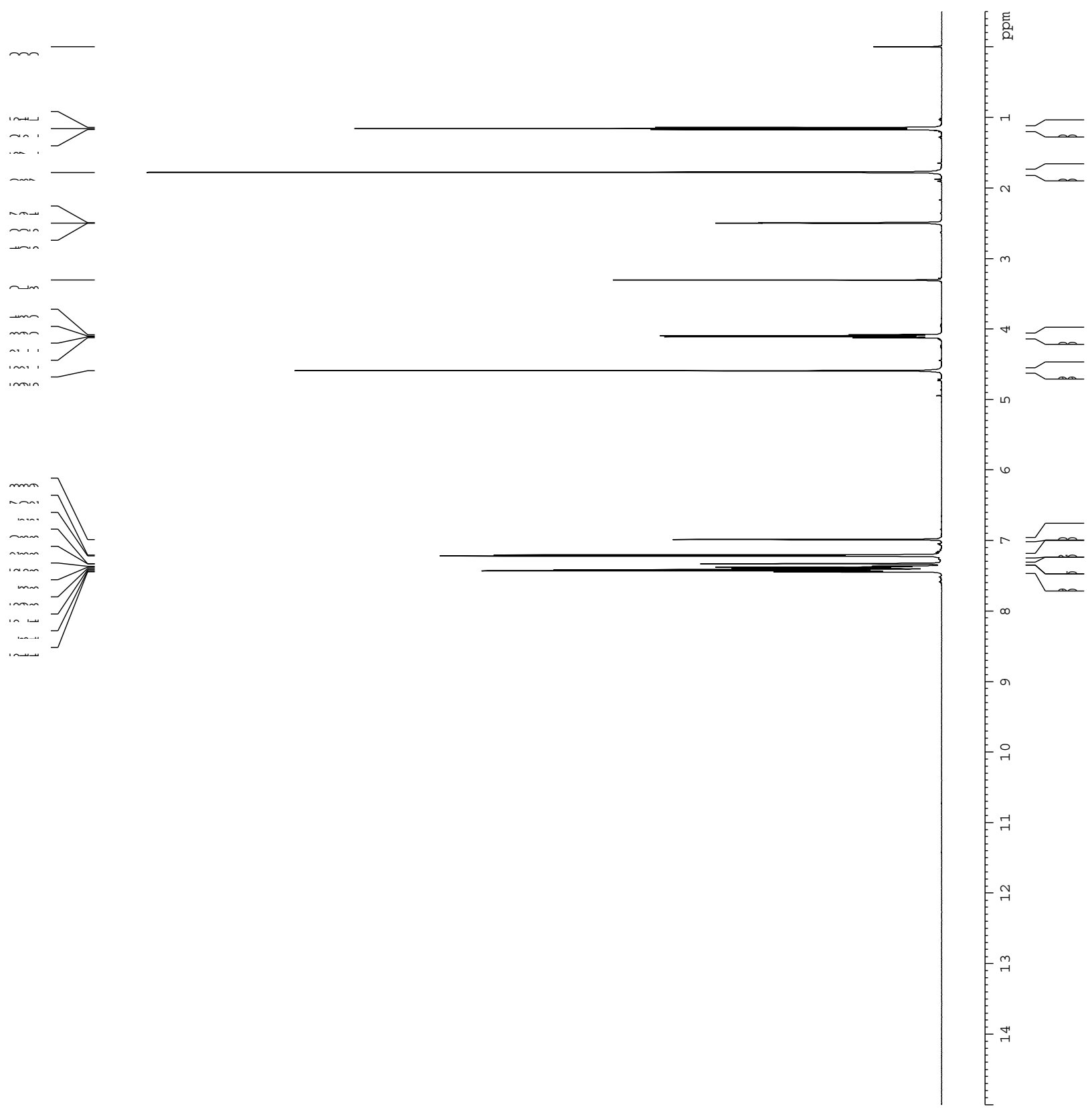

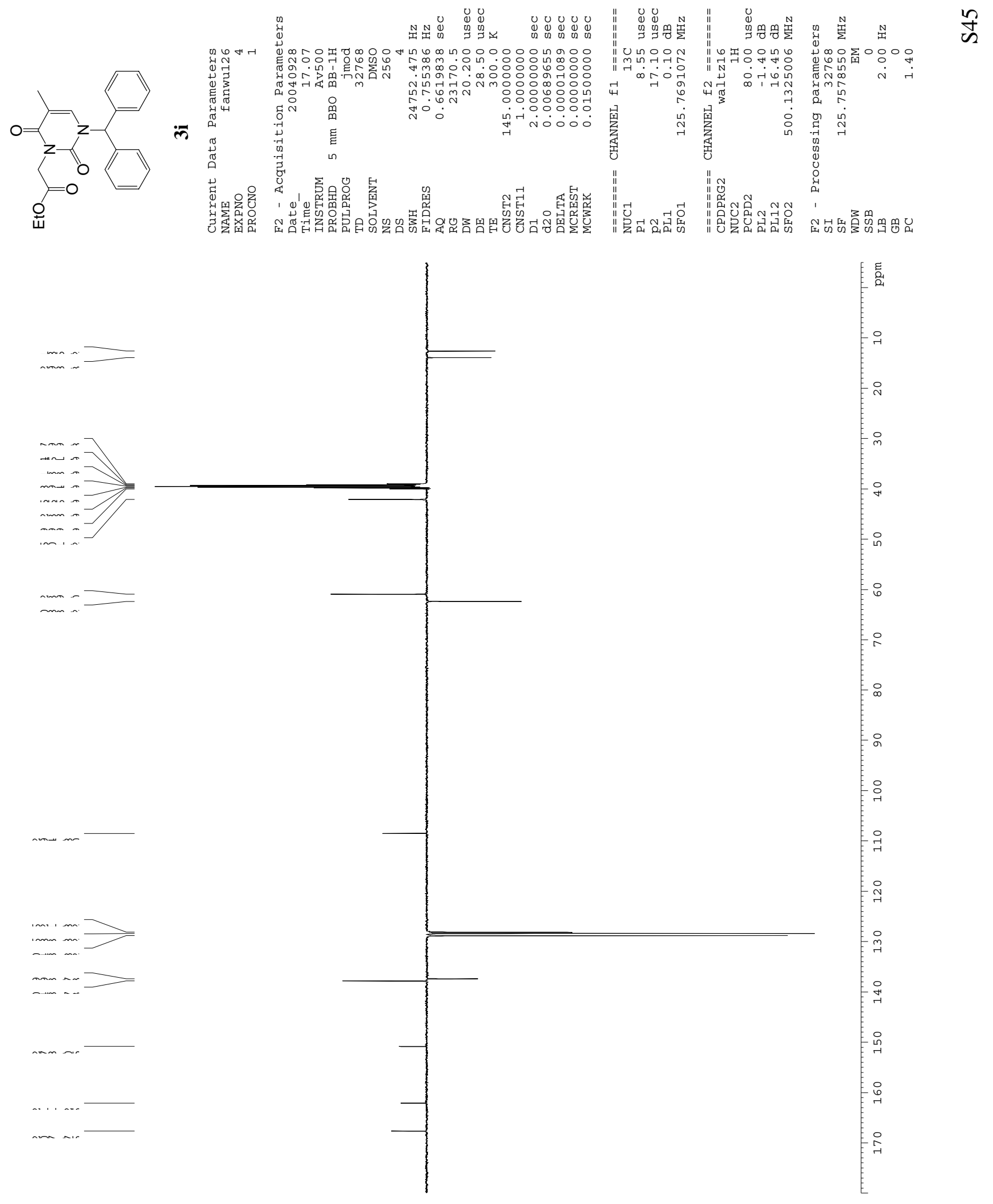


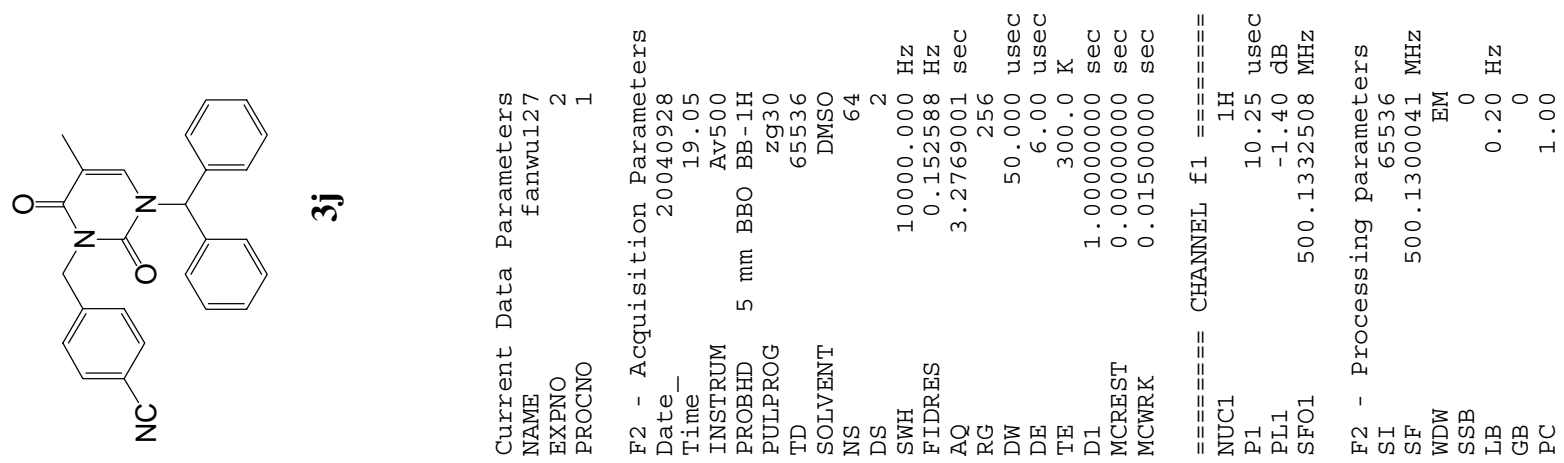

ป
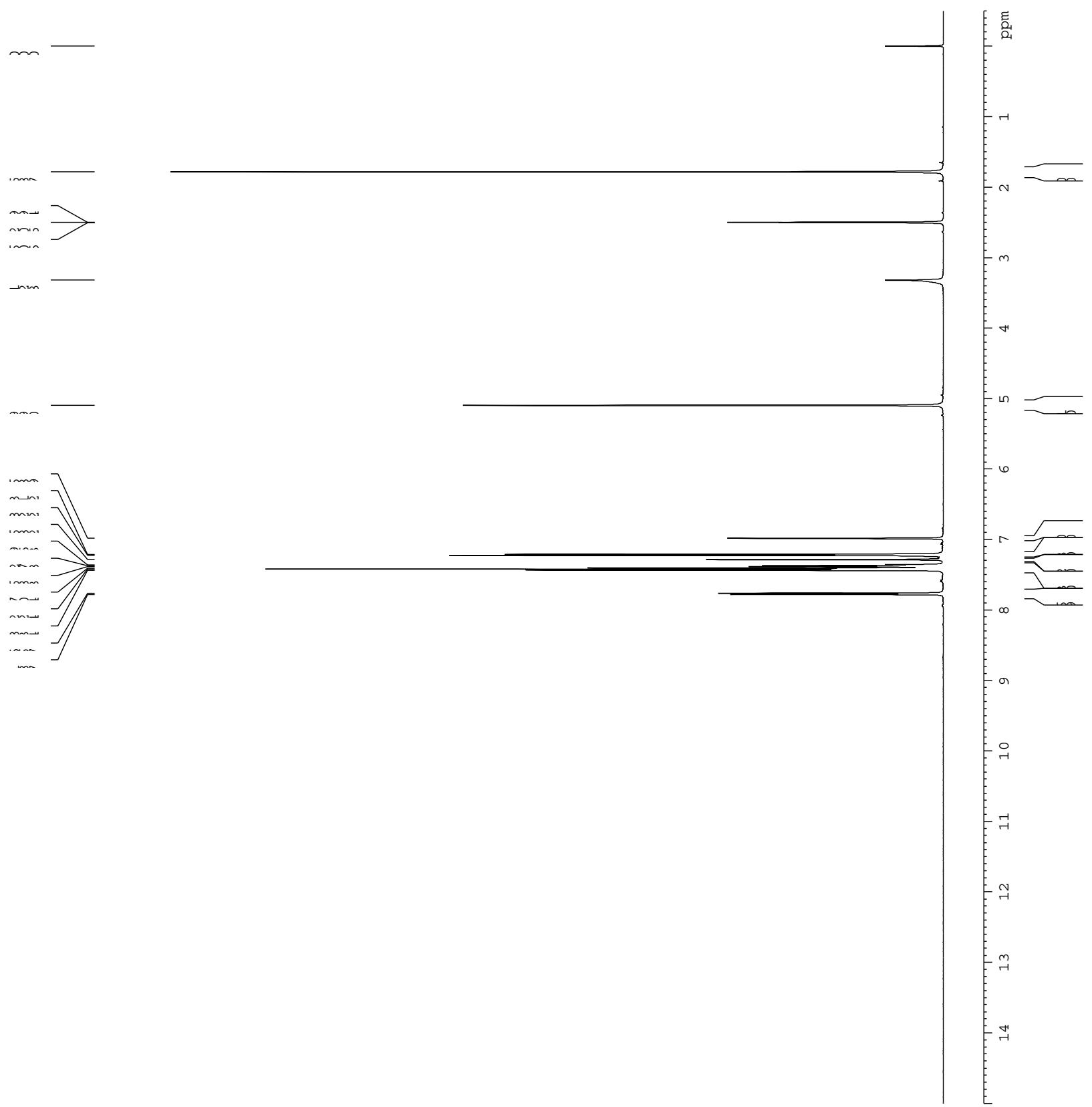

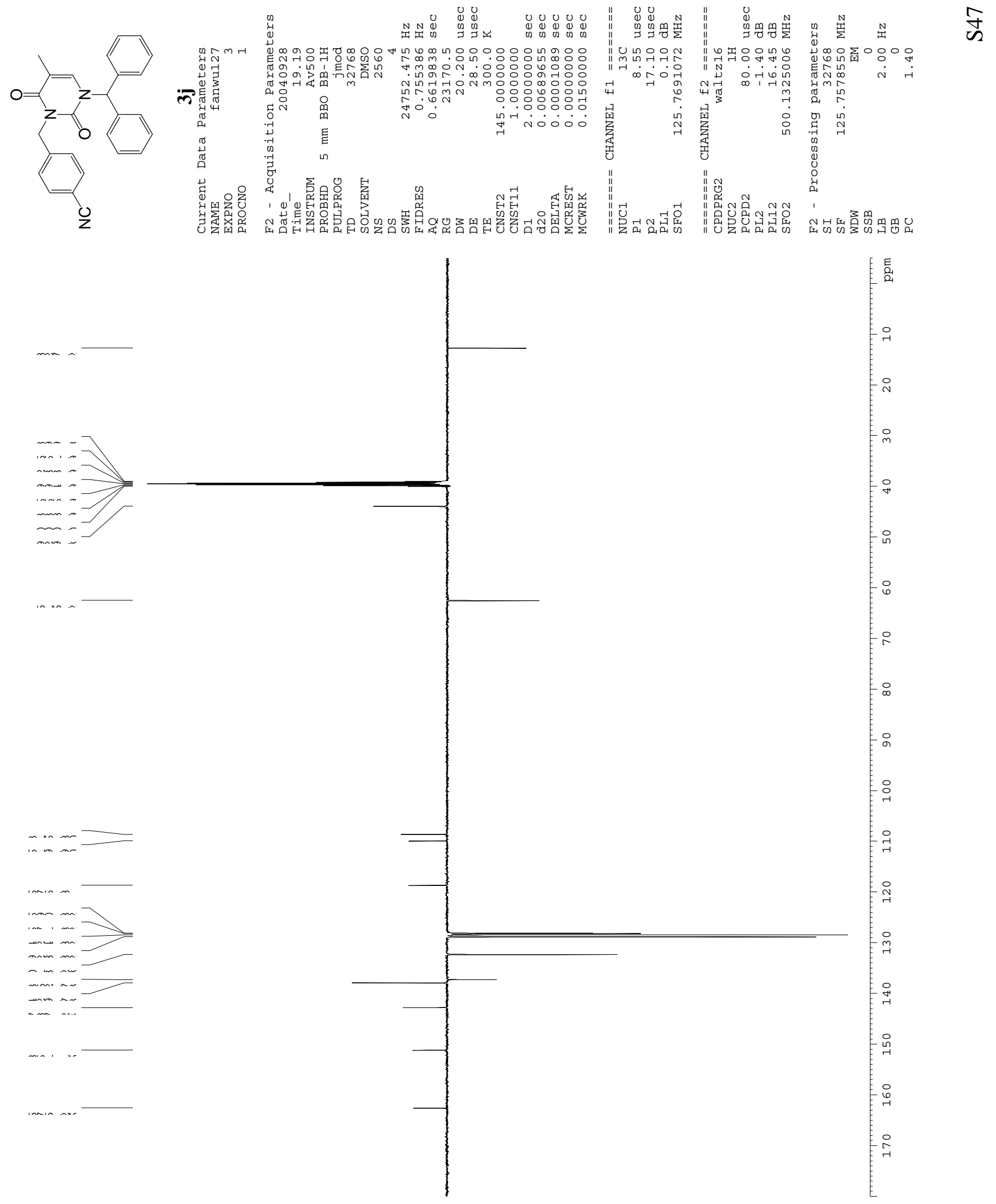

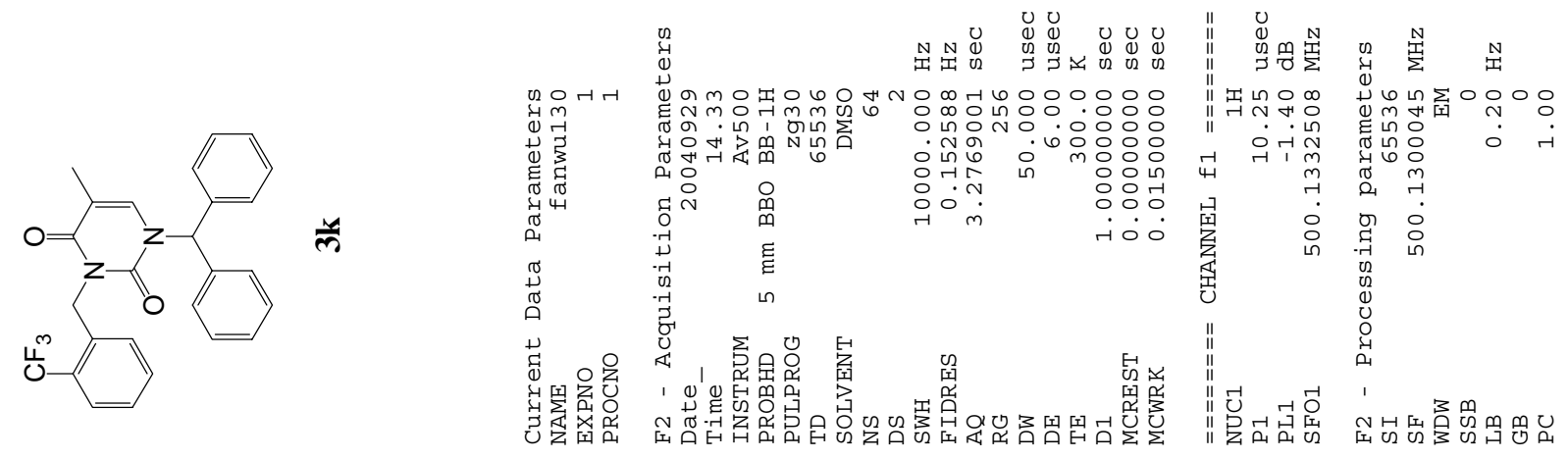

$\stackrel{\infty}{+}$
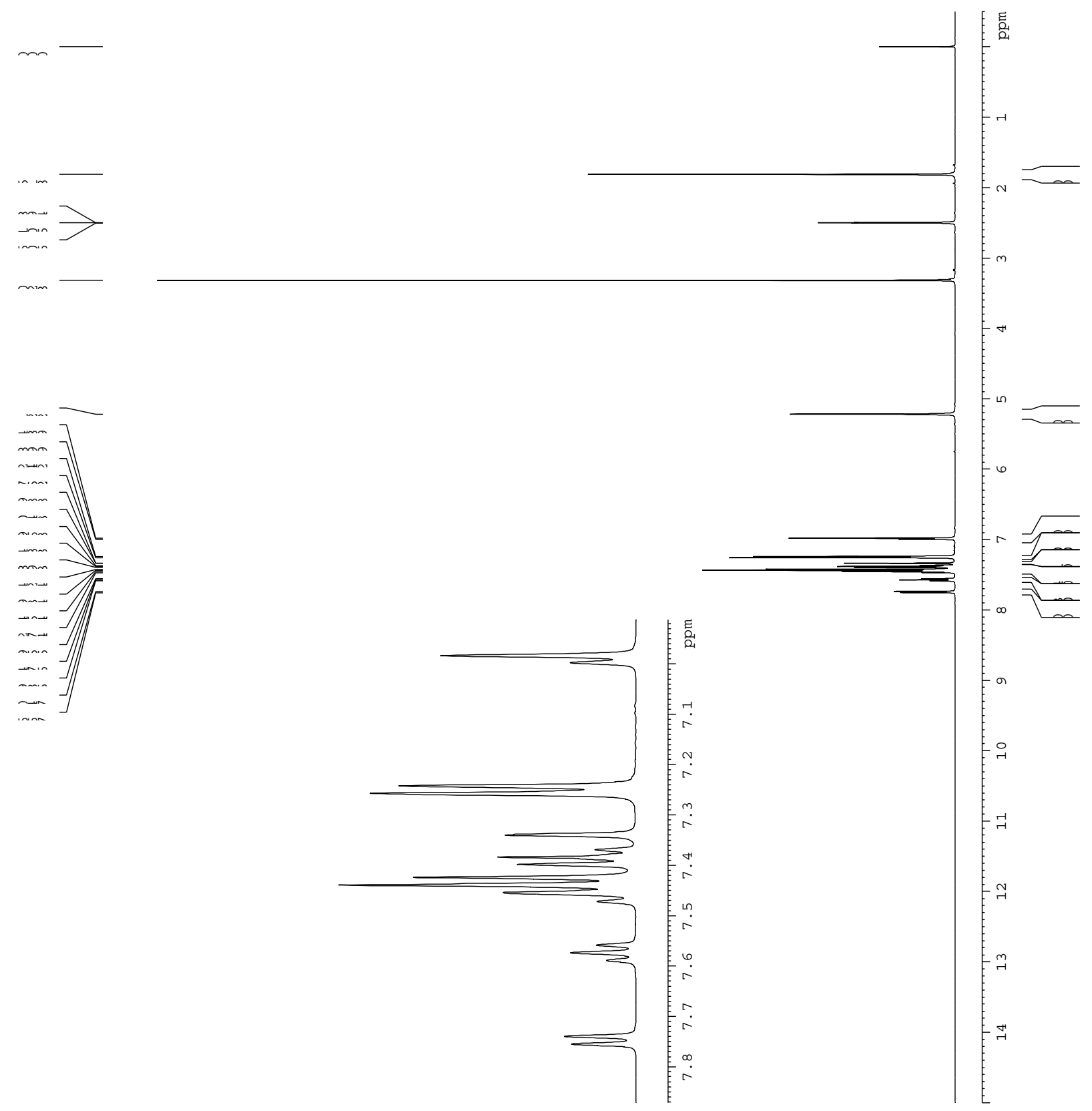

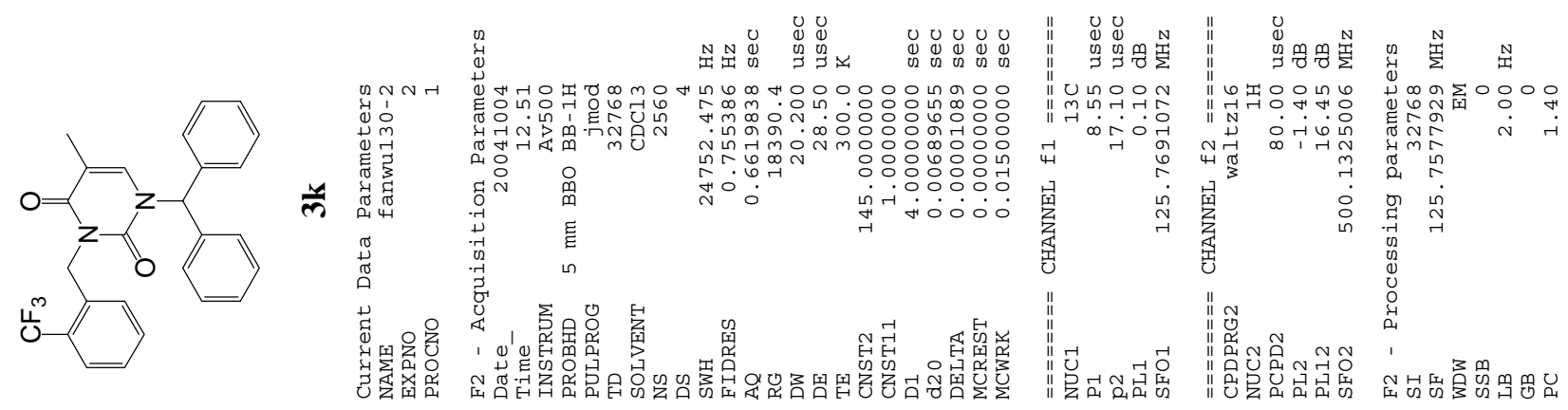

ป

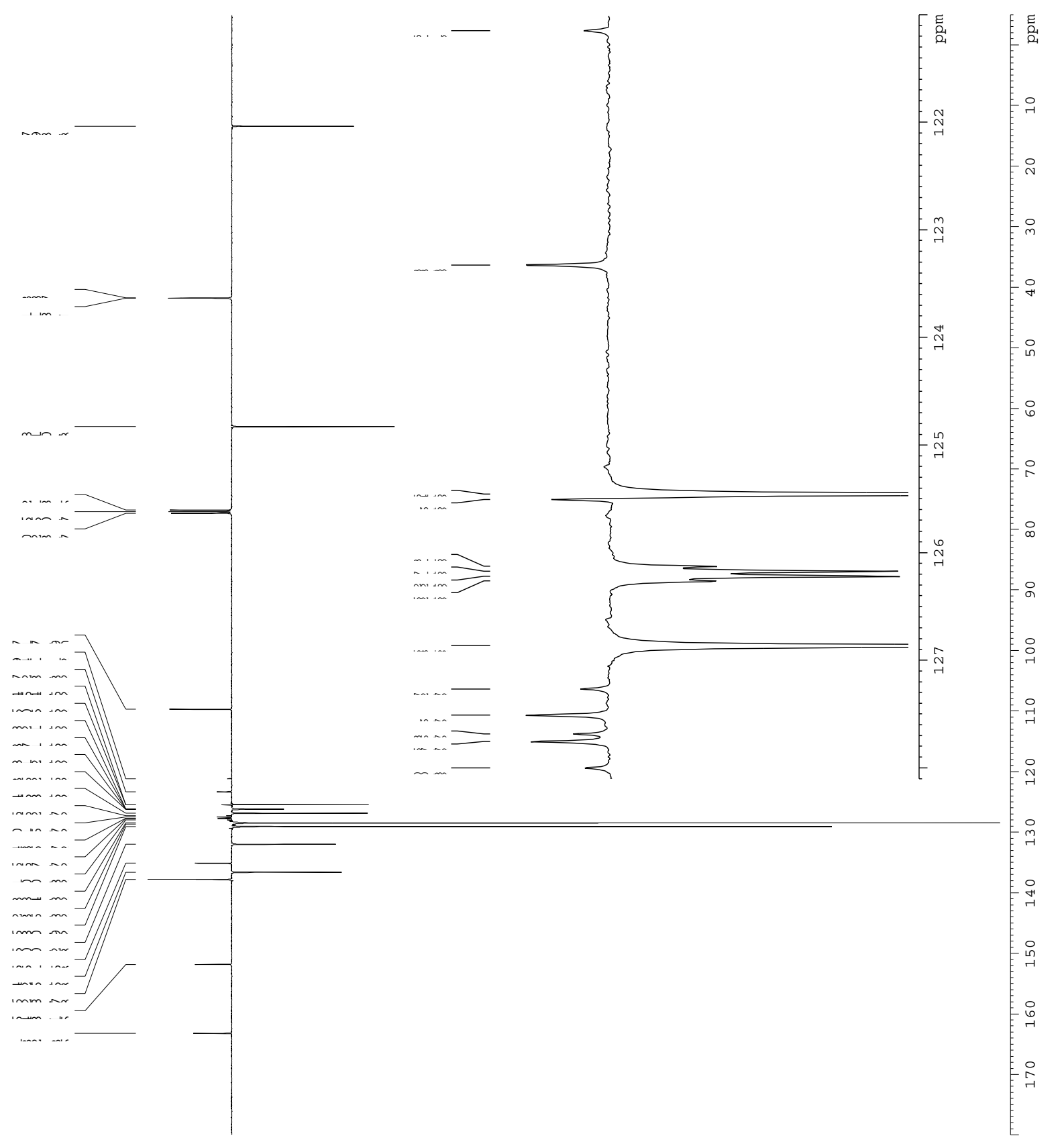



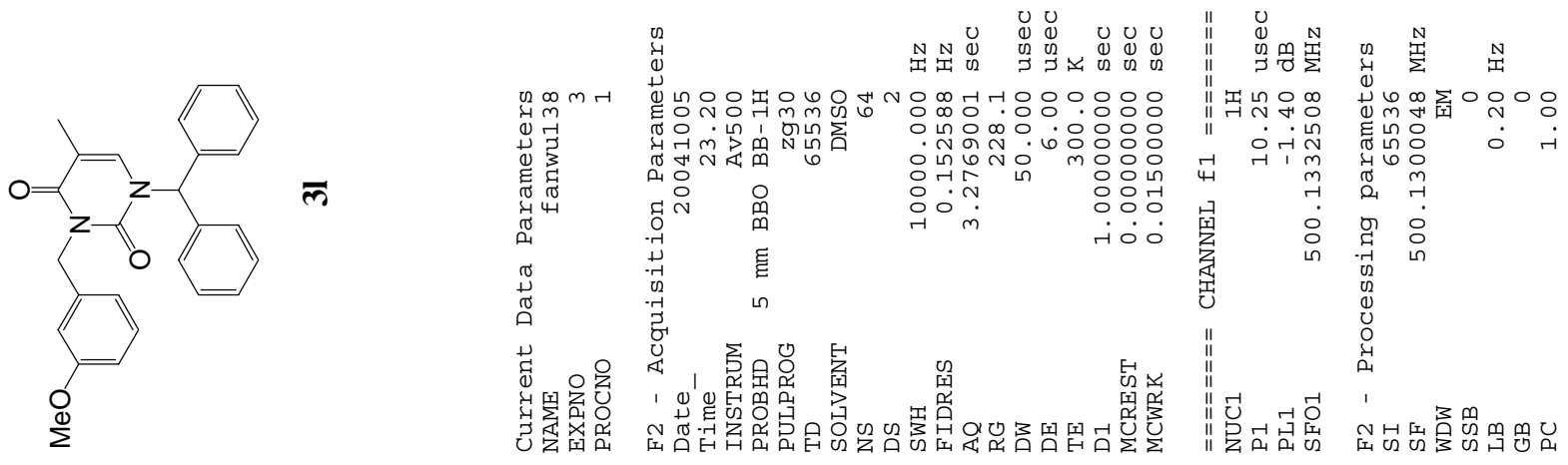

ค

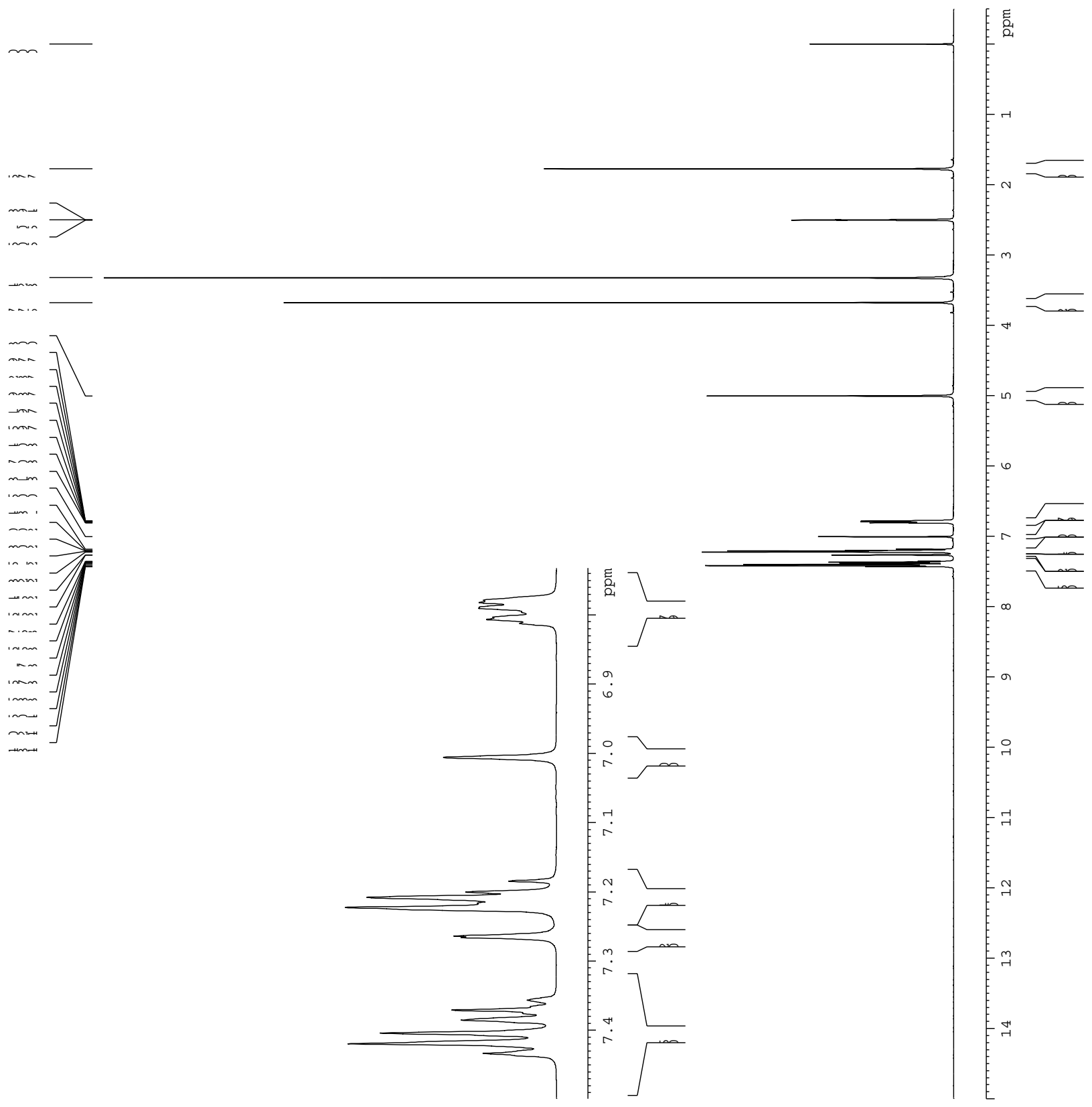



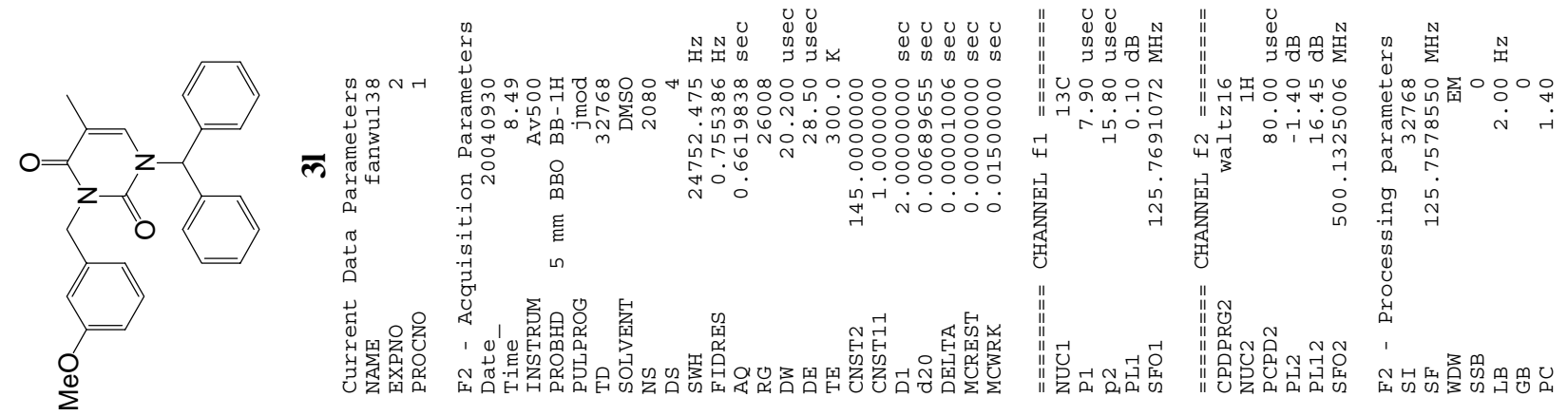

n
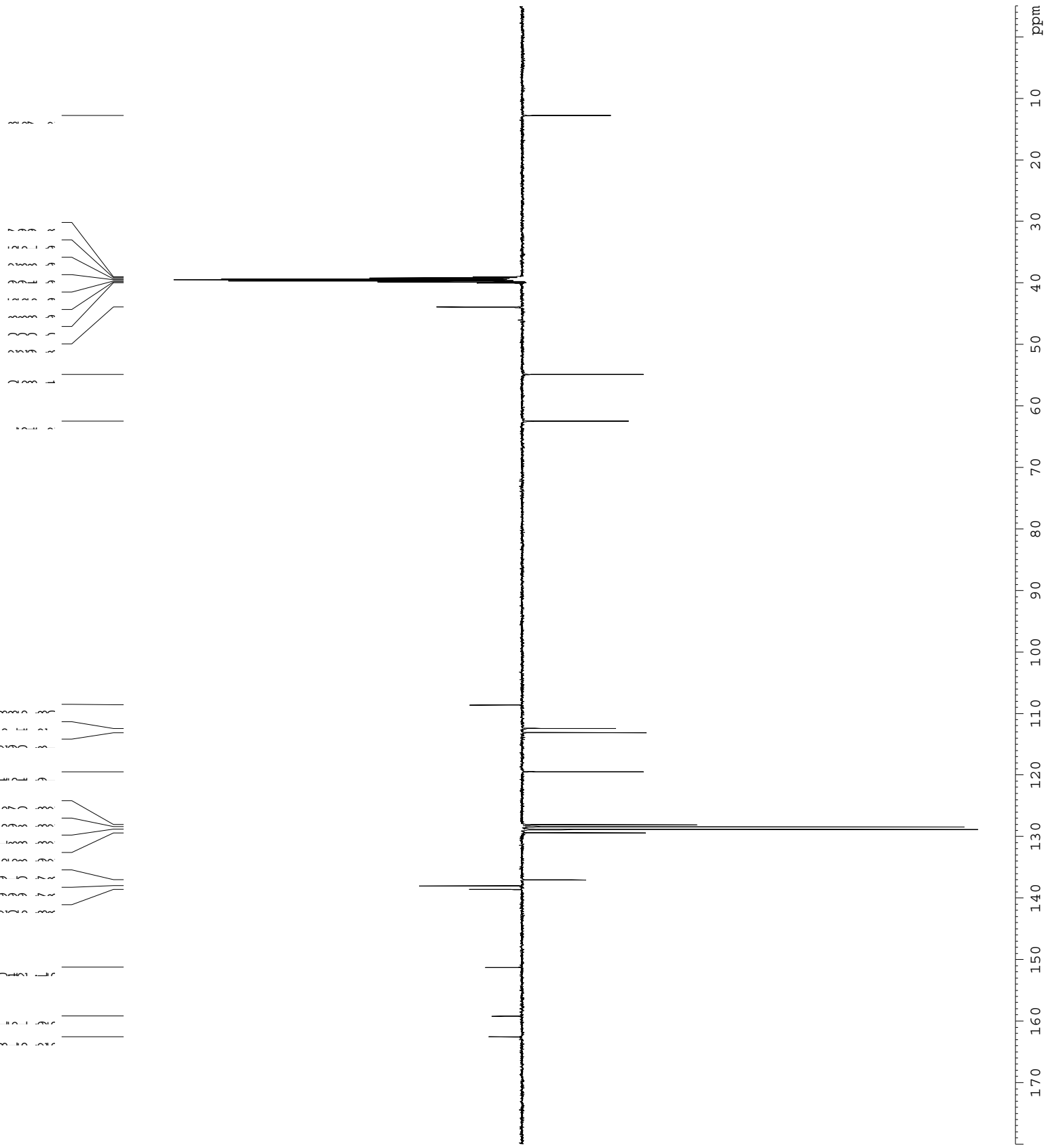


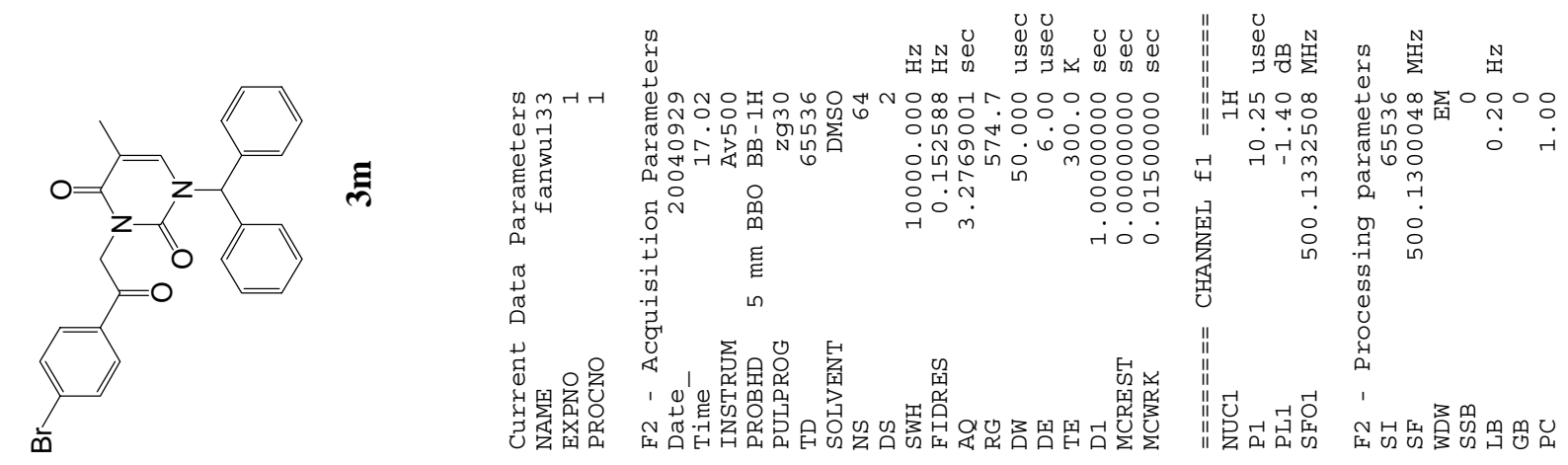

กิ
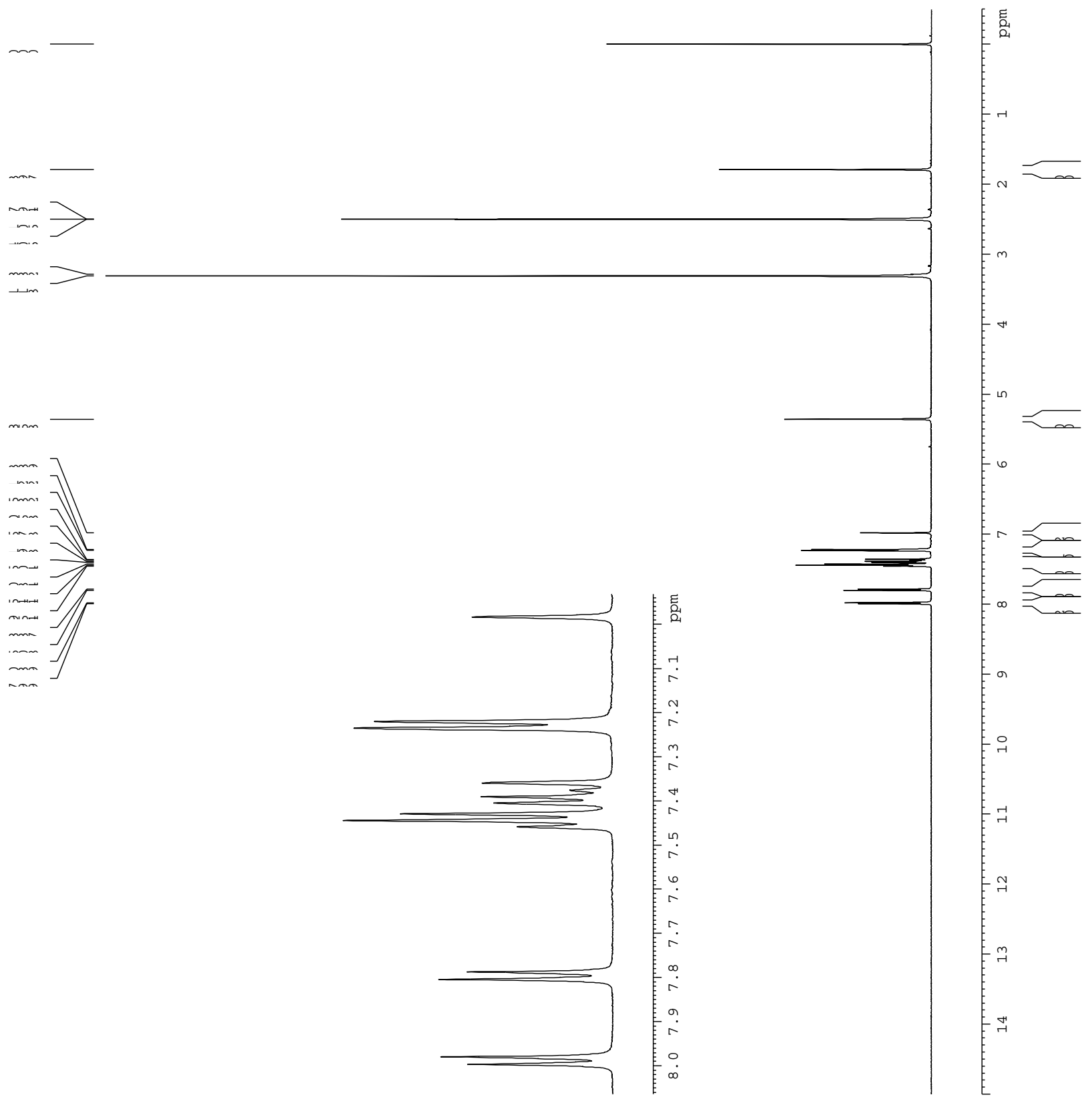

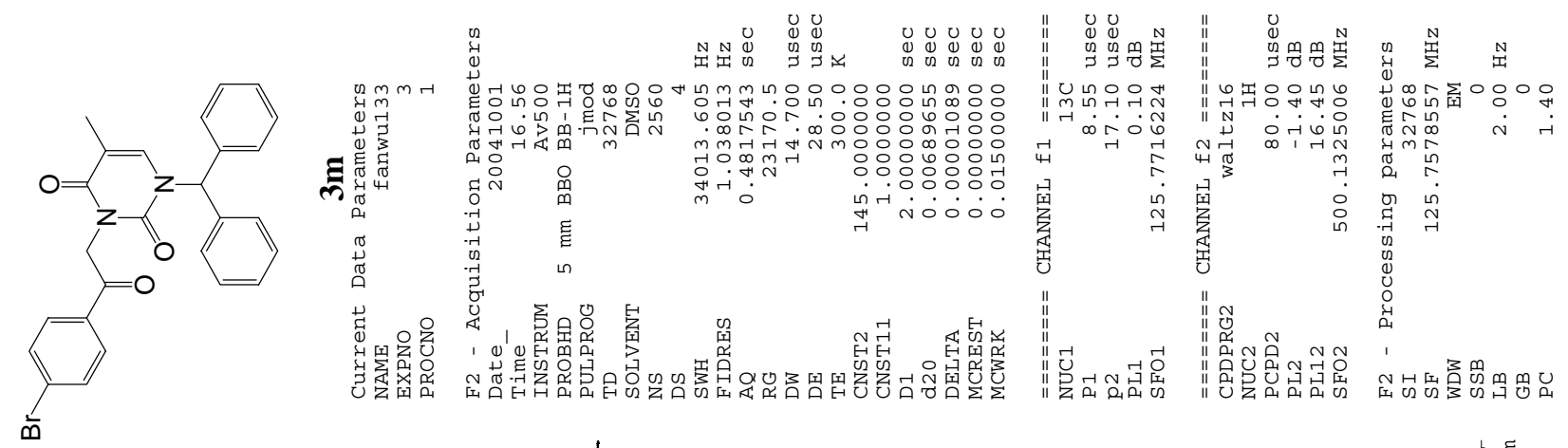

is
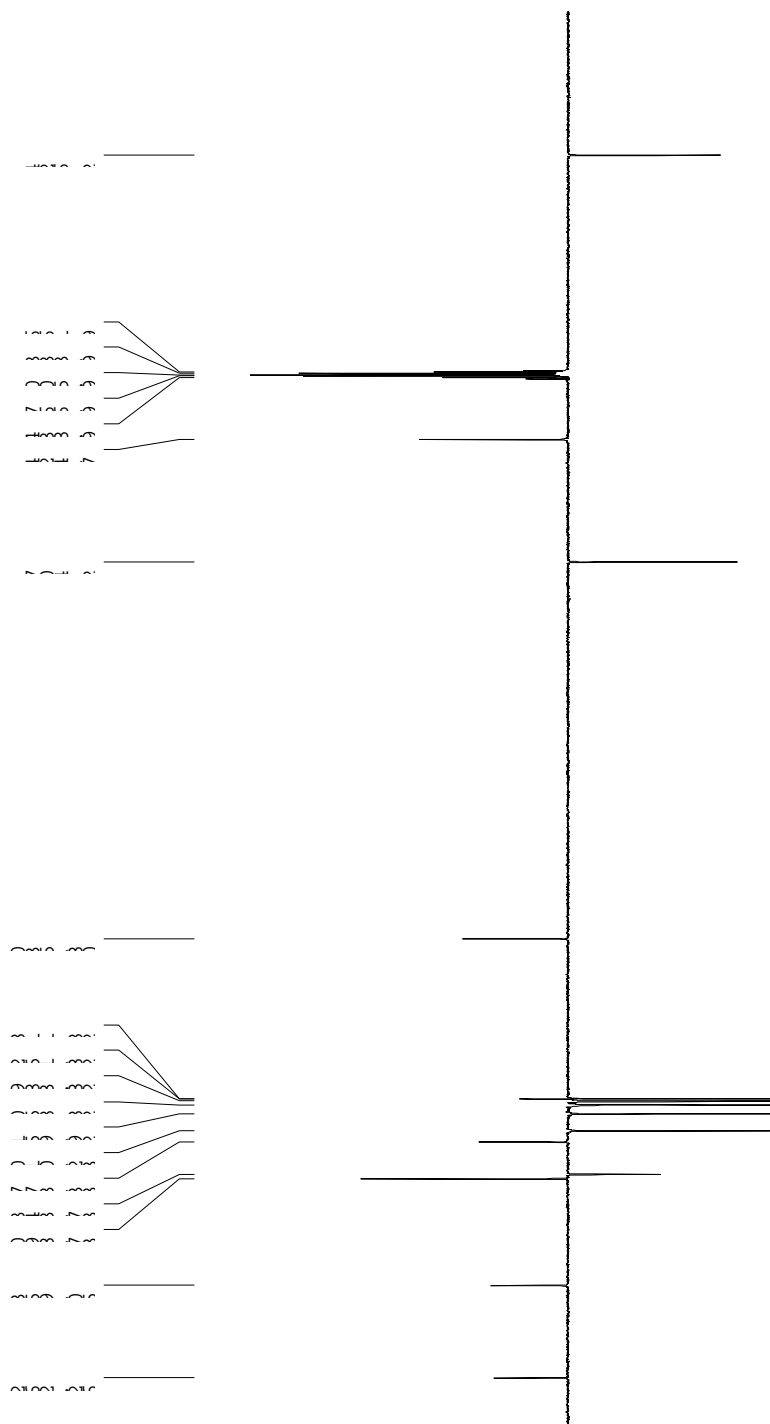

$\therefore$

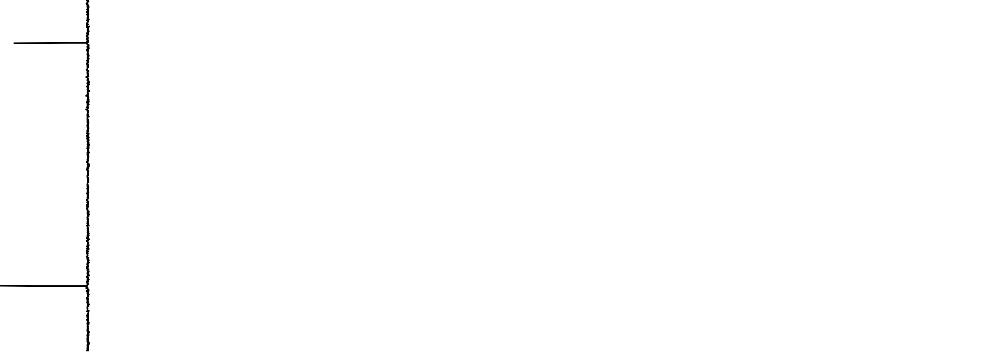



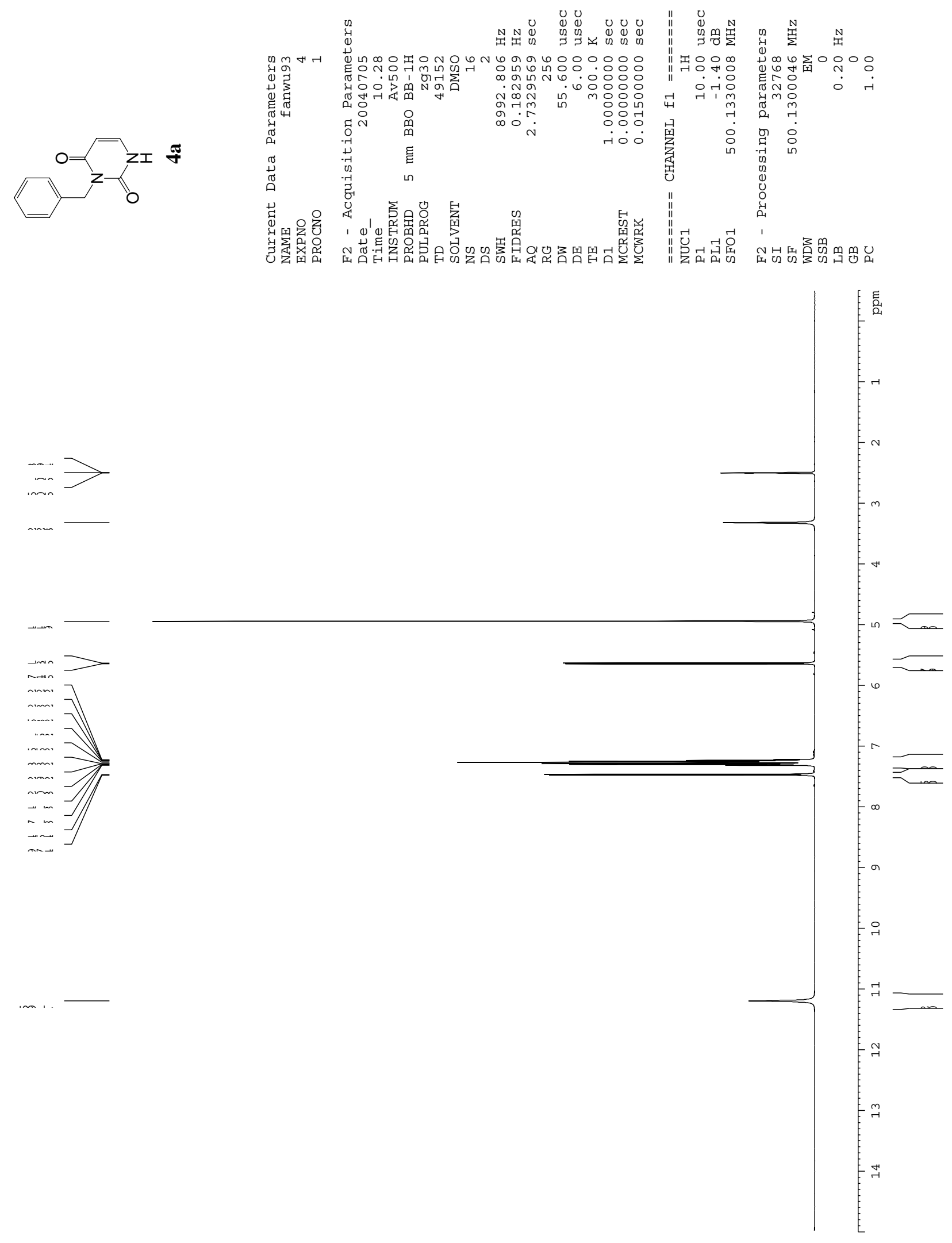

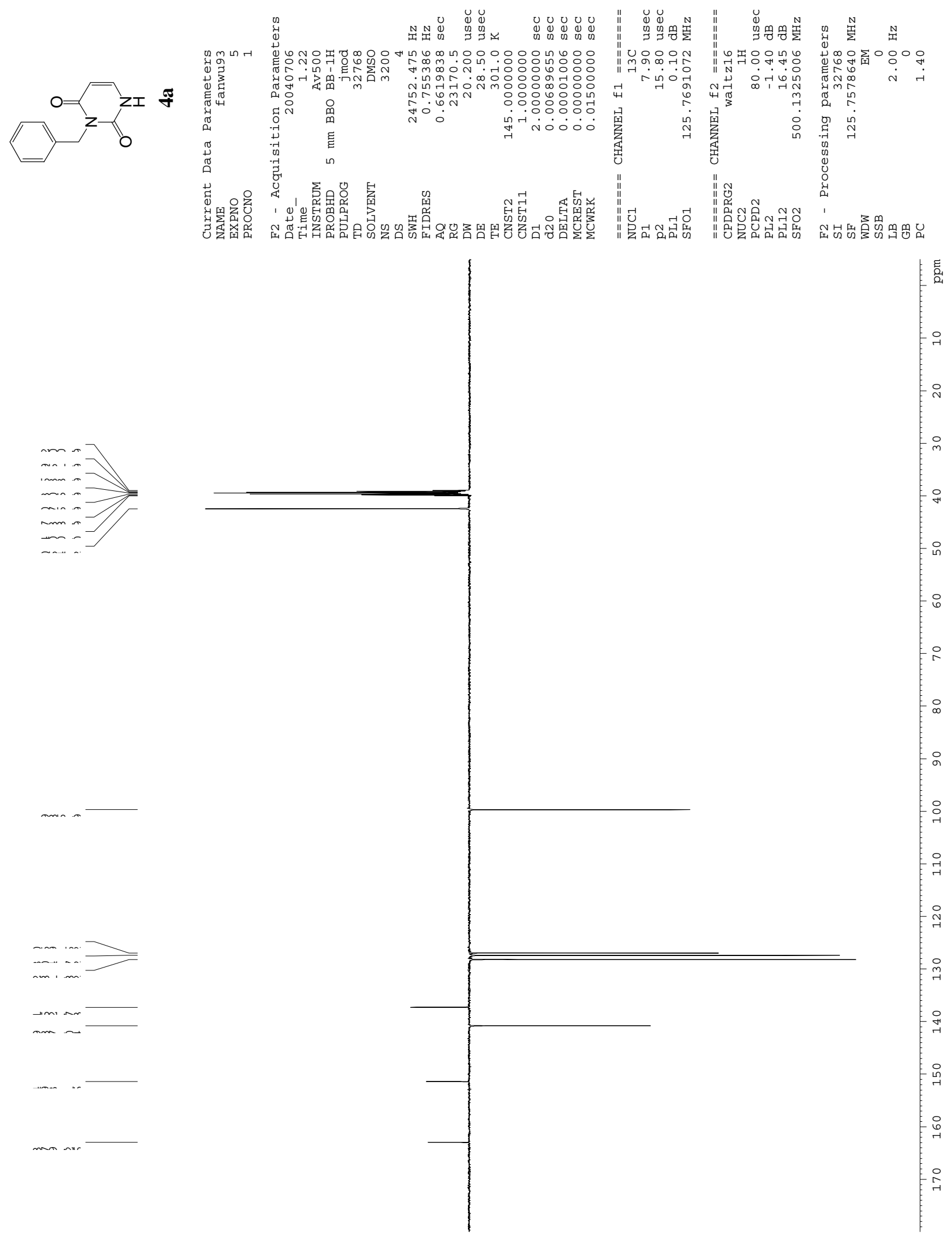

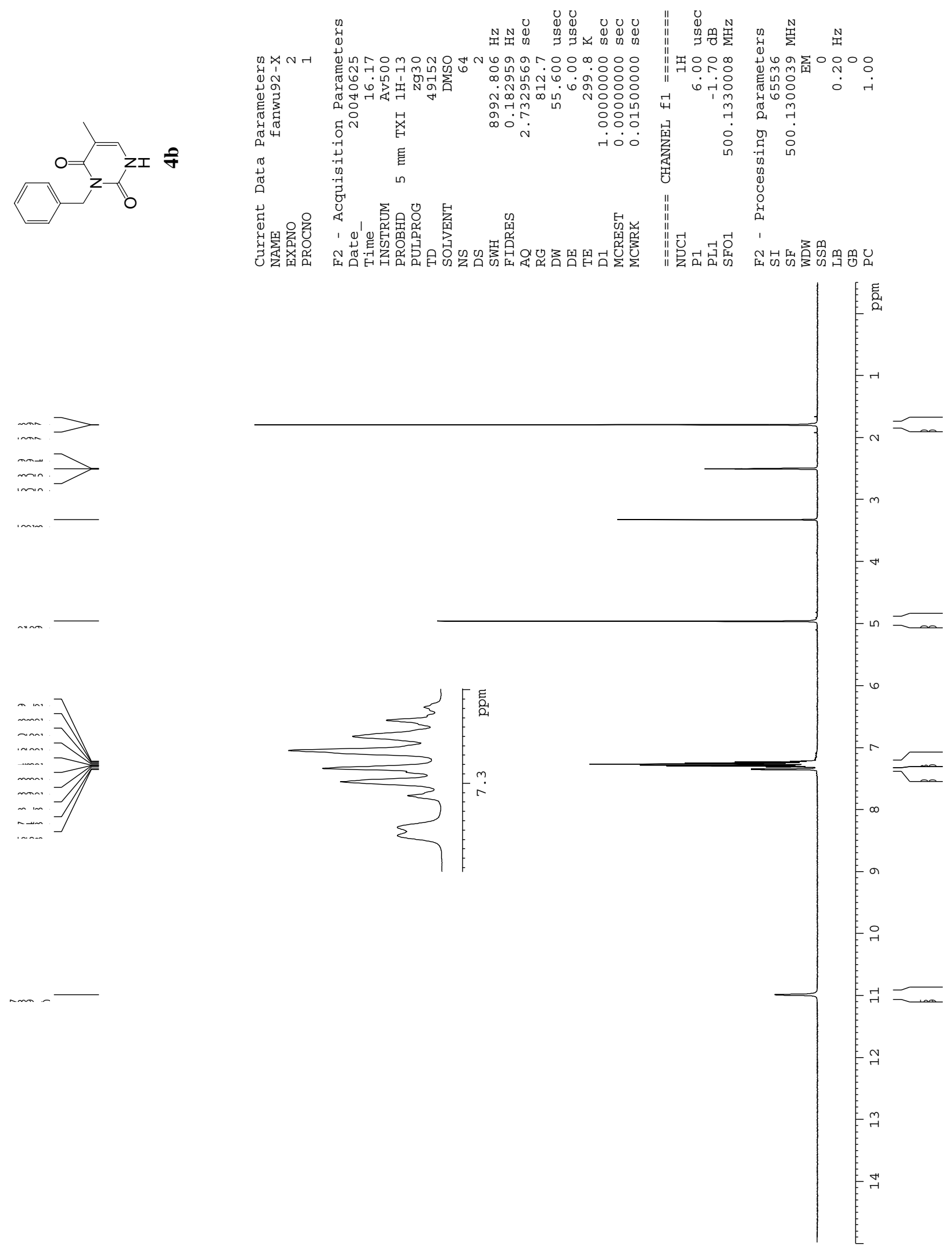


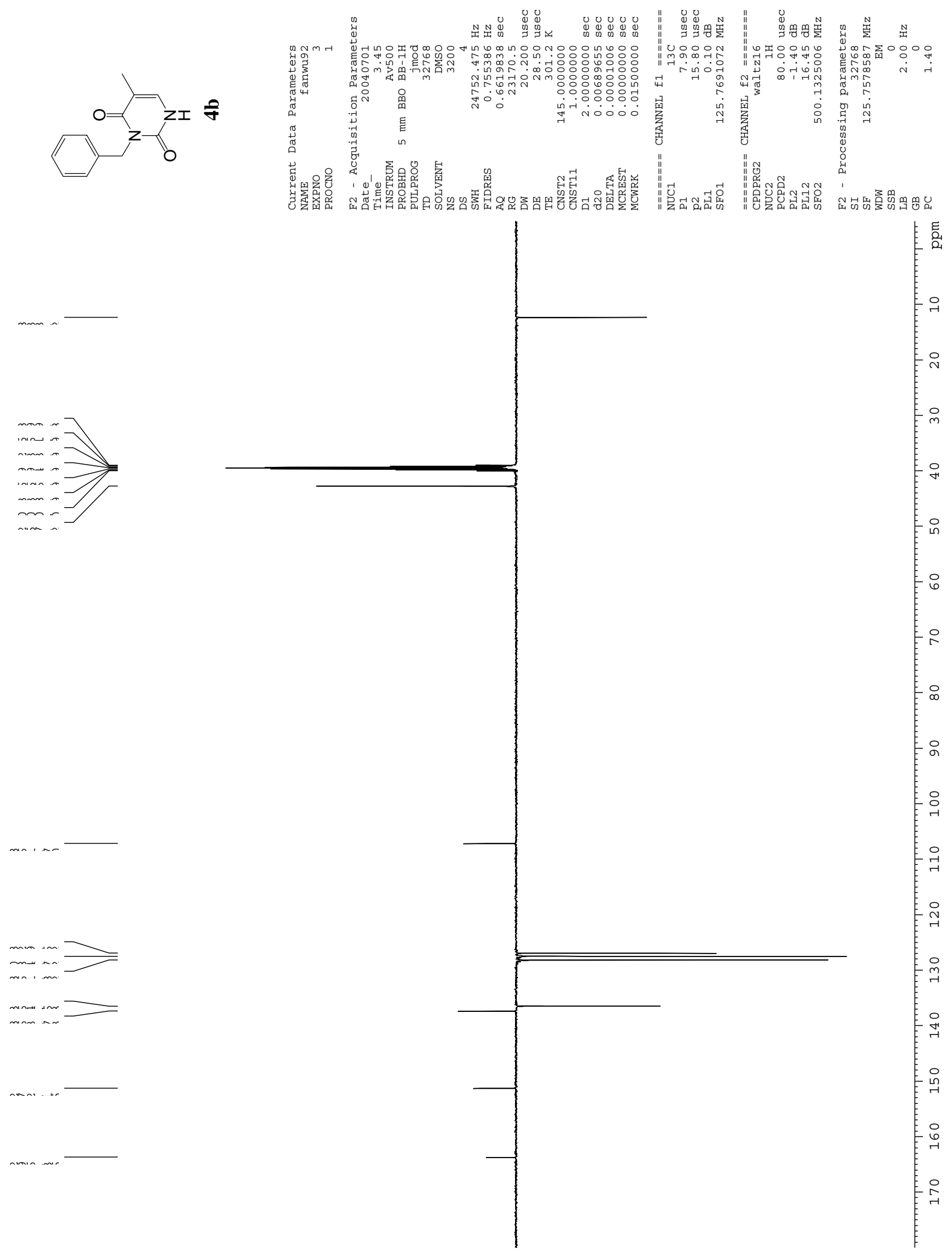



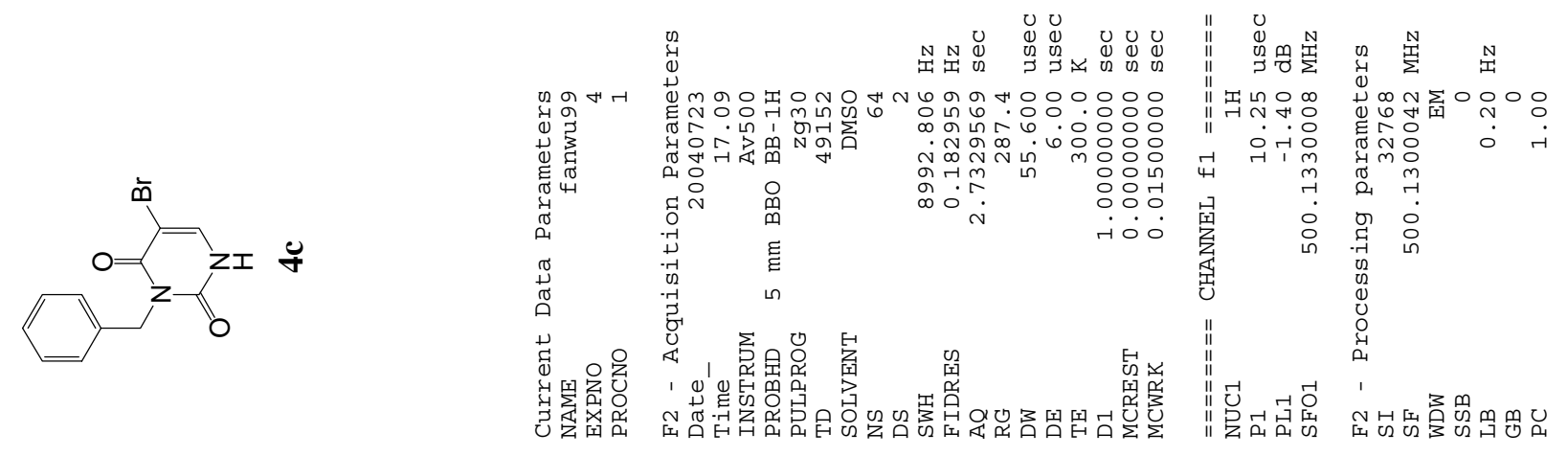

年
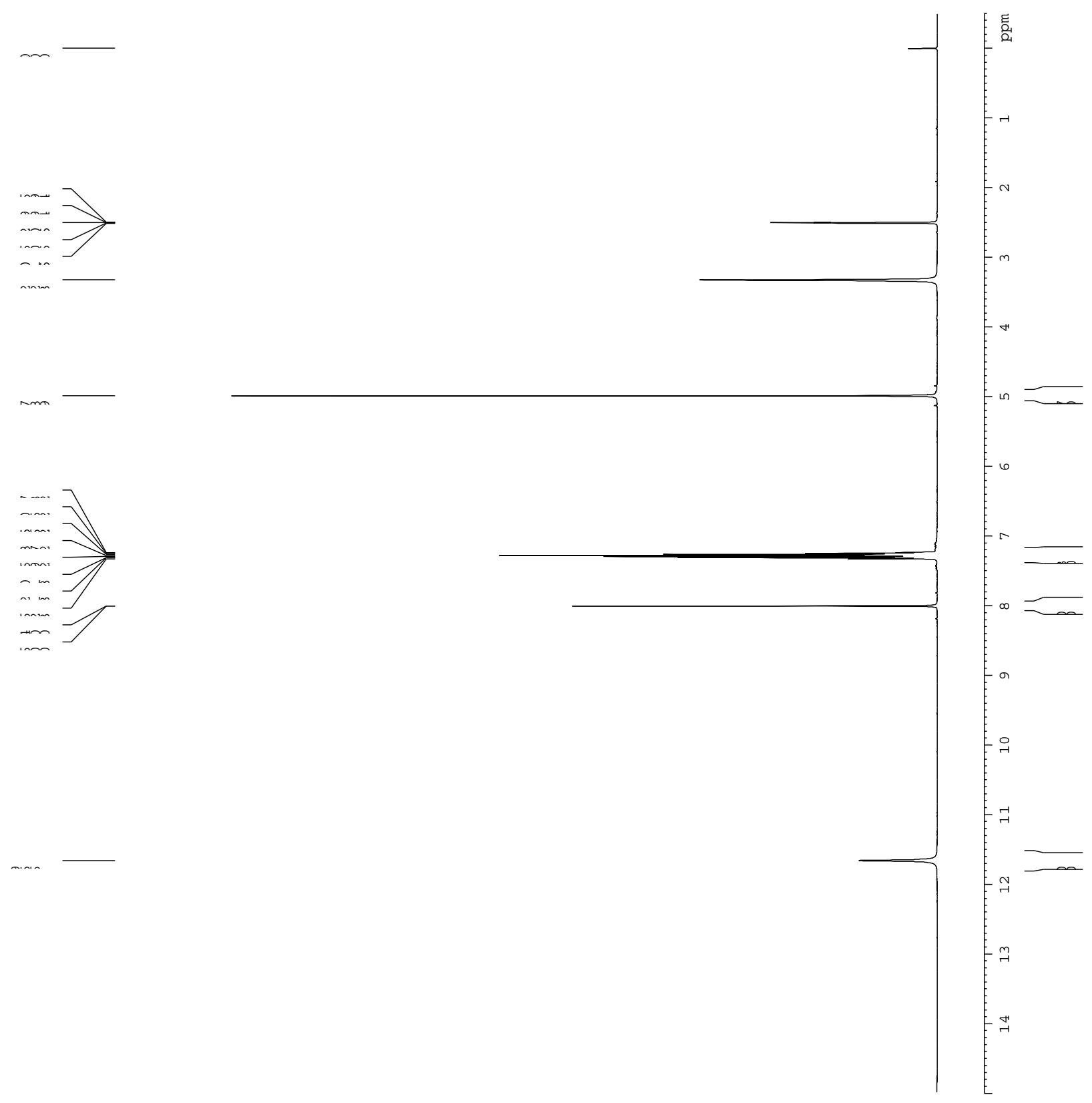

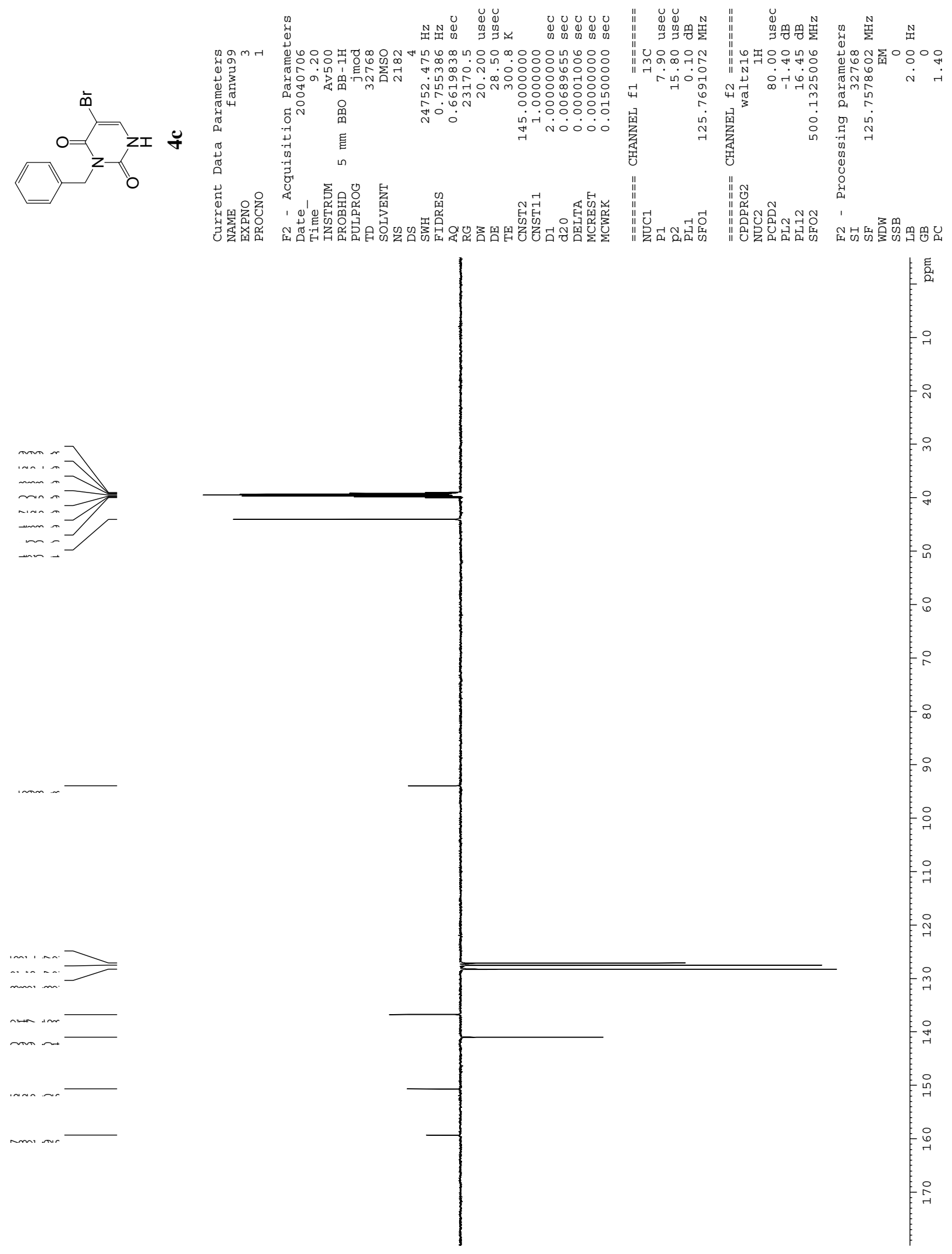

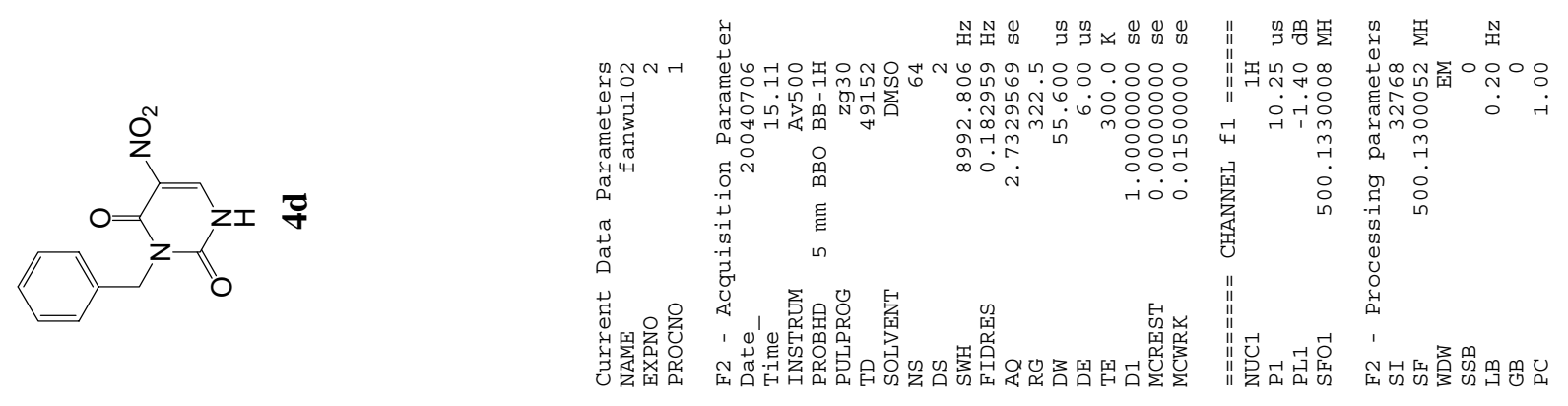

용
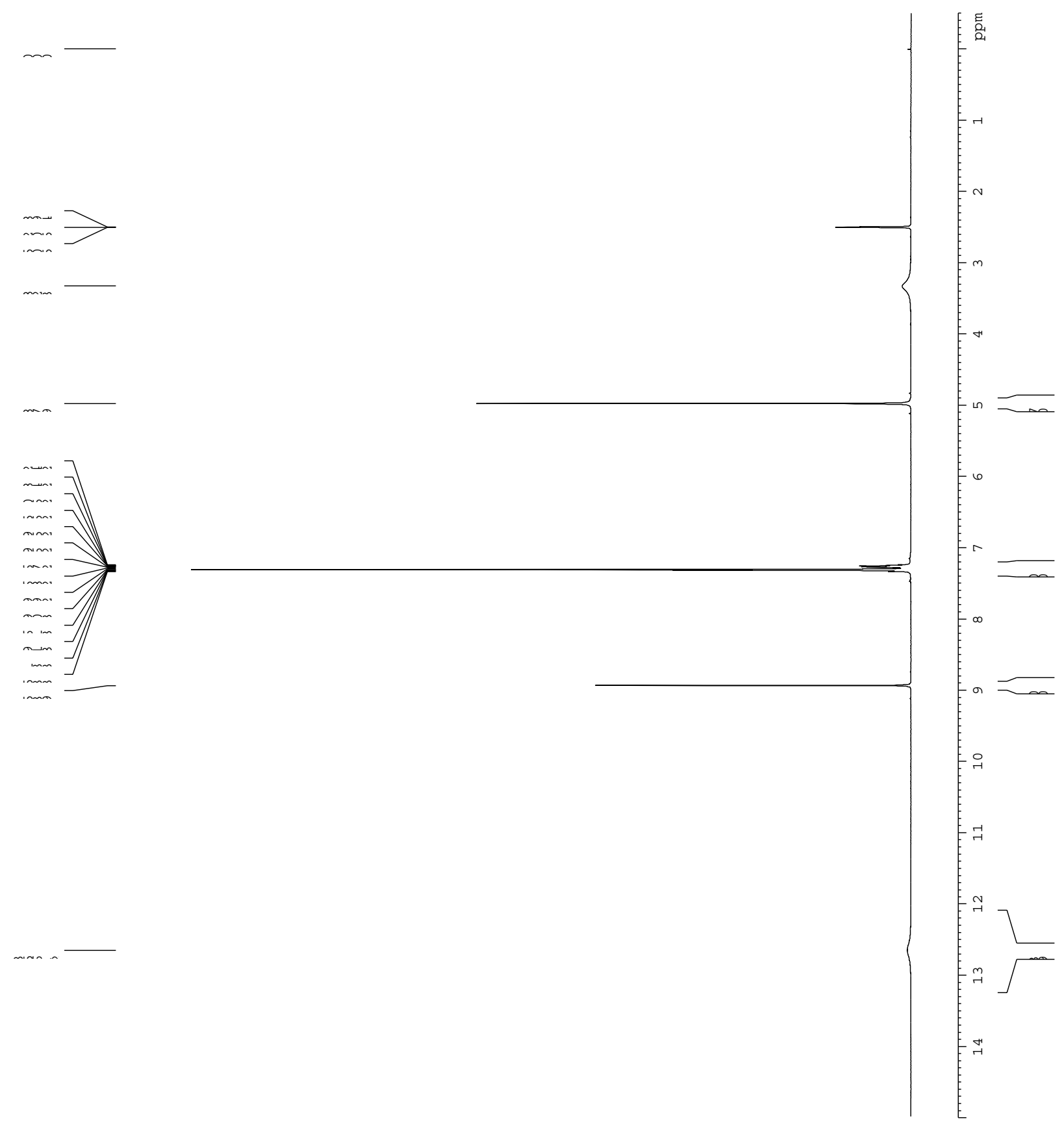

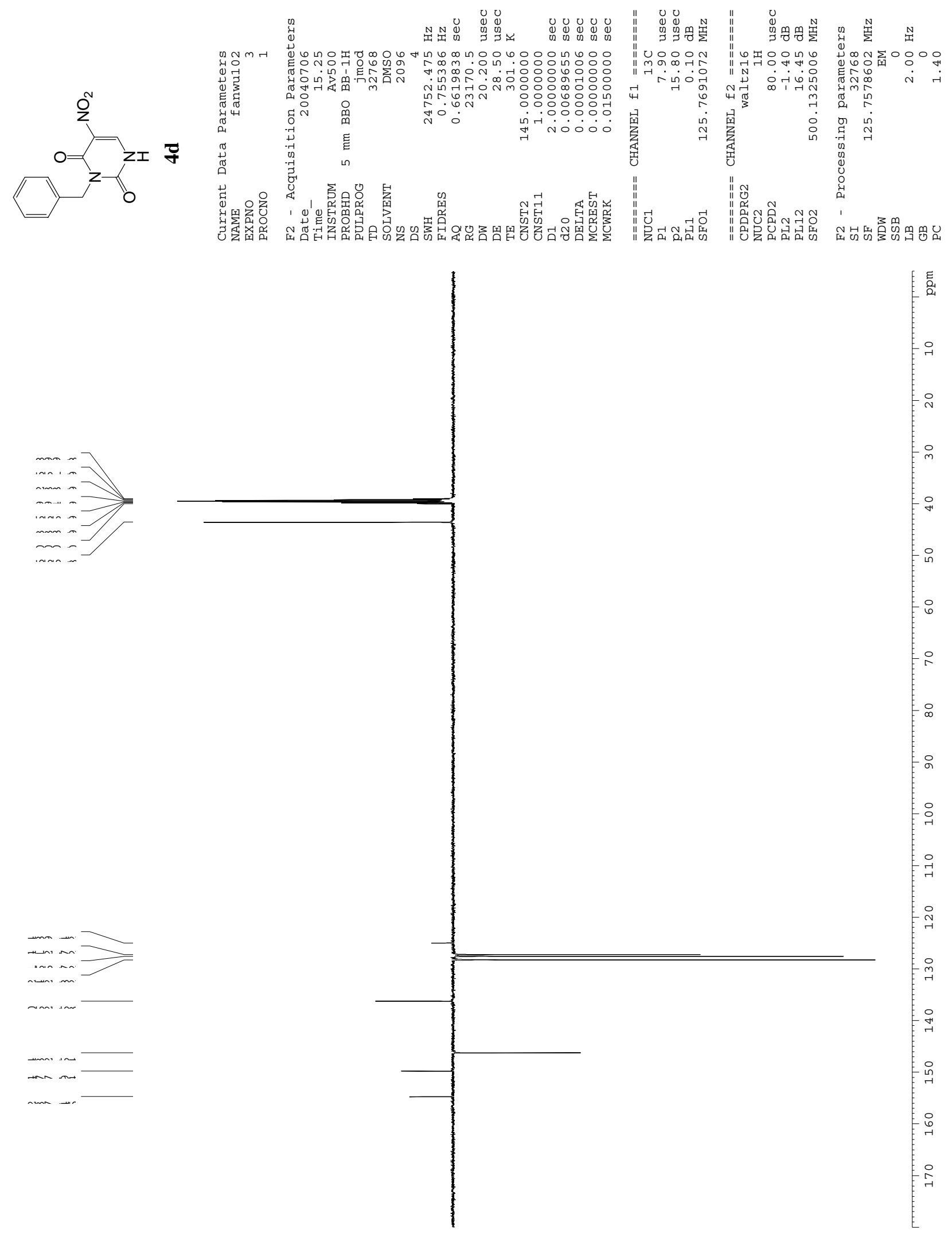

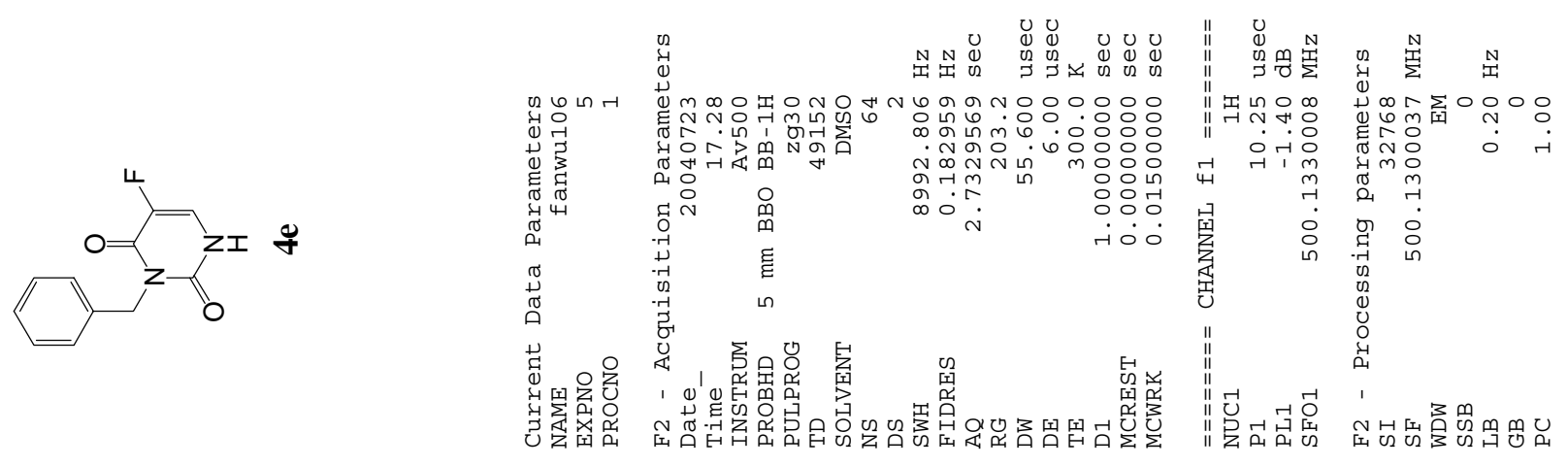

ชู
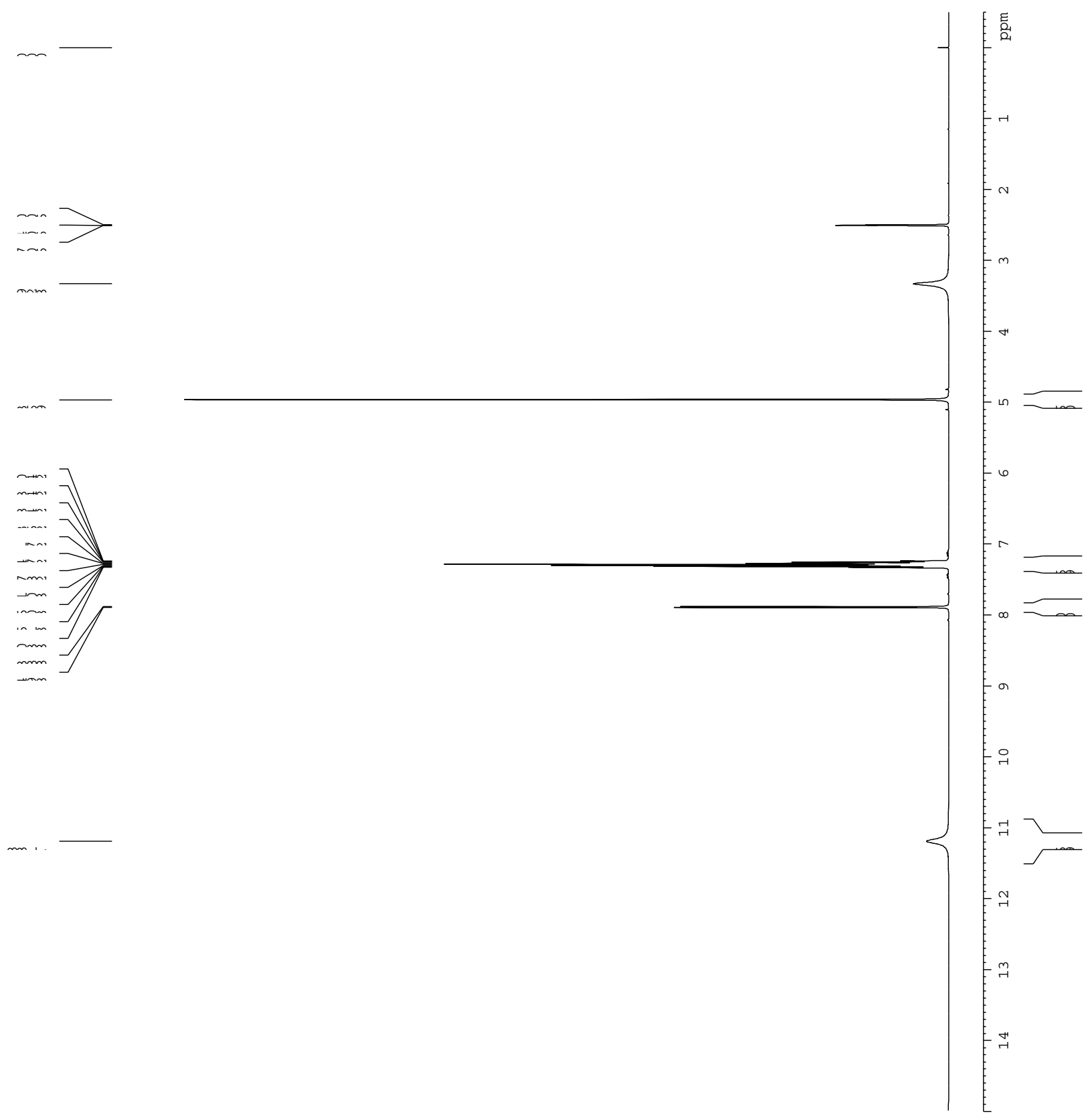

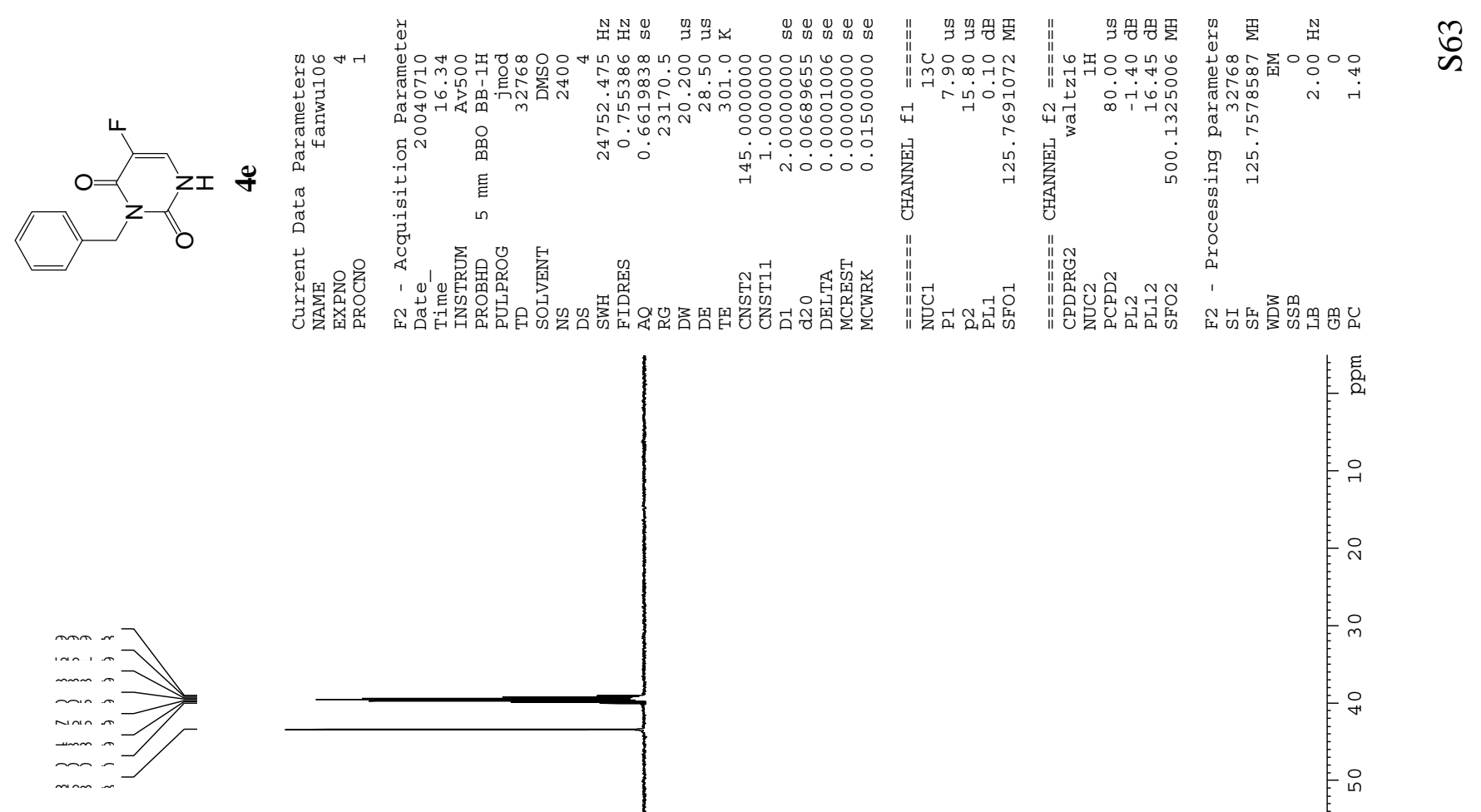

है

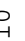
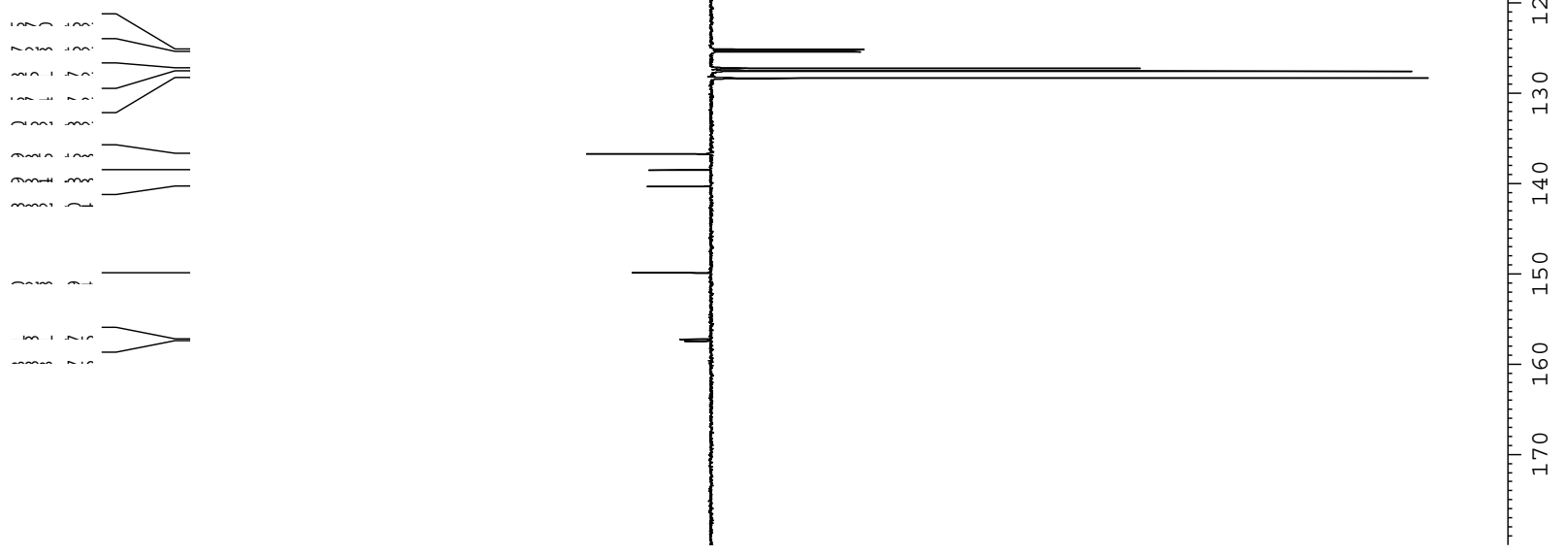

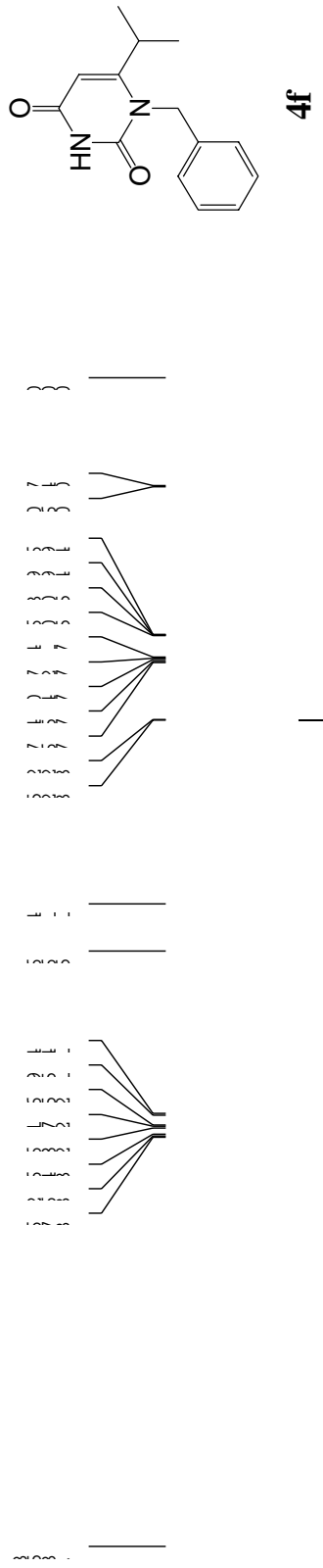
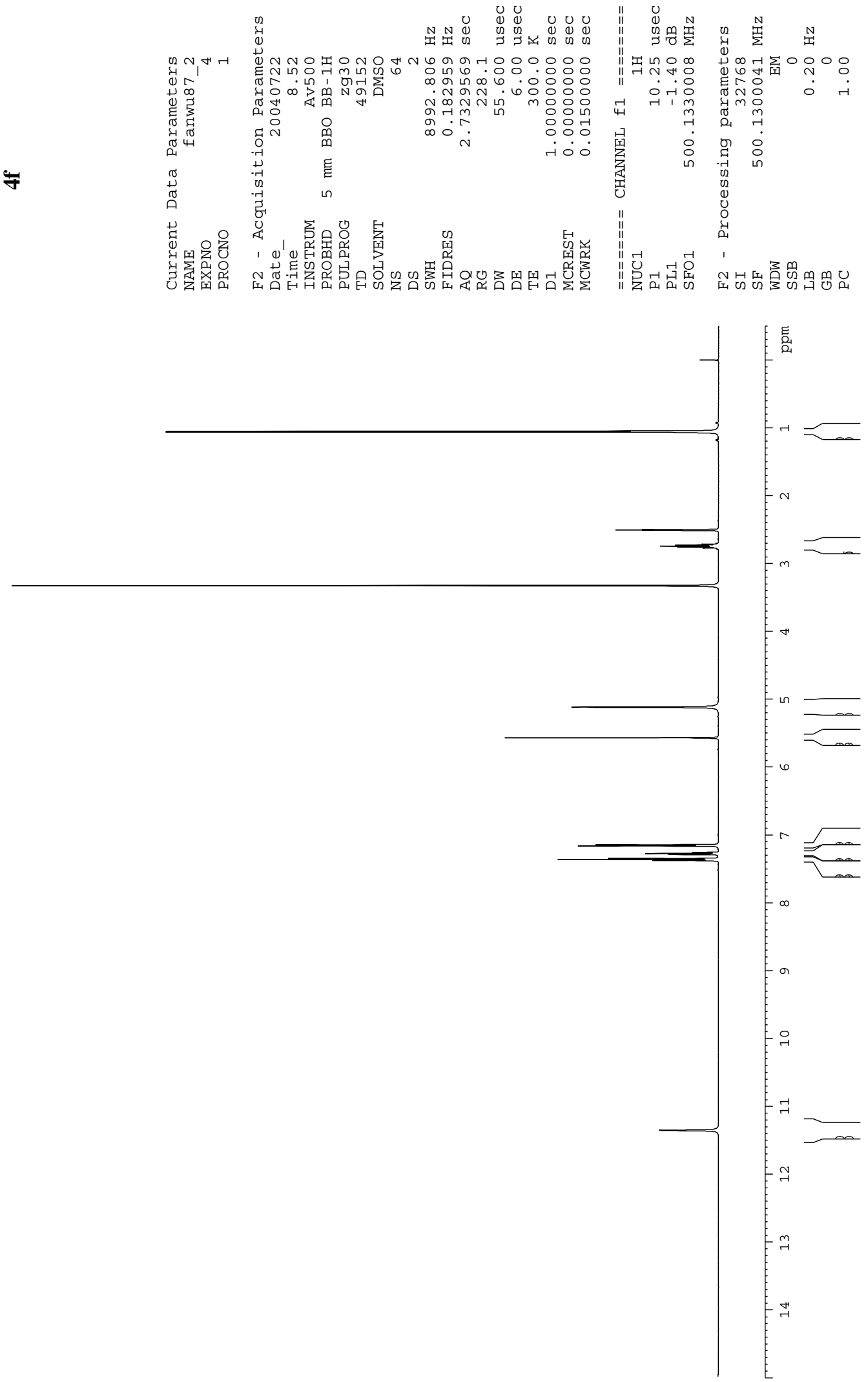

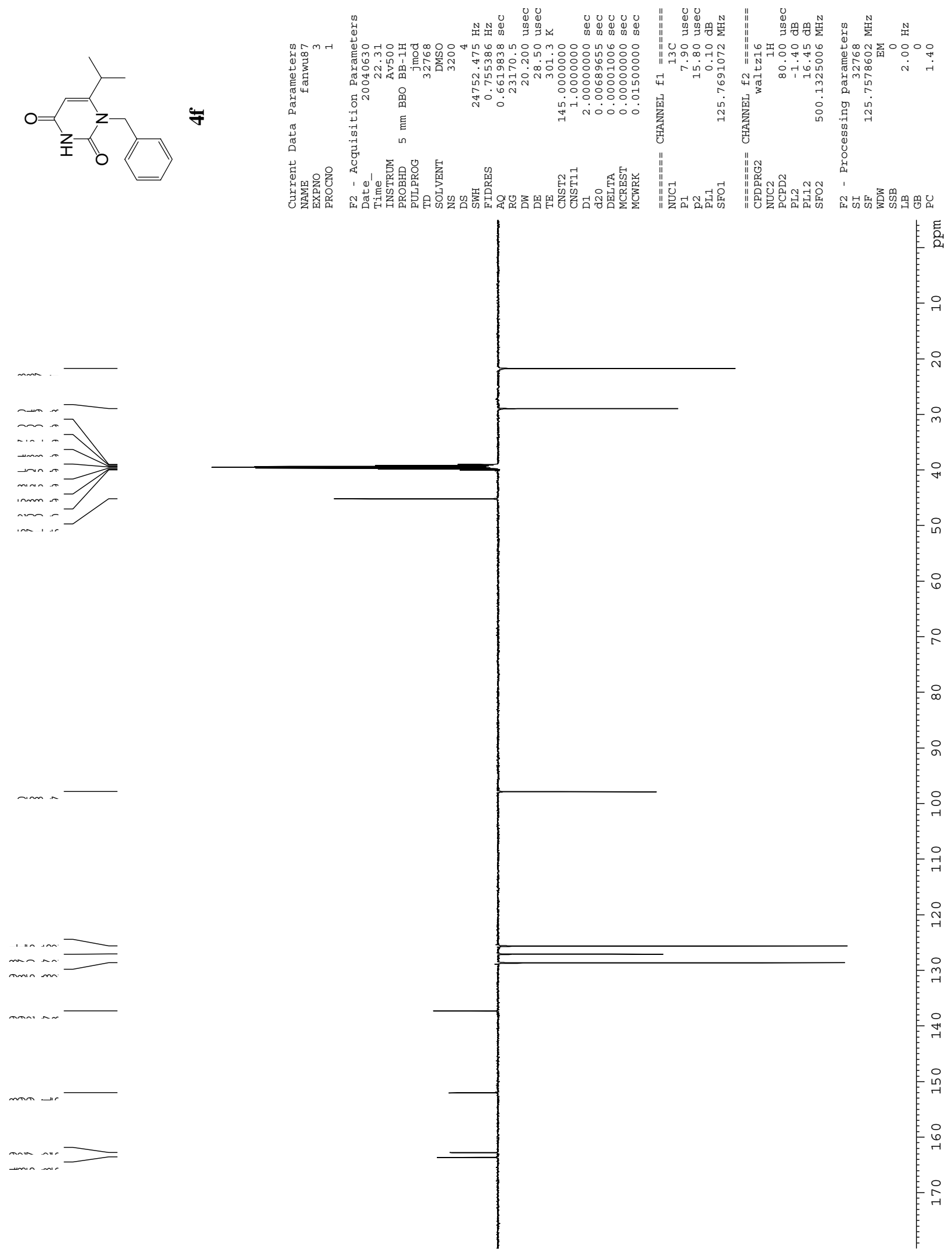

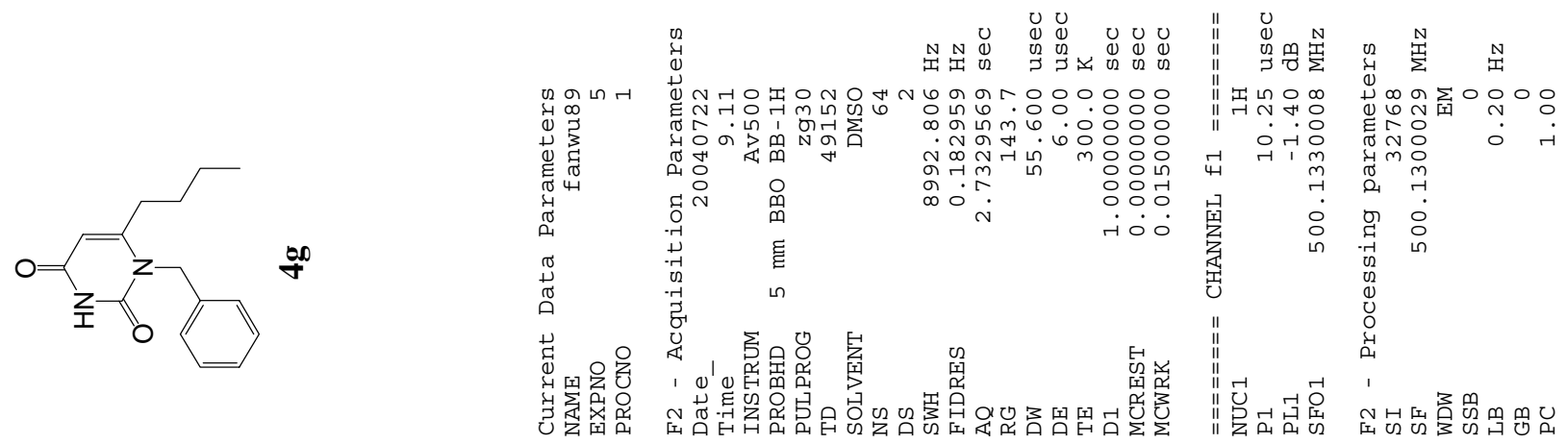

రి
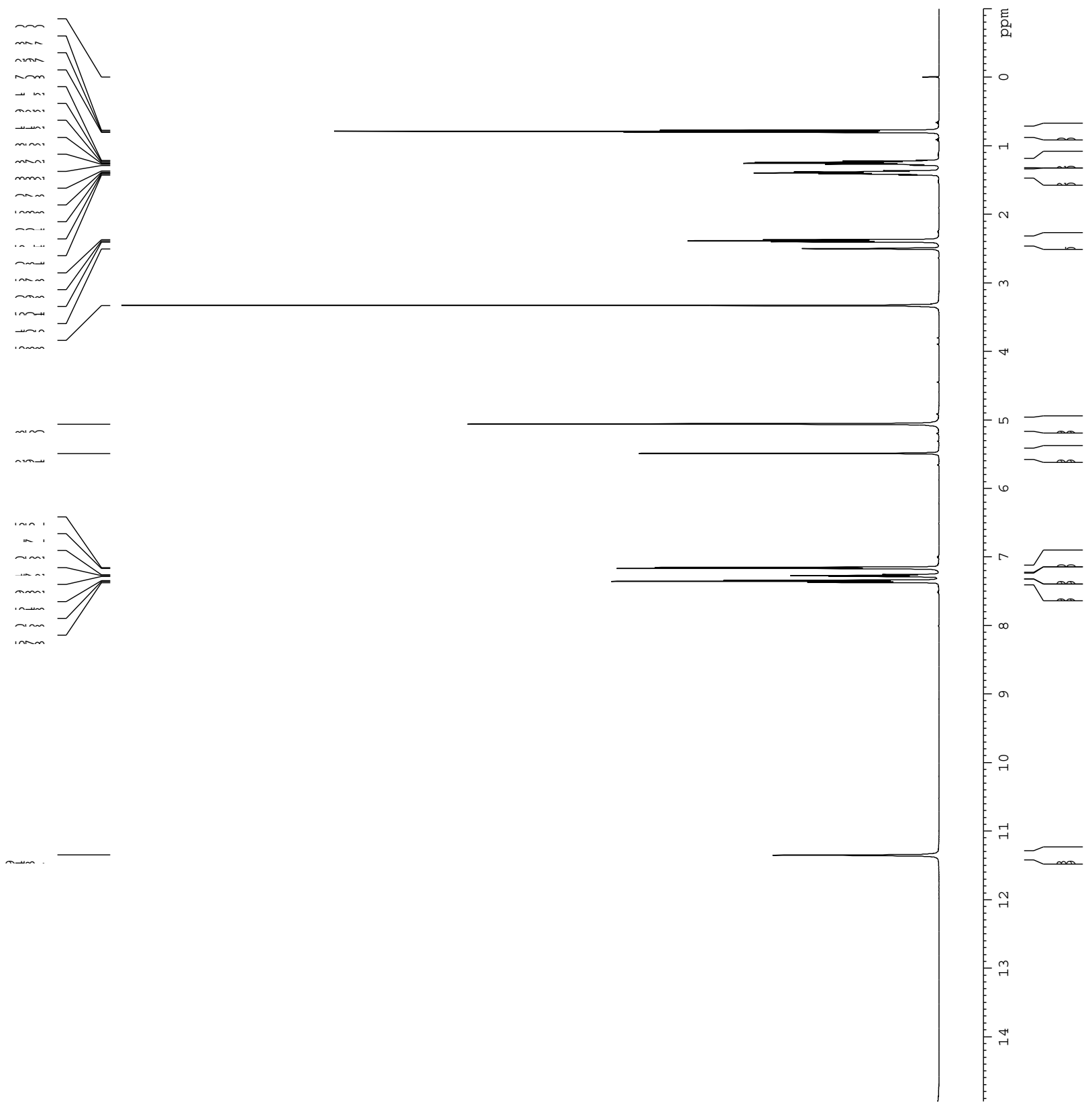

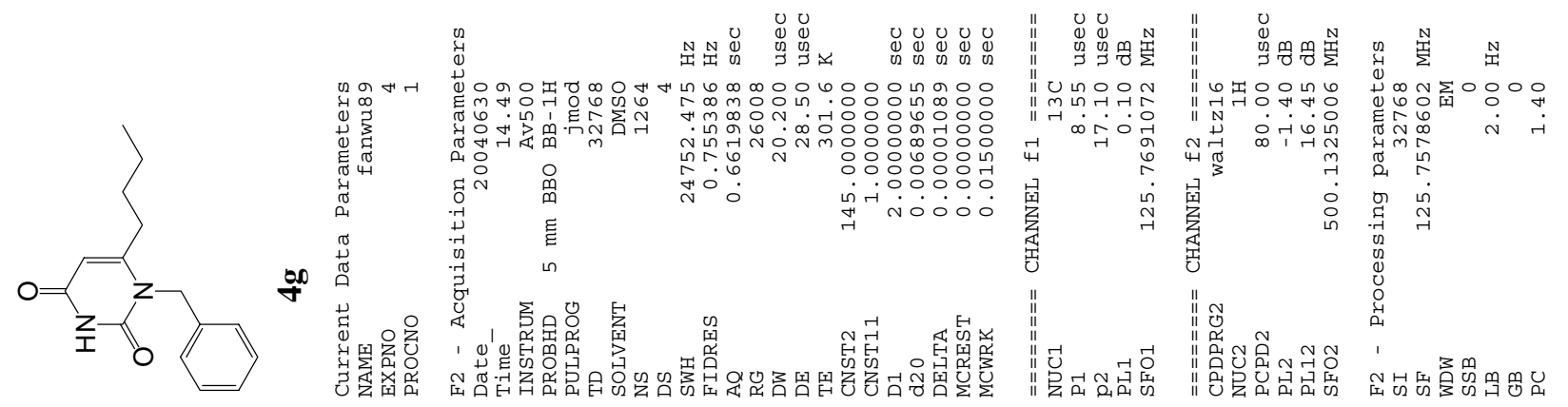

ڤ
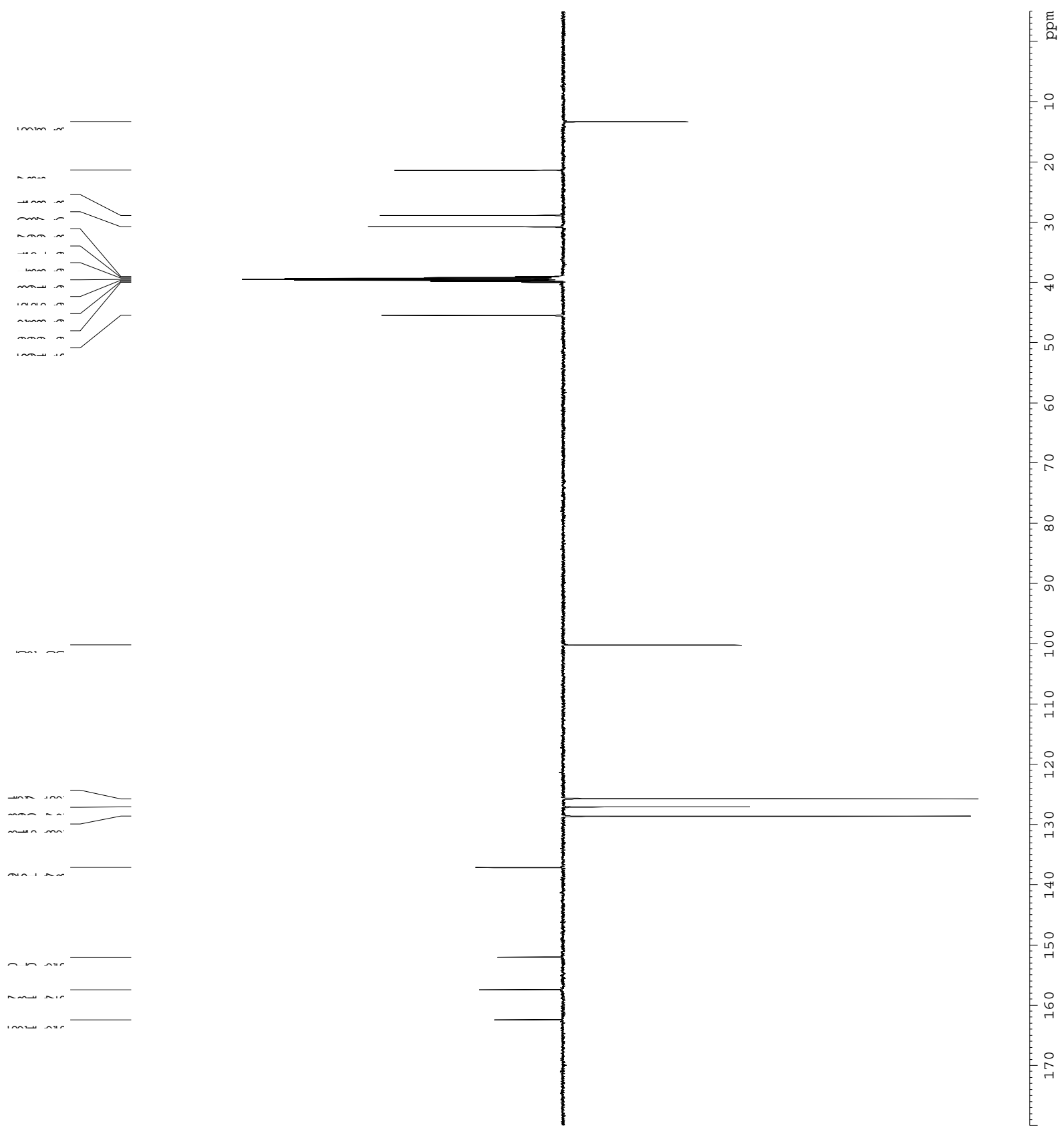

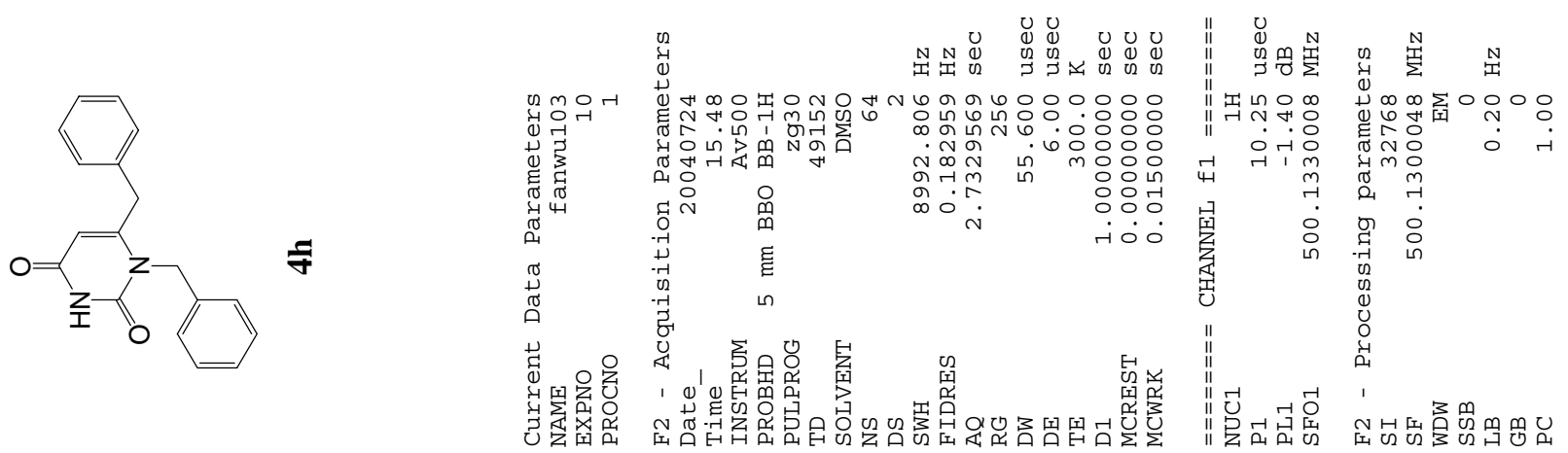

$\underset{\sim}{\infty}$
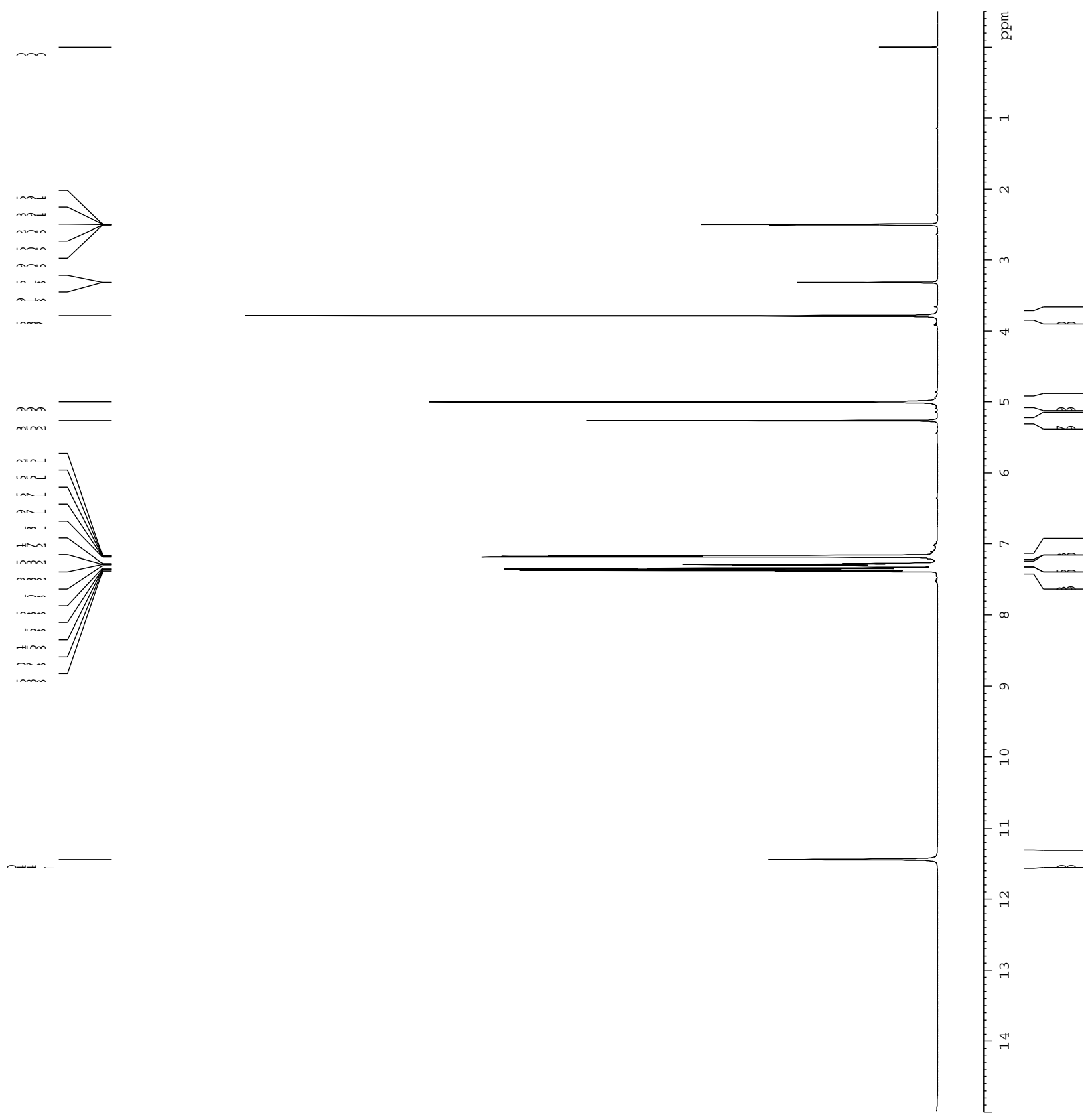


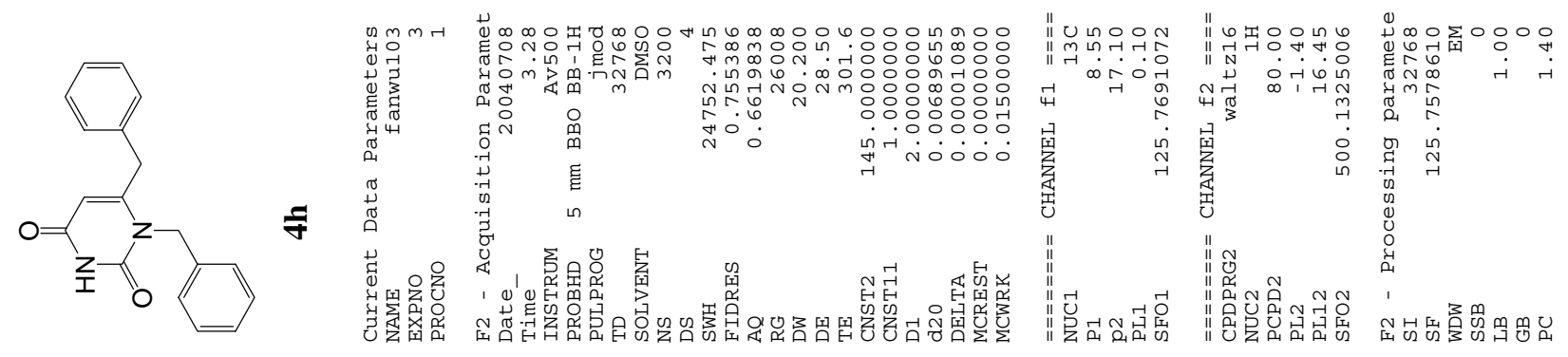

a

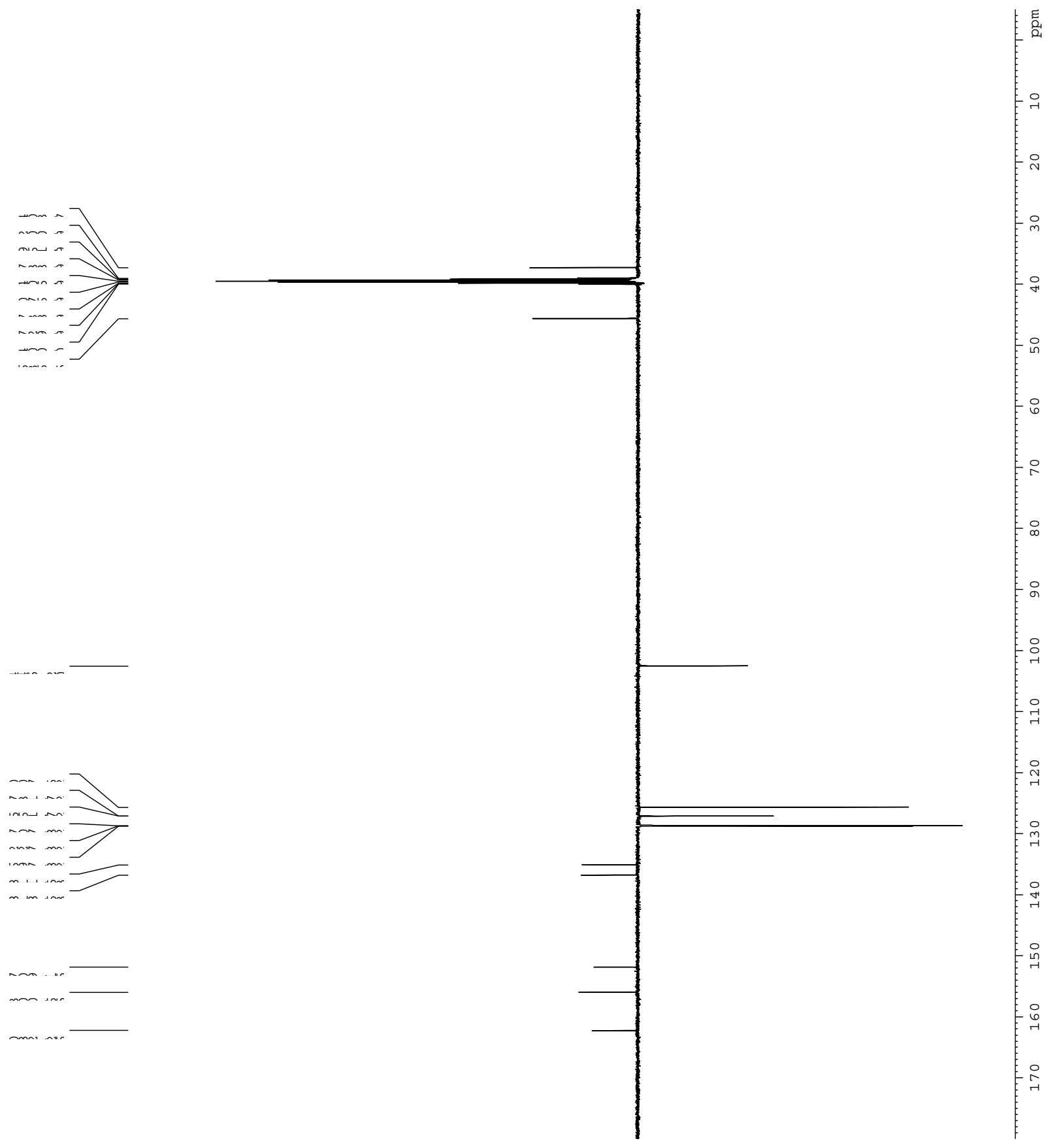



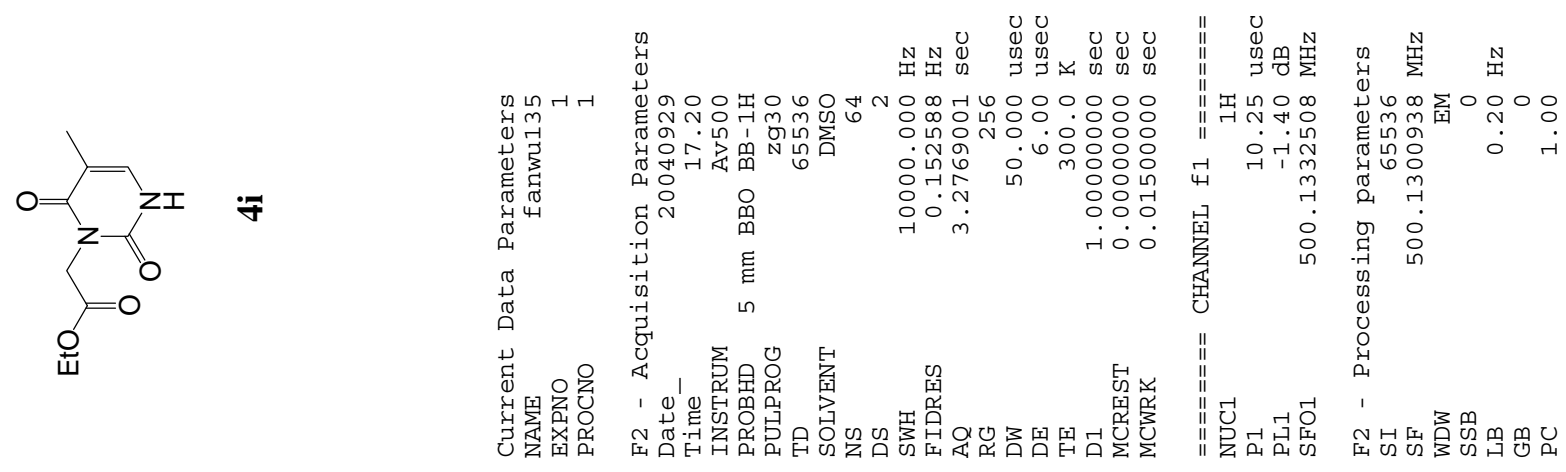

$\frac{2}{2}$
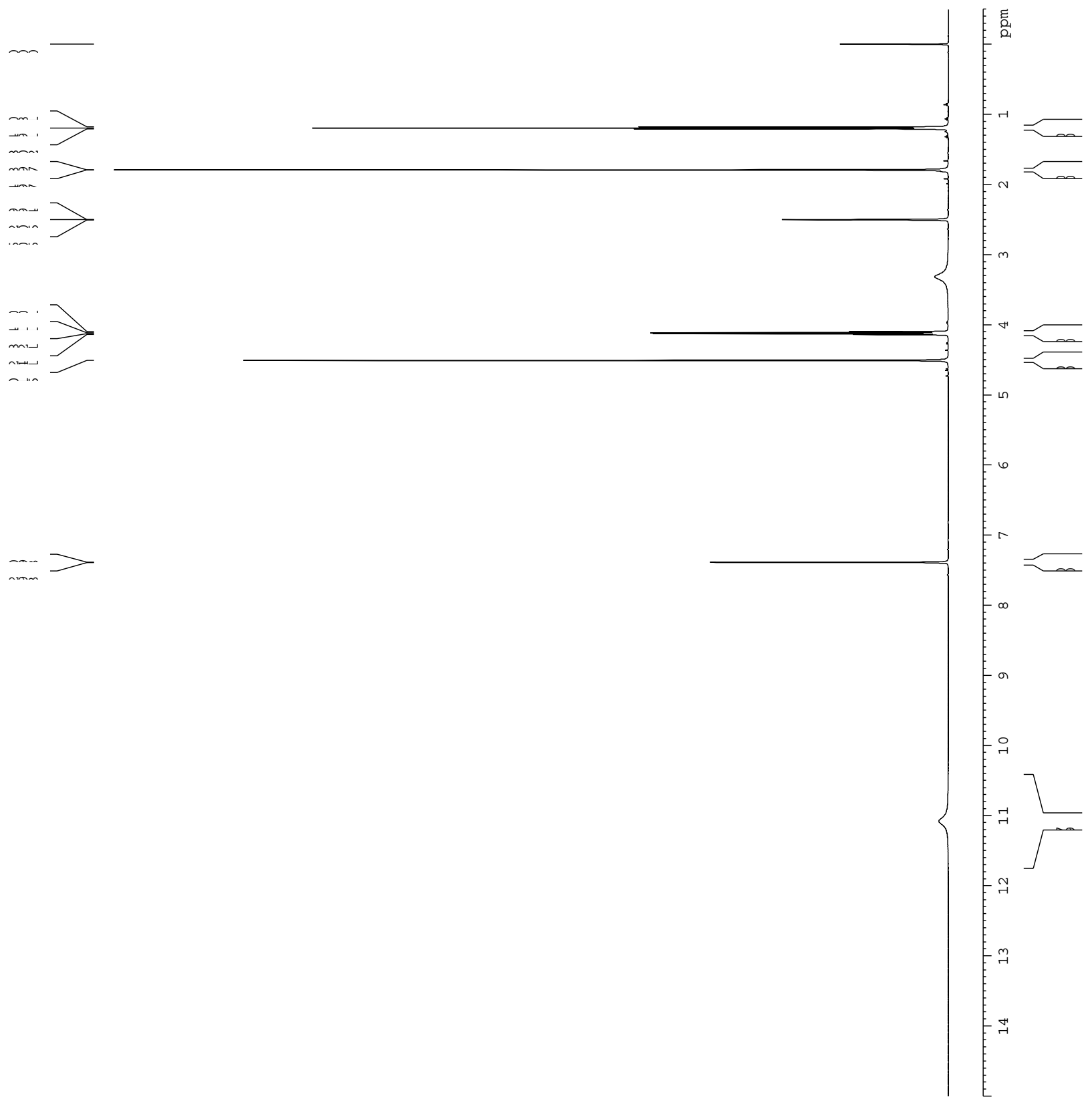

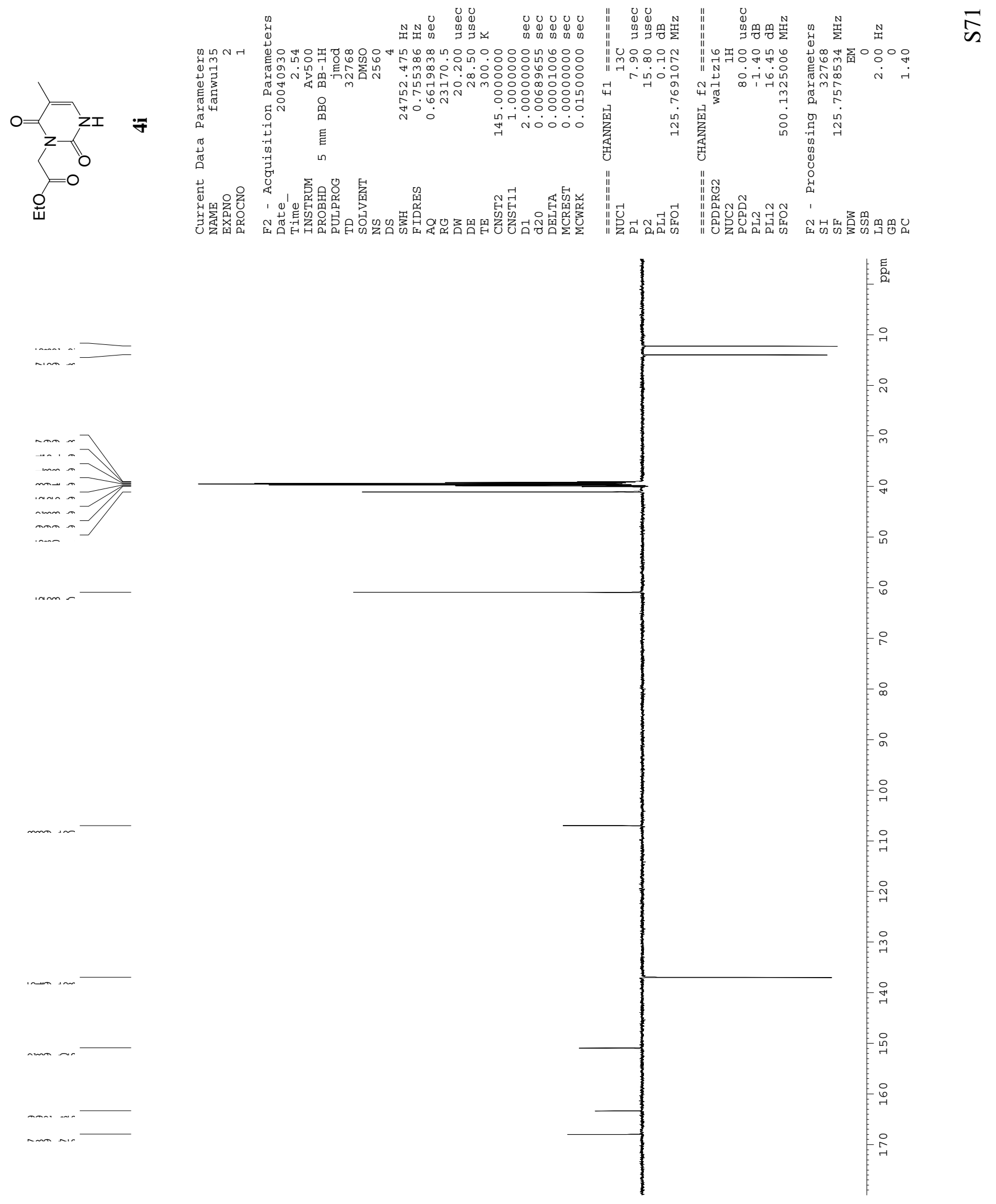

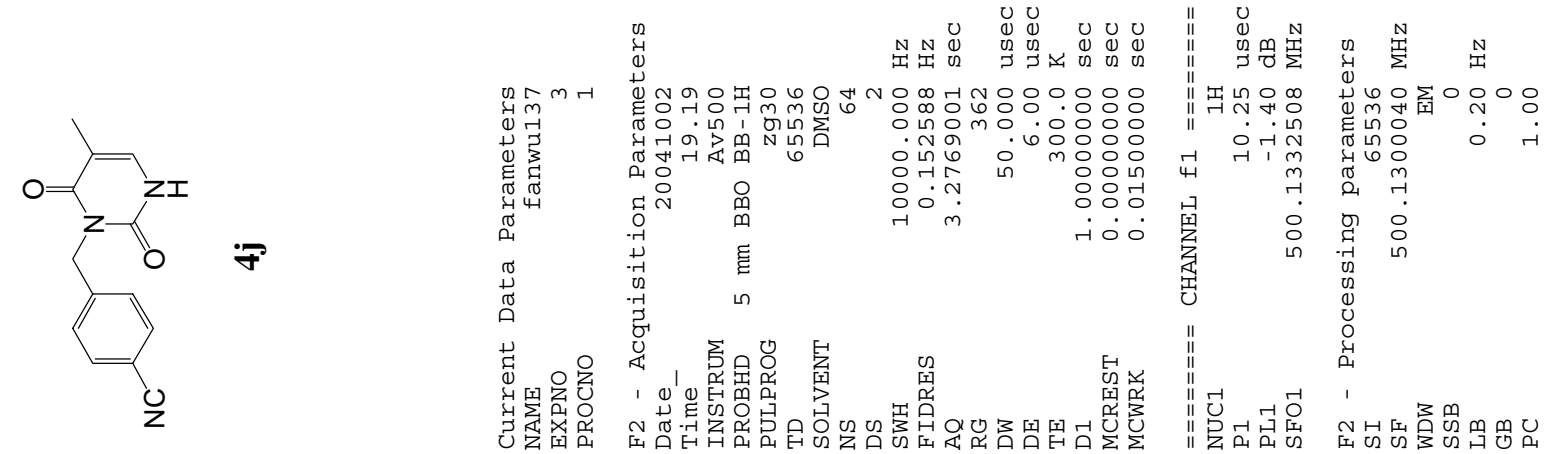

N
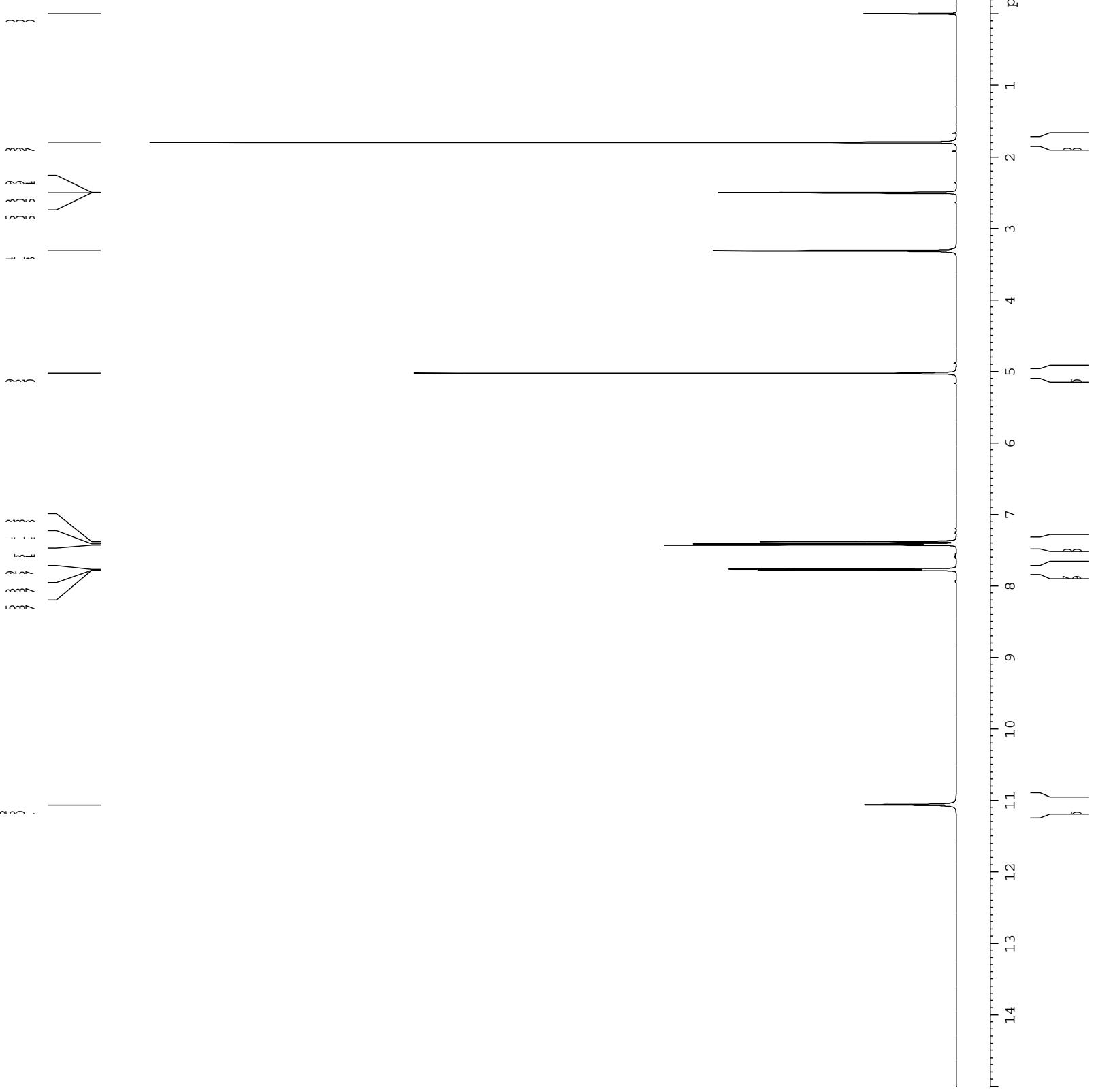

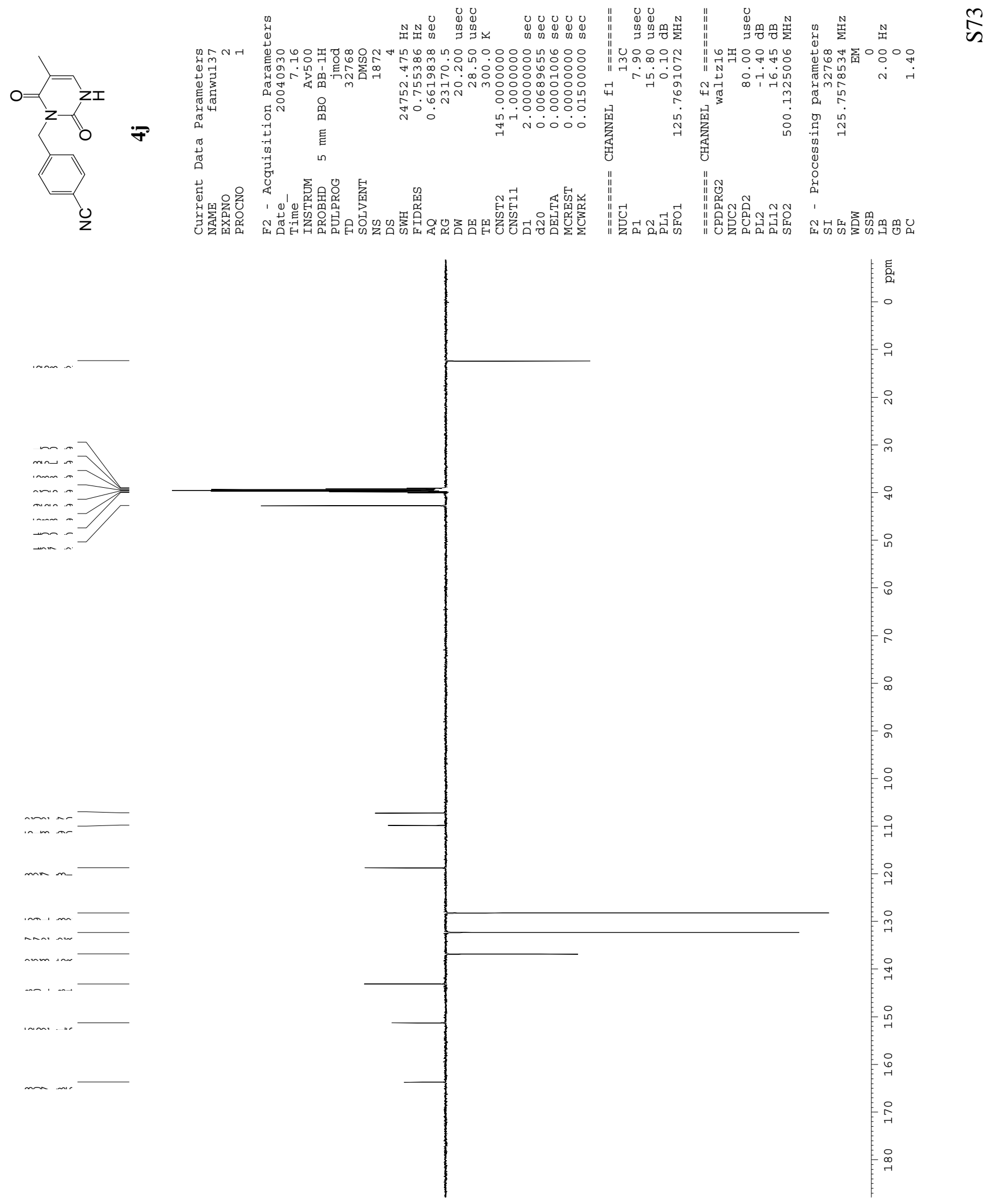

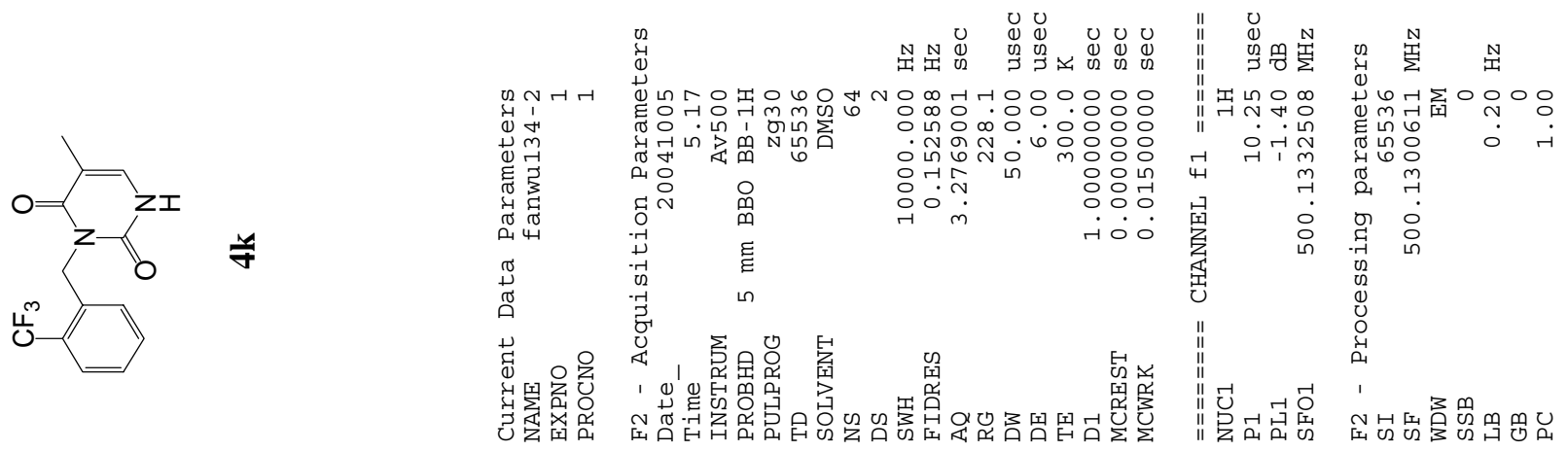

$\frac{t}{n}$
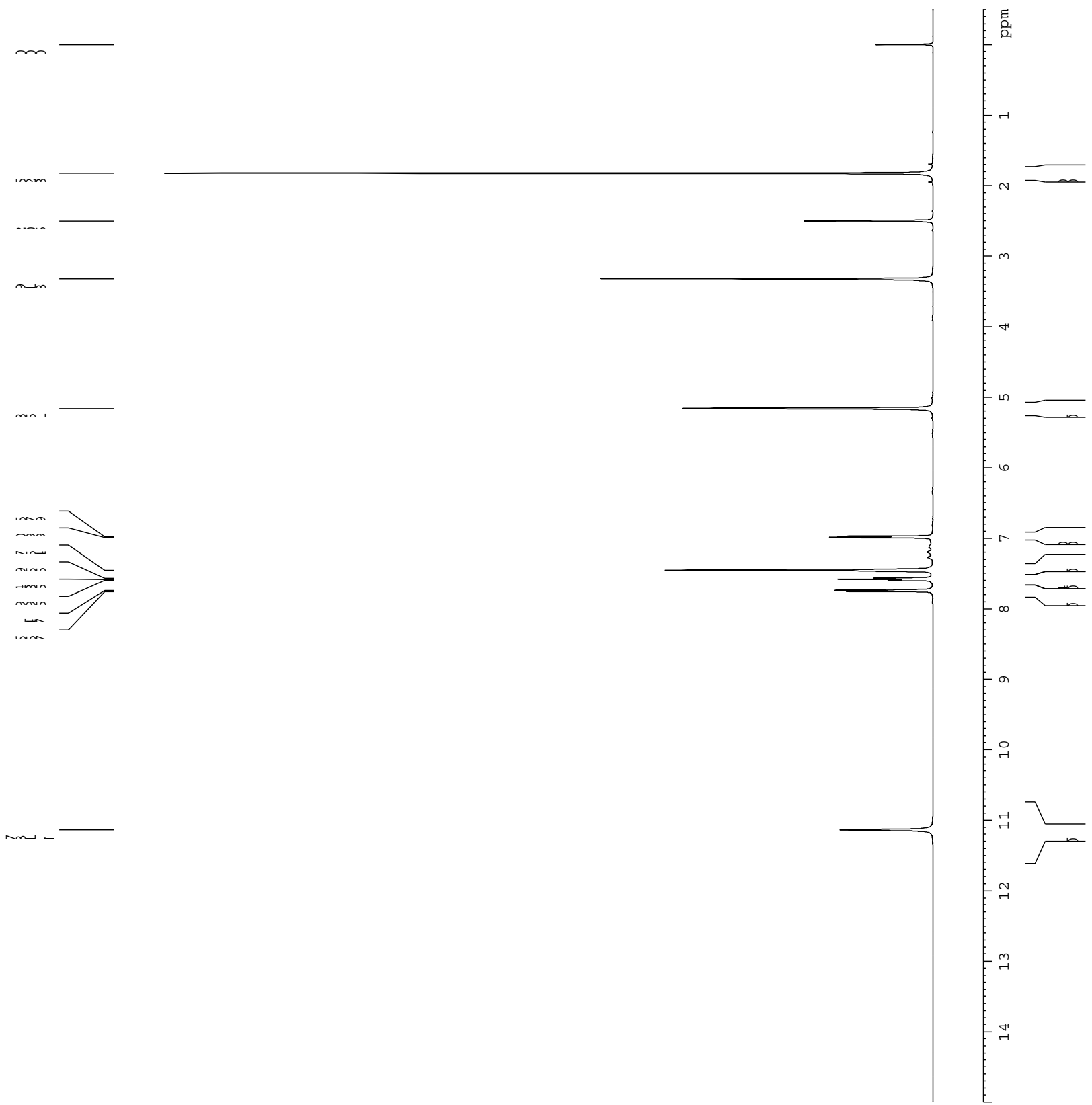

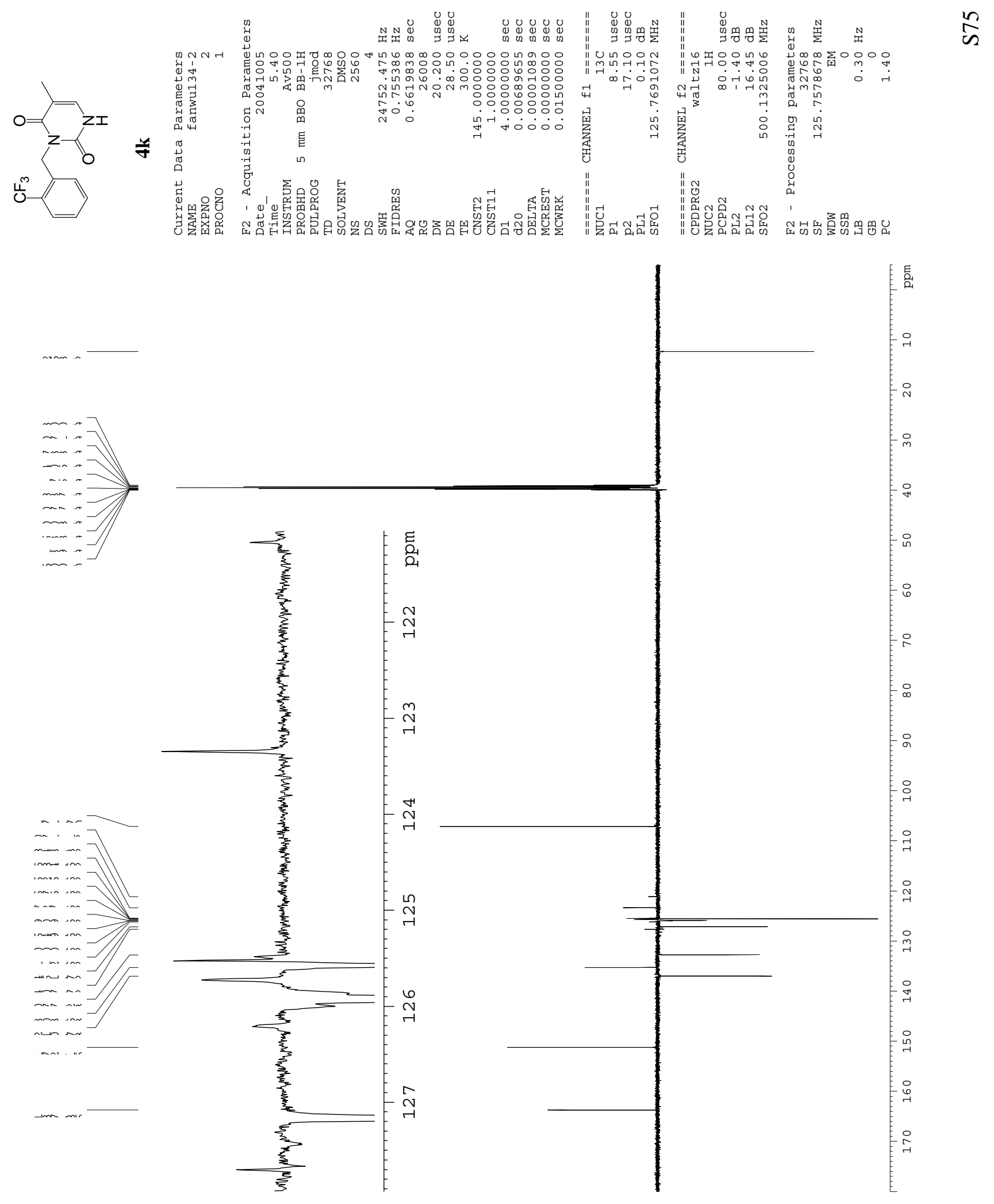

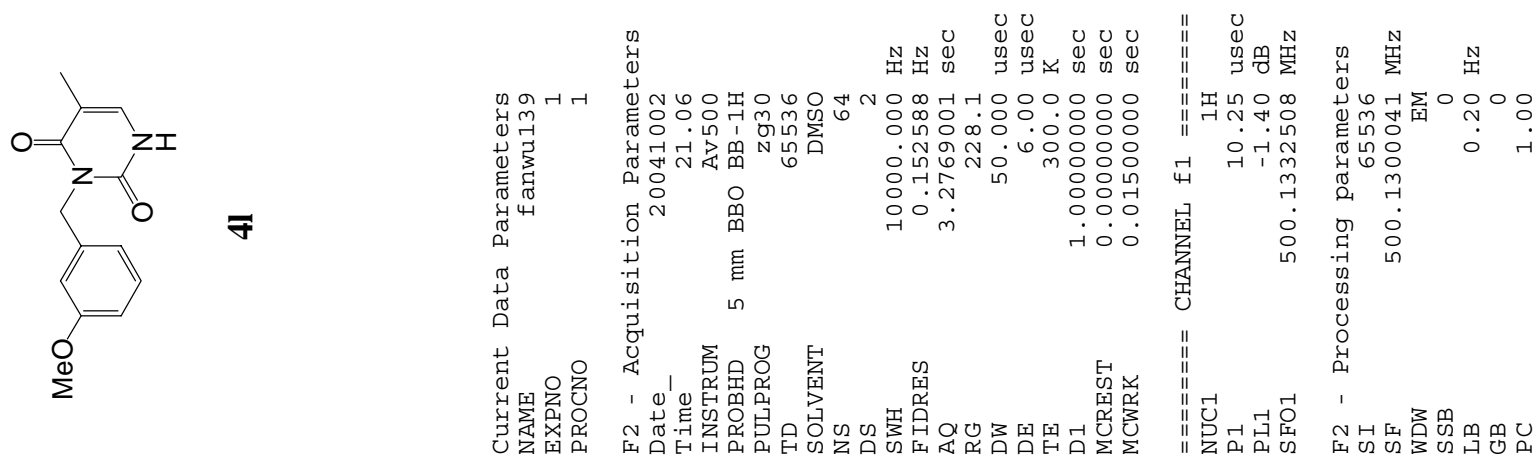

$\frac{0}{2}$
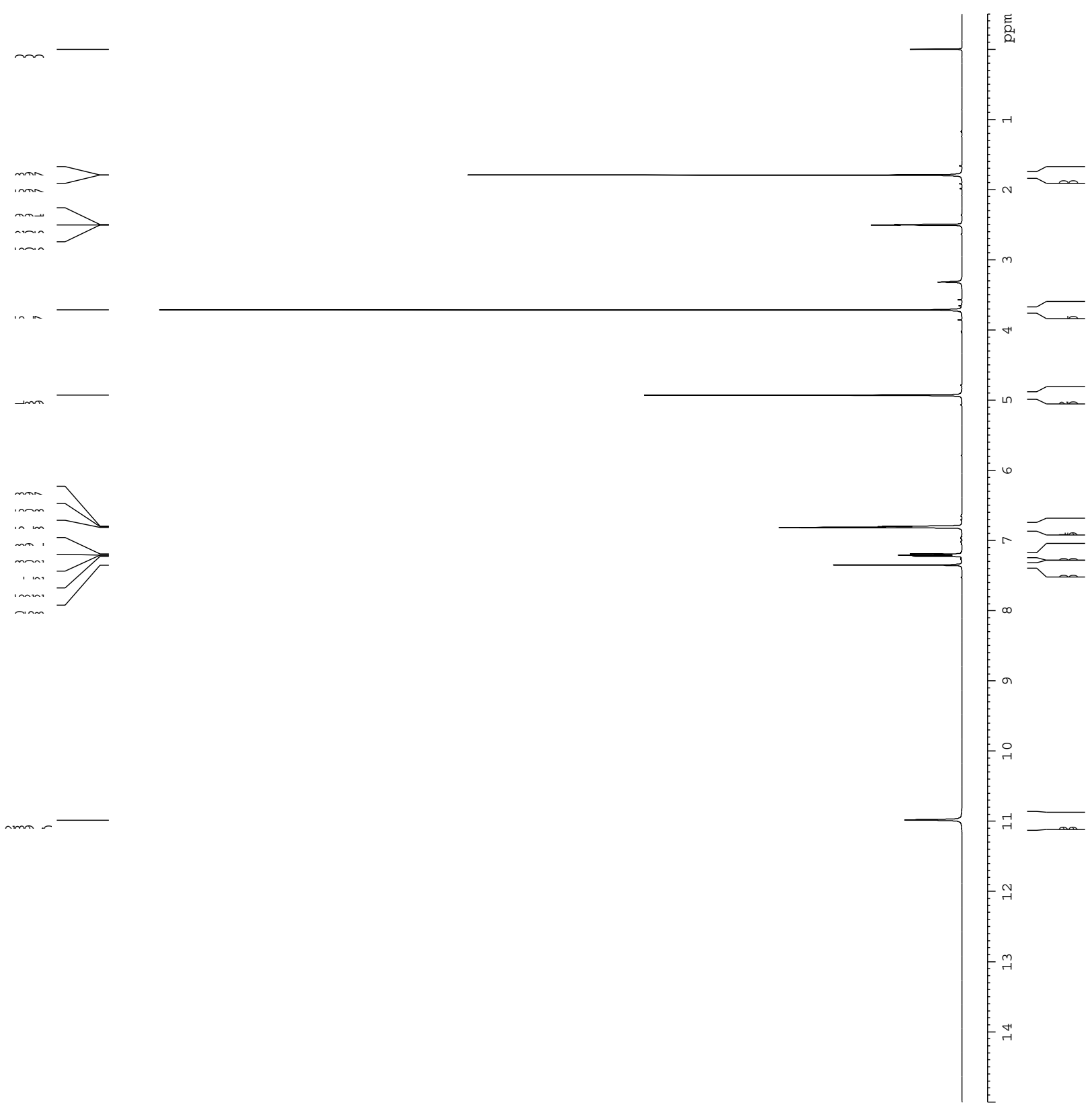

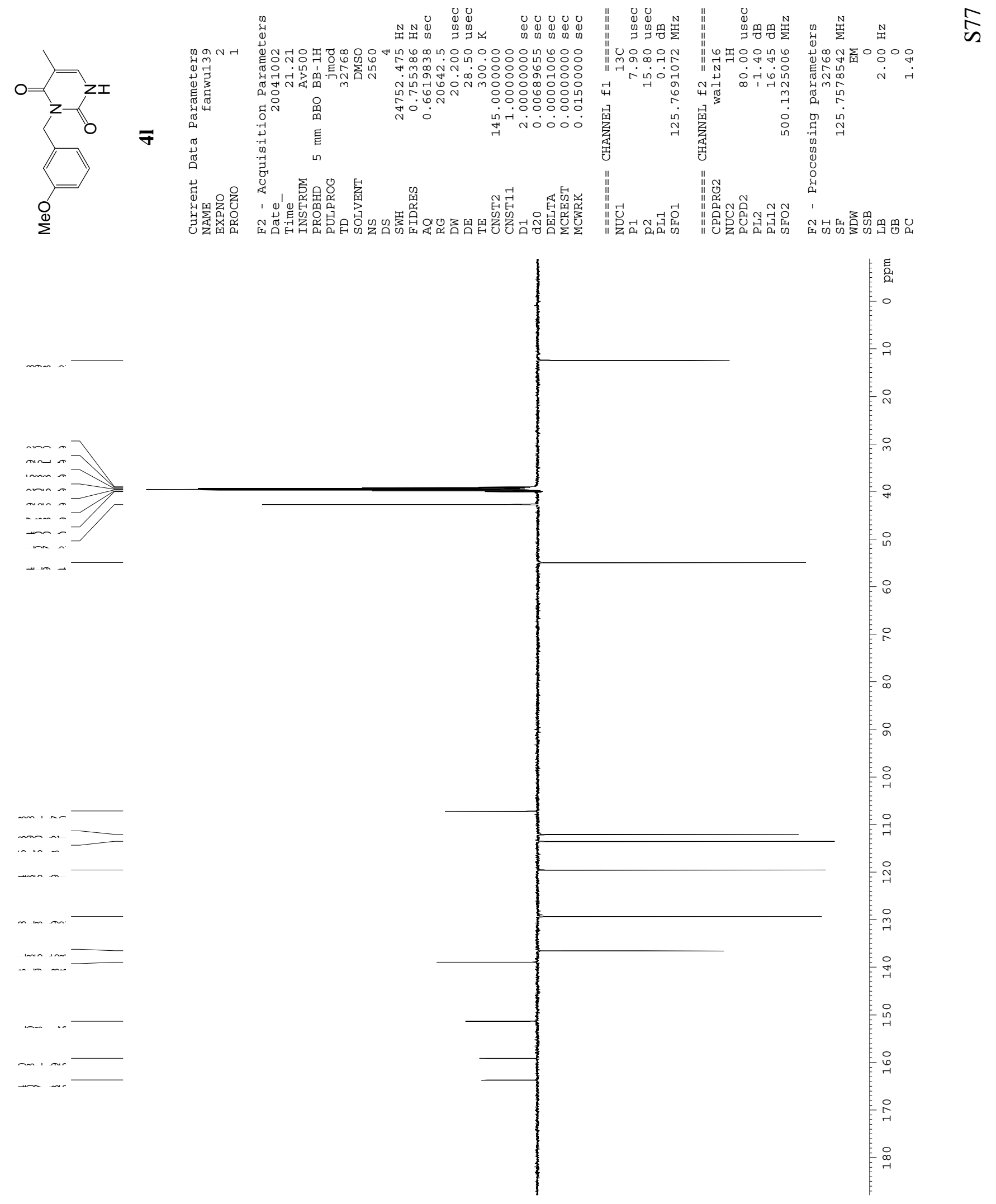

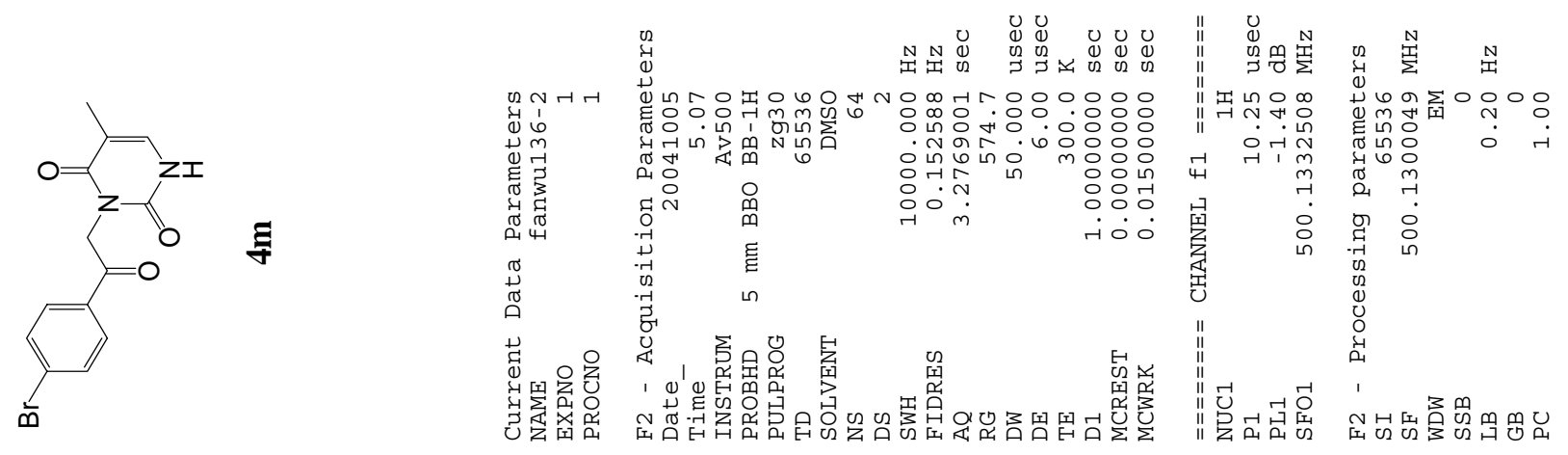

$\stackrel{\infty}{\sim}$
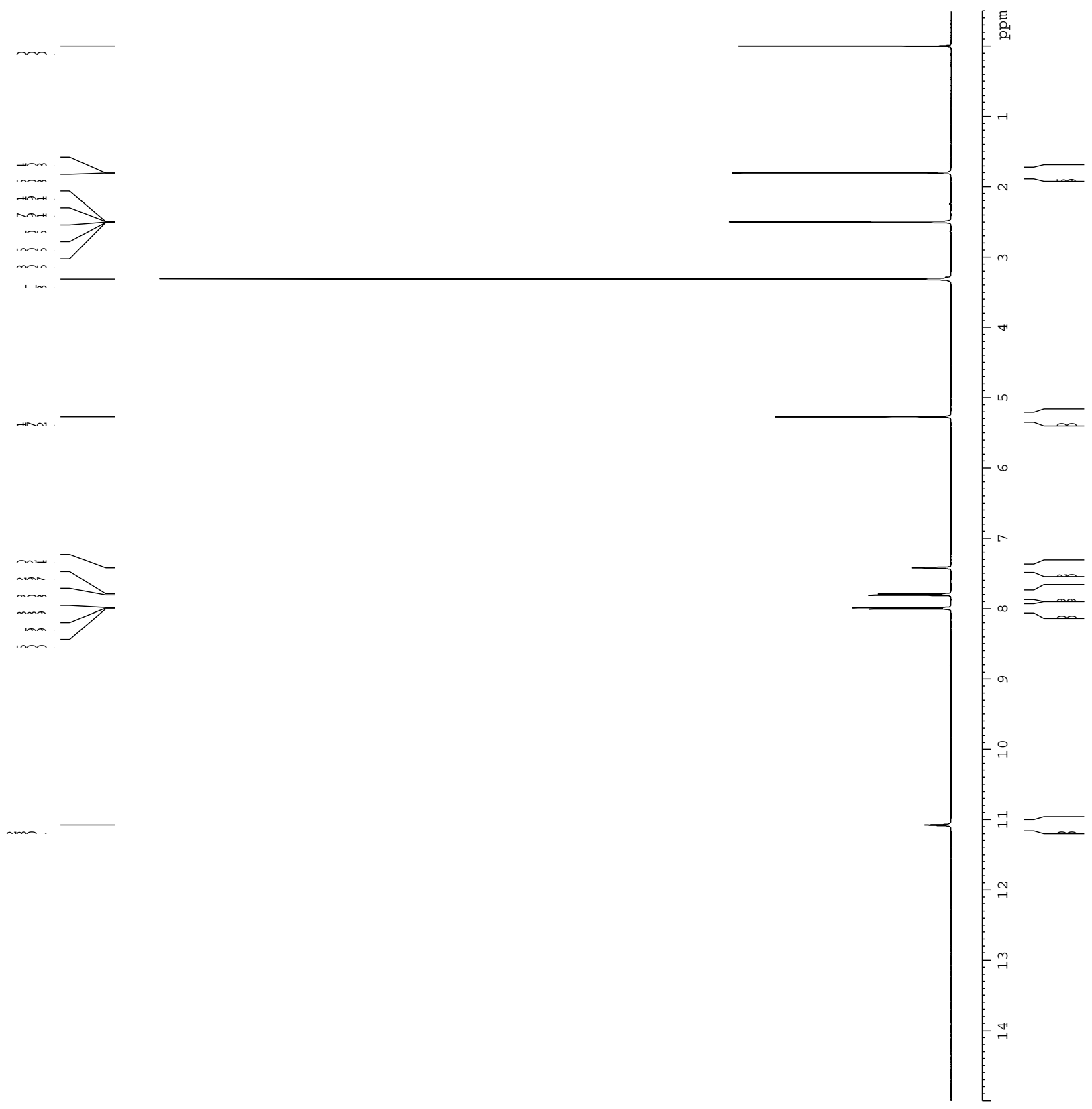

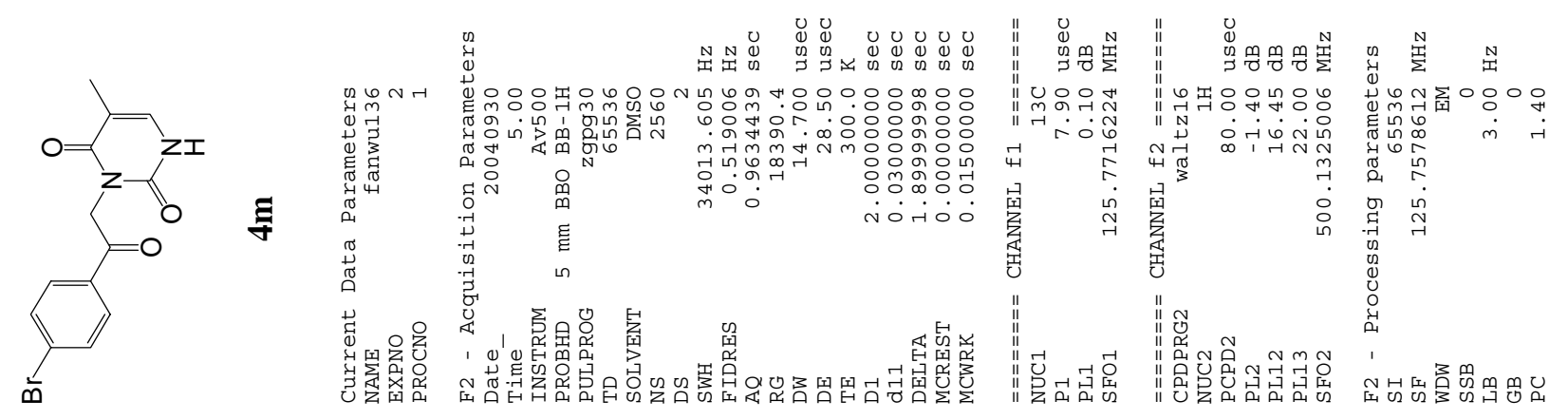

$\frac{9}{2}$

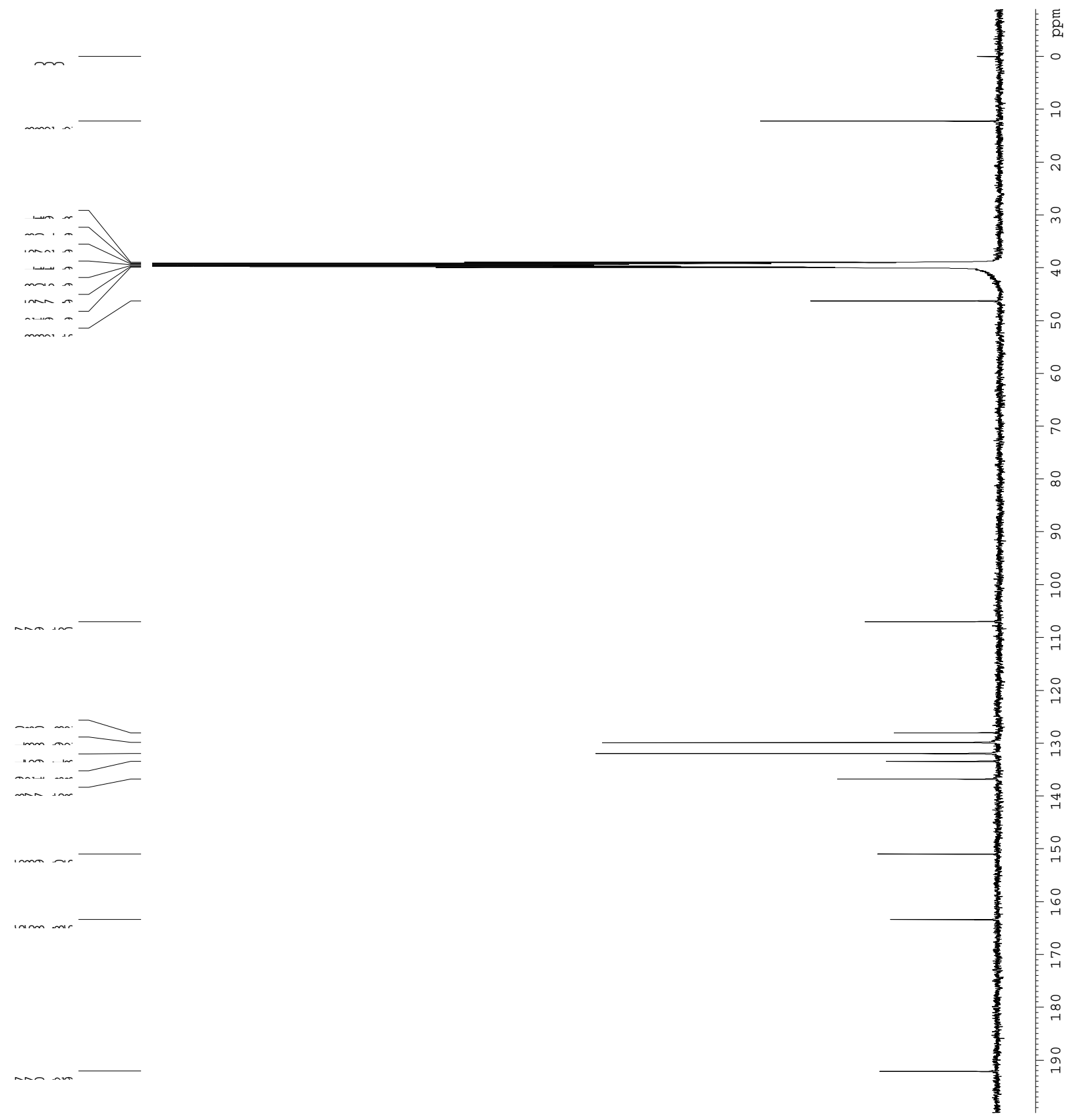

